Volume 6 Number 1 January 2018

Online ISSN 2307-7921

Print ISSN 2070-0296

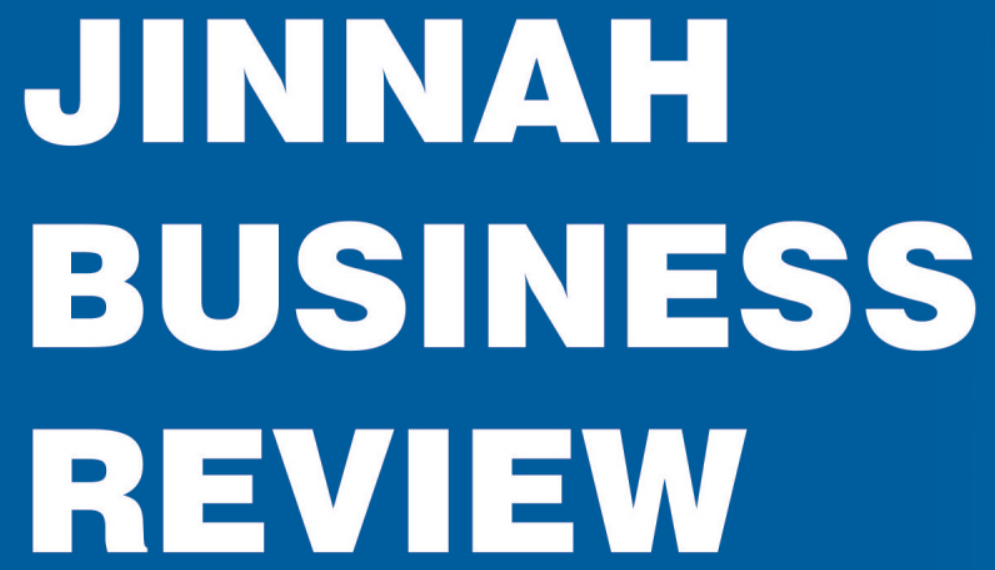

Safety Leadership and Injuries: A Study on the Manufacturing Sector of Pakistan, Using Safety Climate as a Mediator

The Impact of Perceived Training Utility on Transfer of Training:The mediating role of Motivation to Transfer

Impact of Procedural Justice on Turnover Intention with Mediating Effect of Trust

Global Portfolio Diversification and Equity Market: Evidence from Trading Partners of Pakistan

The Relationship of Employee Engagement, Organizational Commitment and Organizational Citizenship Behavior

Impact of Ethical Leadership on Project Success: Mediating role of Employee Trust and Moderating role of Ethical Orientation

Impact of Ethical Leadership on Whistle Blowing Intention Through Mediating Role of Moral Attentiveness:Moderating Role of Collectivism

Implementation of TAM (Technology Acceptance Model) in Project Based Organizations 



\section{JINNAH BUSINESS REVIEW VOLUME: 6 NUMBER: 1}

JANUARY 2018

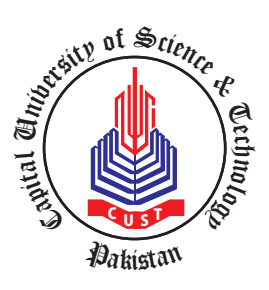




\section{Editor-in-Chief}

Professor Dr. Sajid Bashir

\section{ADVISORY BOARD}

\section{Dr. Charles Martin}

Professor, Wichita State University, USA

\section{Dr. Tackas Sandor}

Dean, Department of Business Corvinus University, Hungary

Dr. Asad Aman

Associate Professor, Lakehead University, Ontario, Canada

\section{Dr. Kubilay Özyer}

Professor, Gaziosmanpasa University, Turkey

Dr. Mazhar Mughal

Associate Professor, Pau Business School, France

Dr. Jose M. Merigo

Professor, University of Chile, Santiago, Chile

Dr. Valerie Earnshaw

Instructor, Harvard University, USA

Dr. Abdul Karim Khan

Assistant Professor, UAE University, UAE

Dr. Khurram Shahzad

Professor, Riphah International University, Islamabad, Pakistan

\section{Dr. Kashif-ur-Rehman}

Professor, Iqra University, Islamabad, Pakistan

Dr. Kamran Naqi

Professor, Hamdard University, Islamabad, Pakistan

\section{Dr. Arif Khattak}

Associate Professor, Bahria University, Islamabad, Pakistan

Dr. S. K. Shahzad

Assistant Professor, Air University, Islamabad

Dr. Muhammad Sarmad

Assistant Professor, SZABIST, Islamabad 


\section{Table of Contents}

1 Safety Leadership and Injuries: A Study on the Manufacturing Sector of Pakistan, Using

Safety Climate as a Mediator

2 The Impact of Perceived Training Utility on Transfer of Training: The mediating role of Motivation to Transfer

3 Impact of Procedural Justice on Turnover Intention with Mediating Effect of Trust

4 Global Portfolio Diversification and Equity Market: Evidence from Trading Partners of Pakistan

5 The Relationship of Employee Engagement, Organizational Commitment and Organizational Citizenship Behavior

6 Impact of Ethical Leadership on Project Success: Mediating role of Employee Trust and Moderating role of Ethical Orientation

7 Impact of Ethical Leadership on Whistle Blowing Intention Through Mediating Role of Moral Attentiveness: Moderating Role of Collectivism

8 Implementation of TAM (Technology Acceptance Model) in Project Based Organizations 



\title{
Safety Leadership and Injuries: A Study on the Manufacturing Sector of Pak- istan, Using Safety Climate as a Mediator
}

\author{
Muhammad Zeeshan Mirza ${ }^{1 *}$, Ahmad Shahrul Nizam Isha ${ }^{2}$ \\ Universiti Teknologi, Malaysia
}

\begin{abstract}
Safety literature is in agreement regarding the effective role safety-specific leadership plays in occupational safety but most of these studies are limited to Western/American context. The current study looks to fill this void by testing safety-specific leadership effectiveness in Pakistani context. Data were collected from 163 workers of manufacturing industry. The results confirmed that safety-specific leadership strengthens followers safety climate perceptions and thereby negatively affects occupational injuries. Practical implications, future research directions and limitations of the study are also discussed.
\end{abstract}

\section{Introduction}

Even though the quest for a safer workplace started way back, still ensuring occupational safety remains the biggest challenge for both theorists and practitioners (Barton and Sutcliffe, 2009; Clarke, 2013). The workers of most developed economy of the world, US still suffer millions of injuries every year (Boden et al., 2001). So the situation of occupational safety even in developed economies is less than ideal and a rigorous research is still going on to find out different ways in which the hazards at workplace can be reduced or removed completely. Therefore, it is not startling to see a plethora of research tackling the issue of workplace safety (Barling et al., 2003; Hofmann and Morgeson, 2004; Parboteeah and Kapp, 2008; Shannon et al., 1997).

Safety and health at work (International Labor Organization, n.d.) affirmed that over 317 million job related accidents happen annually and the economic encumber pose by them is estimated around $4 \%$ of global Gross Domestic Product every year. The figures are staggering and disturbing at the same time but whats more sad is that in a developing country like Pakistan, there is extinction of any reliable figures about the actual number of work related injuries/death which can explain the ground reality of working conditions. The last time any statistics about the number of occupational accidents in the country was provided way back in 2002-03, which reported 7400 fatal accidents in Pakistan for year 2002, whereas the number of serious and/or minor accidents is even greater (Pasha et al., 2003). The figures are of only those factories which are registered under the Factories Act of

*Corresponding author.

Email: zeeshanmirza21@hotmail.com
1934, while a big chunk of factories in Pakistan are not registered under this act. Almost every day media breaks a story about a workplace accident and if work related injuries/deaths are calculated correctly the figures will be shocking. Due to extinction of any compensation/insurance schemes there is no recognized reporting system of industrial accidents (Pasha et al., 2003).

There are two reasons for the worse workplace safety conditions; one is that in developing countries occupational safety is not considered being a real problem, mostly because of inappropriate governance mechanism and labor laws, which can force the organizations to embrace workplace safety. Second, the researchers have also neglected this issue as not much research can be identified which have tackled this important issue or suggested some remedies for it. In a collectivist society like Pakistan, where a single person is usually the only financial supporter of his/her family, injury, disability or death of a worker means that the lives of several individuals will be badly affected, which makes the occupational safety an even more important issue for the workers of Pakistani organizations.

Ahmad (2013) stated that the chances of a Pakistani factory worker to get killed at work are eight times greater than a factory worker in France, which further explains the dismal condition regarding the situation of occupational safety in Pakistan. But even in developed countries, the work-related injuries are happening at a frequent rate (Zacharatos et al., 2005), which means that its not just about the cost issue (although its an important factor) but also about having a safety culture within an organization. 
The importance of leadership in achieving higher level of safety at workplace is evident in literature (Clarke, 2013; Cohen, 1977; Hofmann et al., 1995; Shannon et al., 1997). But there are limited studies outside Europe/America on the role of leadership in ensuring occupational safety (Pilbeam et al., 2016); especially with the emergence of concept such as safety specific transformational leadership (Barling et al., 2003). Few studies which have tested the relationship showed the positive role leadership plays in improving safety at workplace (Kelloway et al., 2006; Mullen et al., 2011; Mullen and Kelloway, 2009). Thus, this calls for more research on the topic, specifically in developing countries like Pakistan where workplace safety is a very serious issue.

The current study will examine the effect of safety specific transformational leadership on occupational injuries. Besides, the safety literature indicates the effect of leadership on safety outcomes is not direct rather indirect through safety climate (Barling et al., 2003; Kelloway et al., 2006; Smith et al., 2016; Zohar and Nemet, 2002; Zohar, 2000, 2010). Hence, the current study also uses safety climate as a mediator between safetyspecific transformational leadership and occupational injuries. Finally, the study will add to the leadershipsafety literature by presenting a research from a totally different cultural context like Pakistan, which will aid in theory development by explaining that whether the leadership-safety construct has any universal application in a culture which is alien from the one where the theoretical linkage was actually presented.

\section{Literature Review}

\subsection{Safety-specific Transformational Lead- ership and Safety Climate}

Safety climate perceptions are developed by employees on the basis of policies or actions implemented by organization to improve the safety situation (Cooper and Phillips, 2004). Neal and Griffin (2002) in the review of safety climate literature noted two important points; first that not much research has been conducted to identify various organizational factors that can build and retain safety climate; second, they identified leadership to be one of the most important factors in ensuring safety climate which has not been given due consideration. Few other studies have also agreed with their view about leadership being an important factor in creating and maintaining safety climate (Hofmann and Morgeson, 1999).

Clarke and Ward (2006) in a detailed study explained that when soft tactics (discussion and motivation) were used by the leaders to persuade employees towards safety, it yielded much better results. In addition to that safety climate strongly mediated this relationship; moreover, they named this safety prone behavior as transformation of employees. A safety-specific leadership improves the safety climate of the organization to a far superior level (Wu et al., 2011). There is also considerable amount of empirical evidence supporting the association between safetyspecific transformational leadership and safety climate (Barling et al., 2003; Clarke, 2013; Kelloway et al., 2006; Mullen and Kelloway, 2009).

H1. Safety-specific transformational leadership is positively associated to safety climate.

\subsection{Safety climate and occupational in- juries}

Zohar (1980) put forward the concept of safety climate for the first time and defined it as the, summary of molar perceptions that employees share about safety (p.96). Safety climate perceptions are shaped on the basis of policies, procedures and practical actions taken by the organizations which shape up the positive or negative perceptions of employees about the safety climate. The more an organization is concerned about the safety situation and takes concrete actions to improve it, the more positive employees perception will be about the safety climate of the organization (Zohar and Luria, 2005). Strengthening positive safety climate perceptions indicates to employees that safety is not to be compromised for any competing demands like profit, production etc. (Zohar, 2010).

Employee perceptions of the safety climate are very important in the reduction of injuries at workplace. Pessimistic perceptions about safety climate can lead to higher number of injuries at workplace (Griffin and Neal, 2000; Zohar, 2000). A number of studies have tested the effect of safety climate on occupational injuries (Clarke and Ward, 2006; Liu et al., 2015; Nahrgang et al., 2011; Neal and Griffin, 2006) and reported that positive safety climate perceptions result in fewer number of injuries at workplace; thus, giving a strong empirical support to the safety climate and occupational injuries relationship.

H2. Safety climate is negatively associated with occupational injuries.

\subsection{Safety climate as a mediator between safety-specific transformational leader- ship and occupational injuries}

Transformational leadership has been considered as an important predictor of occupational safety (Zohar and Luria, 2004). Mullen and Kelloway (2009) argued that a general form of transformational leadership may be beneficial in some specific areas (e.g. organizational performance) but may not be as effective 
in other areas (e.g. maintaining higher level of safety standards). Safety-specific transformational leadership which was designed to specifically intervene in the safety situation manages to ensure a much safer workplace (Clarke, 2013; Smith et al., 2016). Barling et al. (2002) noted that four Is of transformational leadership (inspirational motivation, intellectual stimulation, individualized consideration and idealized influence) when become safety-specific, they play an important role in articulating followers safety climate perceptions. Once followers safety climate perceptions are strengthened by the safety-specific leaders, it ultimately results in fewer number of injuries (Christian et al., 2009; Nahrgang et al., 2011).

Zohar (2010) stated that in organizational environment there are number of competing demands, such as profit, production, productivity and safety. The positive safety climate perception conveys to employees that safety is not to be compromised for the competing demands. And leaders play the central role in developing the perception that safety is not to be compromised for any competing demand (Zohar, 2010). A number of studies have clearly reported the mediating role of safety climate between safety-specific transformational leadership and occupational injuries (Barling et al., 2003; Clarke, 2013; Kelloway et al., 2006; Mullen and Kelloway, 2009). Thus, based on this empirical evidence, the current study also proposes safety climate to be a mediator between safety-specific transformational leadership and occupational injuries.

H3. Safety climate mediates the relationship between safety-specific transformational leadership and occupational injuries.

\section{Theoretical framework}

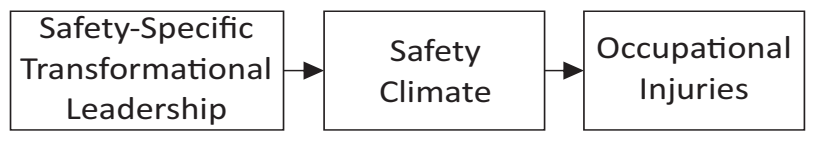

Figure 1: Conceptual Framework

\section{Methodology}

\subsection{Sample \& Procedure}

Cross-sectional data were collected from 163workers of manufacturing industries (garments, plastic and textile) from the Punjab province of Pakistan. The overall response rate was $57.7 \%$. Most of the workers were male ( $88 \%$ ), between $25-35$ years old ( $44 \%)$, and having an organizational tenure of more than 5 years $(58.5 \%)$.
Data were collected using survey method; while sample was drawn using convenient sampling technique.

\subsection{Instruments}

\subsubsection{Safety-Specific Transformational Leader- ship}

Safety specific transformational leadership was measured using the scale developed by Barling et al. (2002). The sample items included my supervisor expresses satisfaction when I perform my job safely, and my supervisor shows determination to maintain a safe work environment. All items were assessed using 5point Likert-type scale ranging from strongly disagree to strongly agree.

\subsubsection{Occupational Injuries}

Data for occupational injuries were collected using the scale of Barling et al. (2002). A statement included in the scale which asked from the employees about the injuries they have experienced at workplace in last 6 months. The sample items are strains or pain, burns, fracture or bruises. All items were assessed using 5point Likert-type scale ranging from strongly disagree to strongly agree.

\subsubsection{Safety Climate}

Safety climate was measured using the scale of Zohar (2000). The sample items included my supervisor says a good word whenever he sees a job done according to the safety rules, and my supervisor approaches workers during work to discuss safety issues. All items were assessed using 5-point Likert-type scale ranging from strongly disagree to strongly agree.

\section{Results}

\subsection{Correlation Analysis}

Table 1 provides the result of mean, standard deviations, correlation and reliabilities. The result of correlation analysis provides initial support to the entire proposed hypotheses. To test our proposed hypotheses and the mediation analysis we used PROCESS macro developed by (Hayes, 2012). The PROCESS macro uses bootstrapping technique for testing of mediation and is considered to be the most efficient and reliable tool for conducting mediation analysis (Hayes and Preacher, 2014).

\subsection{Regression Analysis}

As proposed in hypotheses 1, safety-specific transformational leadership is positively associated with safety climate $(\beta=0.32, \mathrm{p}<0.01)$ providing support to 
Table 1: Mean, Standard Deviations, Correlation and Reliabilities

\begin{tabular}{lccccc}
\hline Variable & Mean & S.D. & $\mathbf{1}$ & $\mathbf{2}$ & $\mathbf{3}$ \\
\hline Safety-specific transformational leadership & 3.28 & 0.68 & $(0.84)$ & & \\
Occupational injuries & 2.72 & 0.76 & $-0.56^{* *}$ & $(0.87)$ & \\
Safety climate & 3.3 & 0.63 & $0.72^{* *}$ & $-0.52^{* *}$ & $(0.88)$ \\
\hline
\end{tabular}

Note: Alpha values are on the diagnol

Table 2: Regression Analysis

\begin{tabular}{lccccccc}
\hline Predictors & \multicolumn{7}{c}{ Outcomes } \\
\hline Main effects: & \multicolumn{3}{c}{ Safety climate } & \multicolumn{3}{c}{ Occupational injuries } \\
& \multicolumn{1}{c}{${ }^{2}$} & $\boldsymbol{t}$ & $R^{2}$ & $\beta$ & $\boldsymbol{t}$ & $R^{2}$ \\
\hline $\begin{array}{l}\text { Safety-specific transformational leadership } \\
\text { Safety climate }\end{array}$ & 0.32 & $7.81^{* *}$ & 0.42 & & & \\
Mediator: & & & & 0.41 & $-9.40^{* *}$ & 0.27 \\
Safety climate & & & & & & \\
\hline
\end{tabular}

Note: ${ }^{* *} p<0.01$

hypothesis one. Hypothesis two proposed that safety climate negatively relates to occupational injuries. The regression results also provided support for this hypotheses $(\beta=0.41, \mathrm{p}<0.01)$. To test our mediation hypotheses, we adopted bootstrapping technique using PROCESS macro on SPSS (Preacher and Hayes, 2008). The recommended $95 \%$ bias corrected confidence interval with 5000 re-samples was used to test the mediation effect. The results shows that safety climate fully mediates the relationship between safety-specific transformational leadership and occupational injuries $(\beta=$ $0.23, \mathrm{p}<0.01)$. Thus, all the proposed hypotheses of the study have been accepted.

\section{Discussion}

The objectives of the study were to test the indirect effects of safety-specific transformational leadership on safety climate, and safety climate on occupational injuries. The results show that both hypotheses one and two have been accepted. The results confirm the findings of the previous studies on the proposed relationships (Barling et al., 2002; Kelloway et al., 2006; Liu et al., 2015; Nahrgang et al., 2011). Furthermore, the last hypothesis of our study confirms the mediating role of safety climate, which has been supported earlier in the literature (Clarke, 2013; Mullen and Kelloway, 2009). However, in a different cultural context like Pakistan, the safety-specific leadership develops workers perceptions of safety climate which ultimately results in reduction of injuries at workplace.

Although, this study is a replication of the previous work, it still does make some important contributions to the safety literature. The role of safety-specific leadership in ensuring occupational safety has largely been carried out in the Western/American context (Pilbeam et al., 2016). The current study verifies those findings in a totally different culture like Pakistan. It provides universal support for the effectiveness of safety-specific transformational leadership in reducing injuries at workplace beyond Western/American cultures. Furthermore, the study provides support for having safety-specific leaders in Pakistani organizations, given the positive findings of the study. Lastly, as the safety literature reports that safety-leadership training is cost effective (Mullen and Kelloway, 2009), Pakistani organizations may be sensitive to cost which prevents them from investing in safety. The current study provides an alternative approach to investing in safety training for their leaders and achieve higher-level of safety at workplace.

\subsection{Limitations and future research direc- tions}

The study adopted cross-sectional data collection technique, thus results must be viewed with caution and the future studies are advised to replicate our work in a longitudinal study design to verify the authenticity of our results. Also, the focus of our study was 
on safety-specific transformational leadership because of its effectiveness over general transformational leadership (Mullen and Kelloway, 2009). However, given that our study provides support for its effectiveness the future studies may look to have comparative analysis between general and safety-specific transformational leadership. Moreover, because of high collectivism in Pakistani culture, it will be interesting to find out whether or not safety-specific trust has any moderating effect between leadership and workers safety climate perceptions.

\section{References}

Ahmad, S. (2013). Paradigms of quality of work life. Journal of Human Values, 19(1):73-82.

Barling, J., Kelloway, E. K., and Iverson, R. D. (2003). Highquality work, job satisfaction, and occupational injuries. Journal of applied psychology, 88(2):276.

Barling, J., Loughlin, C., and Kelloway, E. K. (2002). Development and test of a model linking safety-specific transformational leadership and occupational safety. Journal of applied psychology, 87(3):488.

Barton, M. A. and Sutcliffe, K. M. (2009). Overcoming dysfunctional momentum: Organizational safety as a social achievement. Human Relations, 62(9):1327-1356.

Boden, L. I., Biddle, E. A., and Spieler, E. A. (2001). Social and economic impacts of workplace illness and injury: current and future directions for research. American journal of industrial medicine, 40(4):398-402.

Christian, M. S., Bradley, J. C., Wallace, J. C., and Burke, M. J. (2009). Workplace safety: a meta-analysis of the roles of person and situation factors.

Clarke, S. (2013). Safety leadership: A meta-analytic review of transformational and transactional leadership styles as antecedents of safety behaviours. Journal of Occupational and Organizational Psychology, 86(1):22-49.

Clarke, S. and Ward, K. (2006). The role of leader influence tactics and safety climate in engaging employees' safety participation. Risk Analysis, 26(5):1175-1185.

Cohen, A. (1977). Factors in successful occupational safety programs. Journal of safety research, 9(4):168-178.

Cooper, M. D. and Phillips, R. A. (2004). Exploratory analysis of the safety climate and safety behavior relationship. Journal of safety research, 35(5):497-512.

Griffin, M. A. and Neal, A. (2000). Perceptions of safety at work: a framework for linking safety climate to safety performance, knowledge, and motivation. Journal of occupational health psychology, 5(3):347.

Hayes, A. F. (2012). Process: A versatile computational tool for observed variable mediation, moderation, and conditional process modeling.
Hayes, A. F. and Preacher, K. J. (2014). Statistical mediation analysis with a multicategorical independent variable. British Journal of Mathematical and Statistical Psychology, 67(3):451-470.

Hofmann, D. A., Jacobs, R., and Landy, F. (1995). High reliability process industries: Individual, micro, and macro organizational influences on safety performance. Journal of safety research, 26(3):131-149.

Hofmann, D. A. and Morgeson, F. P. (1999). Safety-related behavior as a social exchange: The role of perceived organizational support and leader-member exchange. Journal of applied psychology, 84(2):286.

Hofmann, D. A. and Morgeson, F. P. (2004). The role of leadership in safety. The psychology of workplace safety, pages 159-180.

Kelloway, E. K., Mullen, J., and Francis, L. (2006). Divergent effects of transformational and passive leadership on employee safety. Journal of occupational health psychology, 11:76.

Liu, J. C., Pereira, G., Uhl, S. A., Bravo, M. A., and Bell, M. L. (2015). A systematic review of the physical health impacts from non-occupational exposure to wildfire smoke. Environmental research, 136:120-132.

Mullen, J., Kelloway, E. K., and Teed, M. (2011). Inconsistent style of leadership as a predictor of safety behaviour. Work $\mathcal{E}$ Stress, 25(1):41-54.

Mullen, J. E. and Kelloway, E. K. (2009). Safety leadership: A longitudinal study of the effects of transformational leadership on safety outcomes. Journal of Occupational and Organizational Psychology, 82(2):253-272.

Nahrgang, J. D., Morgeson, F. P., and Hofmann, D. A. (2011). Safety at work: a meta-analytic investigation of the link between job demands, job resources, burnout, engagement, and safety outcomes.

Neal, A. and Griffin, M. A. (2002). Safety climate and safety behaviour. Australian journal of management, 27(1_suppl):67-75.

Neal, A. and Griffin, M. A. (2006). A study of the lagged relationships among safety climate, safety motivation, safety behavior, and accidents at the individual and group levels. Journal of applied psychology, 91(4):946.

Parboteeah, K. P. and Kapp, E. A. (2008). Ethical climates and workplace safety behaviors: An empirical investigation. Journal of Business Ethics, 80(3):515-529.

Pasha, T. S., Liesivuori, J., and Finland, K. (2003). Country profile on occupational safety and health in pakistan. Kuopio (Finland): Finnish Institute of Occupational Health.

Pilbeam, C., Doherty, N., Davidson, R., and Denyer, D. (2016). Safety leadership practices for organizational safety compliance: Developing a research agenda from a review of the literature. Safety science, 86:110-121. 
Preacher, K. J. and Hayes, A. F. (2008). Asymptotic and resampling strategies for assessing and comparing indirect effects in multiple mediator models. Behavior research methods, 40(3):879-891.

Shannon, H. S., Mayr, J., and Haines, T. (1997). Overview of the relationship between organizational and workplace factors and injury rates. Safety Science, 26(3):201-217.

Smith, T. D., Eldridge, F., and DeJoy, D. M. (2016). Safetyspecific transformational and passive leadership influences on firefighter safety climate perceptions and safety behavior outcomes. Safety science, 86:92-97.

Wu, T.-C., Chang, S.-H., Shu, C.-M., Chen, C.-T., and Wang, C.-P. (2011). Safety leadership and safety performance in petrochemical industries: The mediating role of safety climate. Journal of Loss Prevention in the Process Industries, 24(6):716-721.

Zacharatos, A., Barling, J., and Iverson, R. D. (2005). Highperformance work systems and occupational safety. Journal of applied psychology, 90(1):77.

Zohar, A. and Nemet, F. (2002). Fostering students' knowledge and argumentation skills through dilemmas in hu- man genetics. Journal of research in science teaching, 39(1):3562.

Zohar, D. (1980). Safety climate in industrial organizations: theoretical and applied implications. Journal of applied psychology, 65(1):96.

Zohar, D. (2000). A group-level model of safety climate: testing the effect of group climate on microaccidents in manufacturing jobs. Journal of applied psychology, 85(4):587.

Zohar, D. (2010). Thirty years of safety climate research: Reflections and future directions. Accident Analysis E Prevention, 42(5):1517-1522.

Zohar, D. and Luria, G. (2004). Climate as a social-cognitive construction of supervisory safety practices: scripts as proxy of behavior patterns. Journal of applied psychology, 89(2):322.

Zohar, D. and Luria, G. (2005). A multilevel model of safety climate: cross-level relationships between organization and group-level climates. Journal of applied psychology, 90(4):616. 


\title{
The Impact of Perceived Training Utility on Transfer of Training: The medi- ating role of Motivation to Transfer
}

\author{
Kamran Iqbal*, Dr. Muhammad Arif, Muhammad Sarwar Zahid \\ Bahria University, Islamabad, Pakistan
}

\begin{abstract}
The purpose of this study was to examine the mediating role of motivation between the relationship of perceived training utility and transfer of training. Data were obtained from 215 employees working in the banking sector. SPSS and AMOS statistical software were used to test the hypothesized model. Consistent with social cognitive theory, results suggested a significant positive relationship of perceived training utility with motivation to transfer and transfer of training. The results further revealed that the relationship between perceived training utility and transfer of training had an indirect effect via Motivation to transfer. This study has made a significant theoretical contribution to the literature by exploring the mechanism through which perceived training utility affects transfer of training. This study will help HRD professionals to understand the importance of perceived training utility in transfer of training.
\end{abstract}

\section{Introduction}

Training has been used as one of the important tools for improvement of overall performance and productivity of employees (Bhatti and Kaur, 2009). Training is designed in order to improve the job-related competencies of employees. Due to rapid changes in technology and globalization, continuous changes have occurred in the business organizations, every organization is striving to gain competitive advantage through the development of Knowledge, skills and abilities in their employees. Organizations consider human capital as one of the most important asset, which is required to maintain sustainable competitive advantage. Organizations invest heavy budget on the training of their employees as it serves as a powerful tool for desired behavioral changes and outcomes required for their existence (Salas and Stagl, 2009). Human capital theory posits that education helps to improve existing KSA, which make employees more productive (Becker et al., 1964). Burke et al. (2006) defined training as systematic acquisition of knowledge, skills and attitudes that together lead to improved performance in a specific environment. Training is considered as leading opportunity for all employees to expand their knowledge. Organization can get benefits from training in term of employees outcomes i.e. job attitude and organizational outcomes, i.e. organizational performance (Tharenou et al., 2007). But training cannot produce positive outcomes unless and until newly learned skills are transferred to an actual job (Montesino, 2002). Blume et al.

*Corresponding author.

Email: sgd.kamran@gmail.com
(2010) has defined training transfer as the extent to which knowledge and skill acquired in a learning setting can be applied in the workplace, and maintained over time. Burke and Hutchins (2007) found that 1040 percent of training usually transfers to the actual job. Kirkpatrick and Davis (1994) mentioned transfer of training as a key criterion for evaluation of training effectiveness. In Pakistan, State Bank of Pakistan (SBP) regulate the financial sector. It provides detailed guidelines for structural reforms to fulfill overall social and economic requirements. According to SBP annual performance review (2007), SBP undergoes restructuring of its human resource in order to improve standards for its services. In banking industry of Pakistan, Management development programs are an integral part of overall development plans of all banks of Pakistan (Dastgeer and ur Rehman, 2012).

Although abundant literature is available on perceived training utility, motivation to transfer and transfer of training, but no study is available that explored the relationship between perceived training utility, motivation to transfer and training transfer in one study. Our contribution to the literature of transfer of training is not only to explore the link between perceived training utility and transfer of training but also how and why motivation works as a bridge in this link.

\section{Literature Review}

Research has pointed three main predictors of transfer of training: employees characteristics, train- 
ing design and working environment (Baldwin and Ford, 1988; Burke and Hutchins, 2007; Lim and Johnson, 2002; March and Olsen, 1998; Schwab et al., 2010). In literature related to training, transfer of training has grabbed the attention of a great number of scholars and professionals. Kirkpatrick and Davis (1994) training four level models demonstrate that transfer of training helps employees and organizations to achieve their performance related goals.

\subsection{Relationship between Perceived Train- ing Utility and Transfer of Training}

Training plays a significant role in enhancing employee job performance which ultimately leads to organizational development. Training result in improved employee performance, however, training effectiveness depends on the participants perception. The perceived training utility is also an important predictor of transfer of training. The perceived utility is conducive due to the fact that if trainees do not understand the utility attached with particular training, then more chances that trainees will not take training as a useful activity to improve their job. Hence, less perceived utility will directly affect the employees job performance and vice versa. Going ahead, the trainees utility perception might change with time and working environment (Chiaburu and Lindsay, 2008). Organizational support theory posits that when employees feel that their efforts are not considered or valued by their organizations, then more likely they will not put serious effort for organizational benefits (Kontoghiorghes, 2001). Furthermore, Clark and Mils (1993), posit that perceived utility training is directly related to trainees perception about training effectiveness to their career or job utility. Clark and Mils (1993) defined Career utility as the perceived usefulness of training for attainment of career goals, such as getting a raise or promotion, or taking a more fulfilling job, whereas, Job utility was defined as the perceived usefulness of the training course to facilitate goals associated with the current job, such as increased productivity, reduced errors, or better problem-solving skills. Training utility is considered as an important element while studying transfer of training. Perceived training utility has a significant effect on transfer of training (Burke and Hutchins, 2007). Chiaburu and Lindsay (2008) established that perception of trainees about the utility of training mainly depend on the relationship between training and expected outcomes. Chiaburu and Lindsay (2008) conducted their research on the topic related to training transfer on employees of big organizations in the service sector of USA and observed a strong relationship between perceived training utility and transfer of training. Grossman and Salas (2011) also found linkage between training utility and motivation to transfer.
Expectancy model could be useful to understand the role of motivation in transfer of training (Baldwin and Ford, 1988). An individual put efforts when he expects positive outcomes, and if a person lacks in positive expectation, it would be least likely that he will put efforts for performance improvement (Vroom, 1964). The concept of perceived training utility can also be understood with the help of expectancy theory. Research has found that trainees with positive expectation from particular training were more motivated to apply their KSAs on actual work (Grossman and Salas, 2011).

\subsection{Motivation to Transfer as a Mediator}

Although there are certain factors that affect transfer of training such as job control (Gijbels et al., 2010), a feasible work climate (Harteis and Gruber, 2004) and interest (Lewalter and Scholta, 2009) but motivation is considered as most worthy element for training transfer as suggested by Latham and Locke (2007), as the time, money, and resources an organization devotes to ways of increasing a persons abilities are wasted to the extent that an employee chooses not to learn what is being taught, or chooses not to apply newly acquired knowledge and skills in the workplace(p. 3) Motivation to transfer is defined byBates (2007) as the direction, intensity and persistence of effort towards utilizing in a work setting the skills and knowledge learned during the training program. Its a trainees desire to apply learned KSA on actual work (Noe and Schmitt, 1986) Research on motivation to transfer has gained popularity among the researchers in recent years (Segers and Gegenfurtner, 2013). Axtell et al. (1997) in their study found that transfer motivation has a strong influence on transfer of training for up to 1 year of duration after training. If Trainees perceive that their performance level will be improved by the using KSA which they will learn during the training program, they will put extra efforts to learn new skills and after learning, apply those skills on actual job.

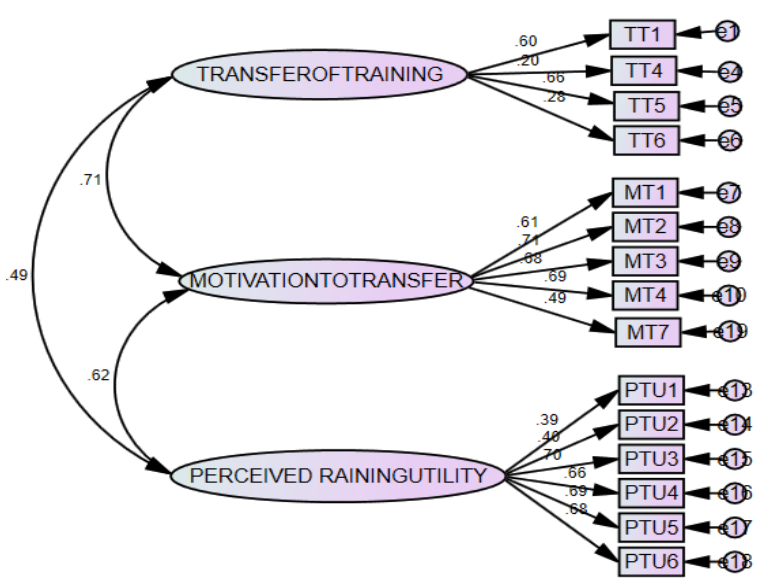


On the basis of above literature the following hypotheses have been proposed:

H1: Perceived training utility is positively related to motivation to transfer.

H2: Motivation to transfer is positively related to transfer of training.

H3: Perceived training utility is positively related to transfer of training.

H4: Motivation to transfer mediates the relationship between Perceived training utility and transfer of training.

\section{Theoretical Framework}

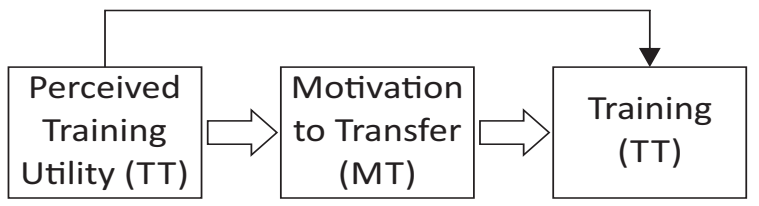

Figure 1: Theoretical Model

\section{Methodology}

The data of this study were collected from the employee of private banks in Pakistan. Judgmental nonprobability sampling technique was employed to select the sample. The survey was personally administered by the researcher himself. Researcher had got approval from branch manager of every bank before distribution of questionnaires to specific branch staff in order to avoid any inconvenience during data collection. A brief description of the study was attached at the start of the questionnaire to describe the aim and background of the study. In addition, assurance of confidentiality was highlighted to the respondents.Sekaran and Bougie (2010) mentioned that this approach is useful to clarify the doubts of the respondents, which result in high response rate. Total about 300 questionnaires were circulated, but only $215(72 \%)$ were finally used for the analysis. All questionnaires were adopted from previous studies. Perceived training utility was adopted from Van Eerde et al. (2008) questionnaire containing six items, sample item, The time spent away from the job to attend training has been worthwhile. The value of Cronbach's Alpha was .756 for this variable. The Questionnaire of transfer of training was adopted from Xiao et al. (1996), containing six items, i.e. I can accomplish the tasks better by using the new knowledge acquired from the training course. The value of Cronbach's Alpha was .622 for this variable. The questionnaire of Motivation to transfer was adopted from
Holton et al. (1997), containing five items i.e., I am thinking about trying to use my new learning on my job. The value of Cronbach's Alpha was .767 for this variable. For all variable Five points Likert scale from strongly agree $=5$ to strongly disagree $=1$ was used to collect the responses.

The sample consists of $62.8 \%$ males and $37.2 \%$ females. Out of total respondents, $47.44 \%$ are married and $52.66 \%$ are Un-married. Most respondents have 14 years of education (B.Com/BA/B.Sc) with $51.6 \%$, followed by $45.1 \%$ with an education of 16 years and above, while only $2.8 \%$ of the respondents have 12 years of education. Out of 215 respondents, total of $24.7 \%$ have age less than 25 , while most of the respondents $(63.7 \%)$ having ages between 25 to 35 . Out of total sample, $38.6 \%$ have organizational tenure of 1 or less, $48.8 \%$ between 2 to 7 years, and $9.3 \%$ between 8 to 13 years, while only $1.9 \%$ with 14 or above organizational tenure. Out of total sample $20.5 \%$ have organizational tenure 1 or less, $25.6 \%$ between 2 to 7 years, and $24 \%$ between $8-13$, while only $9.3 \%$ with 14 or above years job tenure. Out of total respondents, $57.7 \%$ were middle-level employees, $24.7 \%$ managerial level employees, while only $16.7 \%$ were lower level employees.

\section{Results}

\subsection{Confirmatory Factor Analysis}

AMOS statistical software was employed to run confirmatory factor analysis (CFA) to verify the uniqueness of the variables. The figure given under table 1 presents the factor loading of the variables used in the study. All ill loaded items have been deleted. CFA revealed that perceived training utility was adequately measured with six items, motivation to transfer with five items, transfer of training with four items. The results of the CFA show that 2/df value 192.821 has a good fit with other indices GFI (.891), AGFI (.849), and CFI (.864) indicating good fit. The value of RMSEA is 0.075 which is considered as acceptable as its value is less than 0.08. (RMSEA) is 0.075 which is considered as acceptable as its value is less than 0.08 .

\subsection{Correlation analysis}

Table 2 shows the level of correlation which exists between the variables of the current study. Results show that all variables are highly correlated. Correlation analysis exhibits that highest correlation is present between perceived training utility and motivation to transfer $(\mathrm{r}=.506, \mathrm{p}<.01)$, followed by correlation between motivation to transfer and transfer of training $(\mathrm{r}=.395, \mathrm{p}<.01)$, and between perceived training utility and transfer of training $(\mathrm{r}=.267, \mathrm{p}<.05)$. 


\subsection{Regression Analyses}

Table 3 shows that perceived training utility has an estimated regression weight of 0.631 ( $p \leq 0.005)$ on motivation to transfer. So our hypothesis $\mathrm{H} 1$ has been accepted, which indicates that perceived training utility has a positive impact on motivation to transfer. Motivation to transfer has an estimated regression weight of 0.529 ( $p \leq 0.01$ ) on transfer of training, leading to acceptance of hypothesis 2 . Similarly, perceived training utility has an estimated regression weight of 0.361 ( $\mathrm{p} \leq$ 0.01) on transfer of training, so our hypothesis 3 has also been accepted, indicating that perceived training utility is positively associated with transfer of training. In order to check the mediating role of motivation to transfer between the relationship of perceived training utility and transfer of training, two models have been compared; first, without any mediating variable and then along with the mediating variable. Results show that when the model was run in presence of mediators, relationship between training utility and transfer of training became non-significant. This shows that motivation to transfer mediates the relationship between perceived training utility and transfer of training according to Baron and Kenny (1986). Hence hypothesis four has also been accepted.
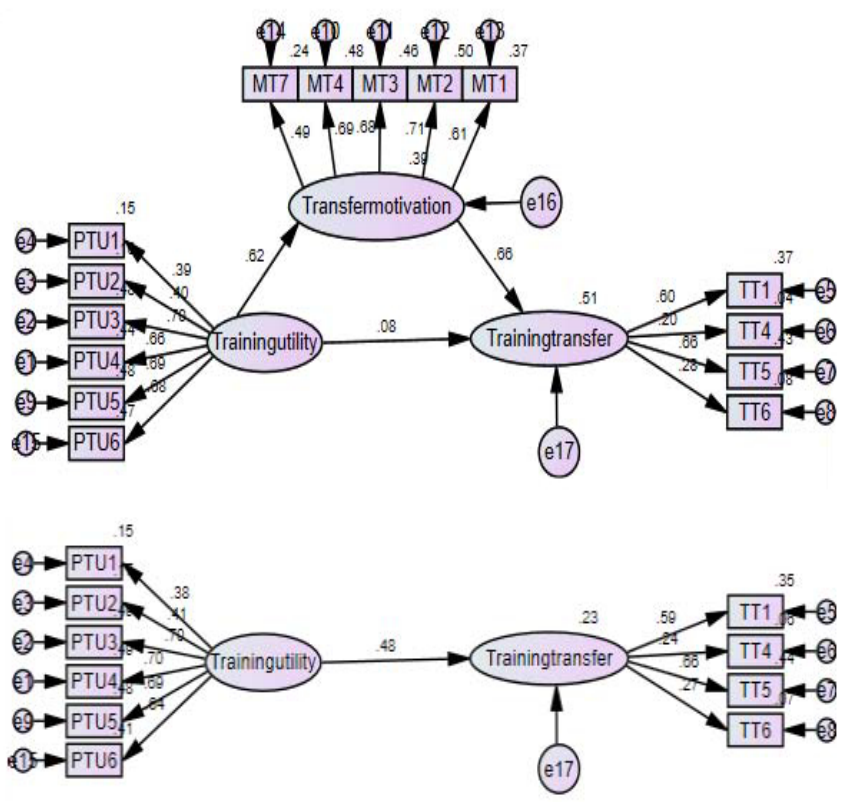

Table 1: Index of fit of the Model

\section{Discussion}

The purpose of the current study was to examine the linkage between perceived training utility and transfer of training through the mediation of motivation to transfer. The study consists of four hypotheses. The first hypothesis stated that Perceived training utility is positively related to motivation to transfer. Regression results show positive association between perceived training utility and transfer of training $(\beta=0.631, \mathrm{p}<.001)$, which are consistent with the past studies (Alliger et al., 1997; Burke and Hutchins, 2007; Chiaburu and Lindsay, 2008). The hypothesis two stated that Motivation to transfer is positively related to transfer of training, results indicate a positive association between motivation to transfer and transfer of training $(\beta=0.529, \mathrm{p}<.001)$ which is consistent with the past studies (Clark and Mils, 1993; Grossman and Salas, 2011). Similarly, hypothesis 3 tested that Perceived training utility is positively related to transfer of training. Regression analysis indicates a positive association between perceived training utility and transfer of training $(=0.361, \mathrm{p}<.001)$ which is also consistent with the past studies (Bhatti and Kaur, 2009; Kirwan and Birchall, 2006; Liebermann and Hoffmann, 2008; Nikandrou et al., 2009). For testing the hypothesis $\mathrm{H} 4$ which stated that Motivation to transfer mediates the relationship between Perceived training utility and transfer of training, Barron \& Kenny (1986) mediation technique was employed by using AMOS software. Results indicated that motivation to transfer mediates the relationship between perceived training utility and transfer of training, therefore, leading to the acceptance of hypothesis four as well. This shows that employees perception about the benefits from a training program plays a key role in motivation to transfer which in turn increase transfer of training.

\subsection{Implications and Recommendations}

Training is considered as most suitable way to improve KSA of employees through their differentiation in the KSA of their human resource. But organizations can only get benefits from their training if trainees put their efforts to transfer learned skills on the actual job. The findings of the present study suggest that perceived training utility and motivation to transfer are the important predictors of transfer of training. The second major finding of the study is that Motivation to

Fit Measures

\begin{tabular}{ccccccccc} 
& Chi-Square & DF & p value & CMIN/DF & GFI & CFI & AGFI & RMSEA \\
\hline Values & 192.821 & 87 & 0.000 & 2.216 & 0.891 & 0.864 & 0.849 & 0.075 \\
\hline
\end{tabular}


Table 2: Descriptive statistics and inter-correlations for all study variables

\begin{tabular}{lccccc}
\hline Variables & Mean & Std. Deviation & PTU & MT & TT \\
\hline Perceived training utility (PTU) & 3.807 & 0.57155 & 1 & & \\
Motivation to transfer (MT) & 3.9684 & 0.58878 & $.506^{* *}$ & 1 & \\
Transfer of training (TT) & 3.6616 & 0.58384 & $.267^{*}$ & $.395^{* *}$ & 1 \\
\hline
\end{tabular}

${ }^{* * *}$ Correlation is significant at .01 levels (two tailed) N: 215

${ }^{* *}$ Correlation is significant at .05 levels (two tailed)

Table 3: Hypotheses testing based on regression weights

\begin{tabular}{lccccc}
\hline Variables & Estimates & S.E. & Critical ratio & P value & Results \\
\hline MT $\leftarrow$ PTU & 0.631 & 0.104 & 6.068 & $* * *$ & Accepted \\
TT $\leftarrow$ MT & 0.529 & 0.123 & 4.31 & $* * *$ & Accepted \\
TT $\leftarrow$ PTU & 0.361 & 0.095 & 3.957 & $* * *$ & Accepted \\
TT $\leftarrow$ MT $\leftarrow$ PTU & 0.067 & 0.103 & 0.648 & 0.517 & Full mediation \\
\hline${ }_{* * *}^{*}$ P value significant at .01 & & & & &
\end{tabular}

transfer mediates the relationship between perceived training utility. Therefore, to increase transfer of training, perceived training utility and motivation to transfer should be taken as important factors. The present study recommends policy maker of banking sector of Pakistan to understand the impact of perceived training utility on the motivation of employees related to transference of learned KSA on an actual job. This study concluded that perception about the benefits attached to a particular training has significant impact on the motivation to transfer and transfer of training. So employees should be communicated well, on how particular training will be beneficial for their job performance and long term career growth.

\subsection{Future Directions}

Firstly, the current study only examined the temporal effect of perceived utility on transfer training however, the future studies should examine how perceived utility changes with time. Secondly, the current study takes the banking sector as a contextual setting. Future study may use various other organizational settings to increase the generalizability of the findings. Thirdly, this study used a cross-sectional survey to test the hypotheses of the study. However, future researchers may use a longitudinal technique, also, mixed methodology may be used. Lastly, this study took motivation as one variable; researchers may test different dimensions of motivation to transfer as suggested by (Gegenfurtner and Hagenauer, 2013). Also, organizational support can be incorporated to evaluate its mediating effect in the relationship.

\section{References}

Alliger, G. M., Tannenbaum, S. I., Bennett, W., Traver, H., and Shotland, A. (1997). A meta-analysis of the relations among training criteria. Personnel psychology, 50(2):341358.

Axtell, C. M., Maitlis, S., and Yearta, S. K. (1997). Predicting immediate and longer-term transfer of training. Personnel Review, 26(3):201-213.

Baldwin, T. T. and Ford, J. K. (1988). Transfer of training: A review and directions for future research. Personnel psychology, 41(1):63-105.

Baron, R. M. and Kenny, D. A. (1986). The moderatormediator variable distinction in social psychological research: Conceptual, strategic, and statistical considerations. Journal of personality and social psychology, 51(6):1173.

Bates, T. (2007). Strategic planning for e-learning in a polytechnic. In Making the transition to e-learning: Strategies and issues, pages 47-65. IGI Global.

Becker, G. M., DeGroot, M. H., and Marschak, J. (1964). Measuring utility by a single-response sequential method. Systems Research and Behavioral Science, 9(3):226-232.

Bhatti, M. and Kaur, S. (2009). Factors effecting transfer of training: a fresh review. In 12th International Business Information Management Conference (IBIMA), Kuala Lumpur.

Blume, B. D., Ford, J. K., Baldwin, T. T., and Huang, J. L. (2010). Transfer of training: A meta-analytic review. Journal of management, 36(4):1065-1105. 
Burke, C. S., Stagl, K. C., Klein, C., Goodwin, G. F., Salas, E., and Halpin, S. M. (2006). What type of leadership behaviors are functional in teams? a meta-analysis. The leadership quarterly, 17(3):288-307.

Burke, L. A. and Hutchins, H. M. (2007). Training transfer: An integrative literature review. Human resource development review, 6(3):263-296.

Chiaburu, D. S. and Lindsay, D. R. (2008). Can do or will do? the importance of self-efficacy and instrumentality for training transfer. Human Resource Development International, 11(2):199-206.

Clark, M. S. and Mils, J. (1993). The difference between communal and exchange relationships: What it is and is not. Personality and Social Psychology Bulletin, 19(6):684-691.

Dastgeer, G. and ur Rehman, A. (2012). Effectiveness of management development in pakistani corporate sector: Testing the d'netto model. Journal of Management Development, 31(8):740-751.

Gegenfurtner, A. and Hagenauer, G. (2013). Achievement goals and achievement goal orientations in education. International Journal of Educational Research, 61(1):1-4.

Gijbels, D., Raemdonck, I., and Vervecken, D. (2010). Influencing work-related learning: The role of job characteristics and self-directed learning orientation in part-time vocational education. Vocations and Learning, 3(3):239-255.

Grossman, R. and Salas, E. (2011). The transfer of training: what really matters. International Journal of Training and Development, 15(2):103-120.

Harteis, C. and Gruber, H. (2004). Competence-supporting working conditions. Professional learning: Gaps and transitions on the way from novice to expert, pages 251-269.

Holton, E. F., Bates, R. A., Seyler, D. L., and Carvalho, M. B. (1997). Toward construct validation of a transfer climate instrument. Human Resource Development Quarterly, 8(2):95-113.

Kirkpatrick, L. A. and Davis, K. E. (1994). Attachment style, gender, and relationship stability: A longitudinal analysis. Journal of personality and social psychology, 66(3):502.

Kirwan, C. and Birchall, D. (2006). Transfer of learning from management development programmes: testing the holton model. International Journal of Training and Development, 10(4):252-268.

Kontoghiorghes, C. (2001). Factors affecting training effectiveness in the context of the introduction of new technologya us case study. International Journal of Training and Development, 5(4):248-260.

Latham, G. P. and Locke, E. A. (2007). New developments in and directions for goal-setting research. European Psychologist, 12(4):290-300.

Lewalter, D. and Scholta, K. (2009). The impact of goal and feedback treatments on selfdetermined motivation and situational interest in a computer-based learning context. Contemporary motivation research: From global to local perspectives, pages 229-248.
Liebermann, S. and Hoffmann, S. (2008). The impact of practical relevance on training transfer: evidence from a service quality training program for german bank clerks. International Journal of Training and Development, 12(2):74-86.

Lim, D. H. and Johnson, S. D. (2002). Trainee perceptions of factors that influence learning transfer. International journal of training and development, 6(1):36-48.

March, J. G. and Olsen, J. P. (1998). The institutional dynamics of international political orders. International organization, 52(4):943-969.

Montesino, M. U. (2002). Strategic alignment of training, transfer-enhancing behaviors, and training usage: A posttraining study. Human Resource Development Quarterly, 13(1):89-108.

Nikandrou, I., Brinia, V., and Bereri, E. (2009). Trainee perceptions of training transfer: an empirical analysis. Journal of European Industrial Training, 33(3):255-270.

Noe, R. A. and Schmitt, N. (1986). The influence of trainee attitudes on training effectiveness: Test of a model. Personnel psychology, 39(3):497-523.

Salas, E. and Stagl, K. C. (2009). Design training systematically and follow the science of training. Handbook of Principles of Organizational Behavior: Indispensable Knowledge for Evidence-Based Management, 2nd edn (Chichester: John Wiley $\mathcal{E}$ Sons), pages 59-84.

Schwab, K., Sala-i Martin, X., et al. (2010). The global competitiveness report 2010-2011. World Economic Forum Geneva.

Segers, M. and Gegenfurtner, A. (2013). Transfer of training: New conceptualizations through integrated research perspectives. Educational Research Review, 8:1-4.

Sekaran, U. and Bougie, R. (2010). (2010). Research methods for business: A skill building approach. Wiley.

Tharenou, P., Saks, A. M., and Moore, C. (2007). A review and critique of research on training and organizational-level outcomes. Human Resource Management Review, 17(3):251273.

Van Eerde, W., Simon Tang, K., and Talbot, G. (2008). The mediating role of training utility in the relationship between training needs assessment and organizational effectiveness. The International Journal of Human Resource Management, 19(1):63-73.

Vroom, V. H. (1964). Work and motivation. new york: John willey \& sons. Inc. VroomWork and Motivation1964.

Xiao, X., Li, J., and Samulski, R. J. (1996). Efficient longterm gene transfer into muscle tissue of immunocompetent mice by adeno-associated virus vector. Journal of virology, 70(11):8098-8108. 


\title{
Impact of Procedural Justice on Turnover Intention with Mediating Effect of Trust
}

\author{
Maryam Tajammal* \\ Capital University of Science and Technology, Islamabad, Pakistan
}

\begin{abstract}
This research conducted a survey to examine the impact of procedural justice on turnover intention through mediation of organizational trust. The study is based on a sample of 141 faculty members of the public and private sector universities of twin cities of Pakistan who completed structured questionnaires for each variable. Data were analyzed using SPSS and results revealed that procedural justice has negative and significant effect on turnover intentions of employees. Furthermore, organizational trust successfully mediates the relationship between Procedural justice and Turnover intention. We conclude study, discuss theoretical implications and also provide future recommendations.
\end{abstract}

\section{Introduction}

In the present time, employees turnover is a global phenomenon. It has become a serious and complicated issue as it is a major problem pervasive in all kinds of organizations in the world. It is difficult for the organizations to sustain success amidst such a problem. Organizations spend a lot in hiring, training, and retaining employees. After huge investment it is painful and costly for them to have high turnover (Khattak, 2010).

Developing countries like Pakistan are also facing this problem in all sectors especially education sector. Annually, huge number of teachers quit teaching and others transfer to other institution. (Ingersoll, 2001) in recent years has come forward with support and confirmation that students and schools are affected by teachers turnover. Although it is a severe issue in Asia but unfortunately, studies are short to inspect turnover intention and studies which consist of wide ranged variable sets (Khatri et al., 2001)

According to Hopkins and Weathington (2006) organizations have to invest time and money in replacing those who go away. To control turnover it is important to know about it before it happens actually. The best option for the organizations is to have knowledge about turnover intentions of employees as it is the development of consideration, preparation, and wish for a job quit as it has positive causal relation with actual turnover (Choi, 2006) and generally is the second last stage of deliberate quitting. Ninety three percent empirical studies suggest high correlation of TOI with real quit. Turnover intention is preferred as compared to definite turnover in the studies as T.O makes matters

*Corresponding author.

Email: maryam.hashmi88@gmail.com worse and is difficult to predict as compared to intention (Hemdi and Nasurdin, 2007).

According to Aryee et al. (2002) it is vital to be acquainted with an employees feelings, whether he/she (individually) is treated unfairly in the organization, he may expect that transfer to another department or function or branch of same organization will depart this feeling of unfair treatment. On the other hand, when the climate of organization is unfair or unjust, employees will perceive that transfer to another department, function or branch of the same organization will not improve their position, as it is procedurally unjust climate. Therefore, they will show more intention to quit. Studies show that the relationship between procedural justice and turnover intentions has been mediated by trust perceptions (Hopkins and Weathington, 2006). Similarly, in various studies, procedural justice was found to be positively linked with trust on organization (Hopkins and Weathington, 2006; TZAFRIR et al., 2012). It has also been posited by Gopinath and Becker (2000), that Procedural justice is only one of its kinds, which brought more changes in turnover than other dimensions of justice.

\section{Literature Review}

\subsection{Procedural Justice}

Organizational justice is considered as a perception of the organization. Organizational justice is what is perceived by the employees about whether they are treated fairly or not. So it is a perception about the 
fairness and the equality of the organization and also such perception has very deep effect on the attitudes and behaviours of the employees (Poon, 2012). Organizational justice has many dimensions out of which procedural justice and distributive justice are more important (Lambert et al., 2012). Distributive justice is basically about the perception of the employees of how fair are the outcomes given to them (e.g. pay, status) but procedural justice is perception of the employees of how fair are the methods or ways used to give those outcomes. Procedural justice is defined as the perception about means and processes used for taking decisions in the organization (Colquitt et al., 2001). It is also about employees perception about whether or not the methods or the processes used by the organizations to make decisions are fair (Lambert et al., 2012). Main concern of the study is about procedural justice because employee who perceives himself to be given fair treatment, procedurally, he considers his organization as a whole fair ( $\mathrm{Li}$ and Bagger, 2012). Procedural justice focuses on the organization but distributive justice focuses more on the outcomes (Tulubas and Celep, 2012). If the employees know that the outcomes are not favorable for them then before showing any reaction they would first see the whole process of outcome determination.

\subsection{Procedural Justice and Organizational Trust}

Robinson (1996) defined trust as ones expectations, assumptions, or beliefs about the likelihood that anothers future actions will be beneficial, favorable, or at least not detrimental to ones interest (p. 575).Organizational trust is a psychological implicit relationship between employee and organization and trust lacks when one of them breaks this relation (Hopkins and Weathington, 2006). Trust can be defined as a psychological state comprising the intention to accept vulnerability based upon positive expectations of the intentions or behavior of another (Rousseau et al., 1998). There are some important parts of the definition. Firstly the trust includes risk; secondly, it involves expectations of the truster that the other party would perform behaviors that are desired to the truster. So the trustee must be able to act according to the desires of the truster and must have the willingness to do so. Thirdly, the desired behaviors of the truster must be somewhat important to the trustee. For example if he is expected to work hard the hard work must be associated with some bonus or extra pay. It is considered as multidimensional; consisting of four dimensions of trust, i.e. the competence, openness, concern and reliability (Wong et al., 2012) and multifocal construct such as employees encompass trust towards co-workers, direct boss, and entire organization (Lehmann-Willenbrock et al., 2013).
A study by Tzafrir et al. (2004) showed a significant impact of procedural justice on trust. Zeinabadi and Salehi (2011) investigated two links to predict OCB; one through organizational trust and second through job satisfaction and organizational commitment, based on data from public schools teachers and principals. Procedural justice has impact on trust. But in this study researchers do not apply the target specific and multidimensional approach. In the study of Hubbell and Chory-Assad (2005) who took data from different organizations on the basis of geographic region and revealed that procedural justice is found to be an antecedent of organizational trust as well as managerial trust. On the other hand, distributive justice only has an impact on managerial trust and no impact on interactional justice or trust. SPENCE LASCHINGER et al. (2012) gathered data from three joint ventures of one province of China to inspect the relationships between organizational justice, perceived organizational support, organizational trust and organizational citizenship behavior. Their results showed a significant impact of procedural justice on trust. Similar results were found by Aryee et al. (2002); Hopkins and Weathington (2006); in their respective studies.

H1. Higher the perception of procedural justice, stronger is the trust of employees on the organization.

\subsection{Procedural Justice and Turnover Inten- tion}

Employees withdrawal is a worldwide phenomenon in the current age. According to Currivan (1999), Turnover is a behavior which describes the process of leaving or replacing employees in an organization. It is a behavioral withdrawal reaction (Geurts et al., 1999), a degree of intention to leave. Turnover intention is a known factor for actual turnover of employees. The intension to quit does not always lead to quitting, but chances of quitting are very high turnover intention is viewed as employees having strong willingness to leave their job in which they are working, due to the reason they are not satisfied with the pay procedures, lack of commitment towards organization, have feeling of inequality and so they want to leave.

Employees, who intend to leave the job, may perceive their organizational procedures, rules, policies, methods as unfair to them (Folger and Cropanzano, 1998). Aryee et al. (2002) in their study took full time employees of public sector of India and found that procedural justice negatively affects the turnover intention of employees. Johan et al. (2013) examined in their study the correlation between procedural justice and turnover intention and found significant negative correlation between the two. Çelik et al. (2016); Lin and Chen (2004) also showed same results in their respec- 
tive studies.

H2. Higher Perception of procedural justice, lower is turnover intention of employees.

\subsection{Trust and Turnover Intention}

In previous research it is shown that trust cushions the undesirable and off-putting working actions for example nonattendance and turnover (Hopkins and Weathington, 2006; Way et al., 2007). It can be concluded that the presence of trust within an organization results in motivation which brings positive outcomes like feeling of support from and attachment to the organization and consequently employees would be eager to remain part of the institute, have low intentions to quit. Employees who find alternative job possibilities, are less committed, and have higher turnover intention (Mobley et al., 1979). When workers dont have any trust in organization then they decide to leave (Koslowsky and Caspy, 1991). An employee attitude towards job is very important, it describes his intentions to leave or not. Low affiliation to organization causes leaving desires in employees and directs them to search another job; this creates a sense of confusion in their mind (Mobley et al., 1978). A feeling of trust, affiliation with current job reduces the chances of quitting the job. Aryee et al. (2002) also shows negative relation between trust and turnover intention.

H3. Higher trust in organization, lower is the turnover intention of employees.

\subsection{Organizational Trust as a Mediator}

Some direct relations in previous researches have been eliminated and ensuring the trust mediation between them e.g. the direct relation of Procedural justice to organizational citizenship behavior and Organizational commitment and they found significant indirect effect between procedural justice and OCB and OC and taking trust as an imperative mediator (Hopkins and Weathington, 2006; Zeinabadi and Salehi, 2011). Similarly, when employees perceived organization as procedurally fair, it enhanced their trust on organization and lead to less intention to leave organization. (Aryee et al., 2002) in their study revealed a partial mediation of organizational trust between procedural justice and turnover intention. Hopkins and Weathington (2006) conducted a study among survivors of an organization that had recently completed an organizational downsizing and also found the partial mediation of organizational trust between procedural justice and turnover intention.

H4. The relationship between procedural justice and turnover intention is mediated by organizational trust.

\section{Theoretical framework}

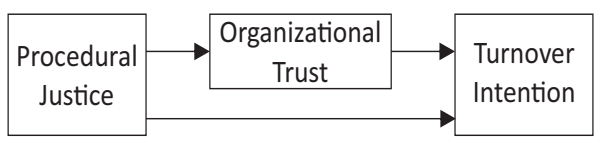

Figure 1: proposed model

\section{Methodology}

\subsection{Sample of study}

The participants are faculty members of the public and private sector universities of twin cities of Pakistan. For this purpose Convenient sampling method was used and questionnaires were distributed in limited universities (PMAS arid agriculture, AIR University, BAHRIA University, NUML, etc). Structured Questionnaires were distributed in different universities and total number of $\mathrm{N}=141$, self administered questionnaires filled by respondents were taken. The $64.5 \%$ respondents were male and remaining $35.5 \%$ were female. Majority respondents $(39.7 \%)$ were lying in the age range of 30-39, followed by $22.0 \%$ between $25-29$ range and $19.9 \%$ between $40-49$ ranges. In marital status $63.8 \%$ were married and $35.5 \%$ single. Majority $(68.8 \%)$ were from private sector and remaining $31.2 \%$ from public sector universities. Maximum respondents job tenure was 3-4 year (33.3\%). Monthly income of majority respondents was between in the range of 4100050000, whereas, $9.9 \%$ respondents did not show their monthly income.

\subsection{Measures}

For uniformity and consistency purpose, we managed all items using a 5-point Likert-type scale ( $1=$ strongly disagree, $5=$ strongly agree). Several scales are modified from their original form.

\subsubsection{Turnover intentions}

A scale for turnover intention was adopted by Aryee et al. (2002). Items included were I often think about quitting my job with my present organization; I will probably look for a new job within the next year.

\subsubsection{Procedural justice}

Procedural Justice Scale was adapted from Moorman (1991). It consists of seven items. This scale shows reliability of .94 in previous study Hopkins and Weathington (2006). Some questions of scale are; my organizations formal procedures are designed to collect accurate information necessary for making decisions; My 
Table 1: Correlation Matrix \& Reliabilities

\begin{tabular}{llccccccc}
\hline & Scale & Mean & SD & Min & Max & $\mathbf{1}$ & $\mathbf{2}$ & $\mathbf{3}$ \\
\hline $\mathbf{1}$ & Procedural Justice & 3.56 & 0.92 & 1 & 5 & $1(.899)$ & & \\
$\mathbf{2}$ & Turnover Intention & 2.42 & 1.15 & 1 & 5 & $-.560^{* *}$ & $1(.878)$ & \\
$\mathbf{3}$ & Organizational justice & 3.71 & 0.81 & 2 & 5 & $.734^{* *}$ & $-.545^{* *}$ & $1(.902)$ \\
\hline$N=141,{ }^{* *} p<.01$ & & & & & & &
\end{tabular}

Table 2: Regression Results

\begin{tabular}{lcccccc}
\hline Predictors & \multicolumn{3}{c}{ Organizational Trust } & \multicolumn{3}{c}{ Turnover Intention } \\
& $\beta$ & $R^{2}$ & $\Delta R^{2}$ & $\beta$ & $R^{2}$ & $\Delta R^{2}$ \\
\hline Procedural justice & $0.650^{* * *}$ & 0.54 & 0.535 & $-.707^{* * *}$ & 0.314 & 0.309 \\
Organizational trust & & & & $-.777^{* * *}$ & 0.297 & 0.292 \\
\hline$N=141,{ }^{* * *} p<0.001,{ }^{*} p<0.05$ & & & & & &
\end{tabular}

organizations formal procedures are designed to provide opportunities to appeal or challenge the decision; My organizations formal procedures are designed to generate standards so that decisions can be made with consistency.

\subsubsection{Organizational trust}

Organizational trust scale was measured with nine items developed by Neininger et al. (2010). 6- Point answering format was converted to 5-point $(1=$ strongly disagree, $5=$ strongly agree) for convenience. Cronbach alpha value for organizational trust was recorded .89 in recent year study (Lehmann-Willenbrock et al., 2013). Sample items for organizational trust were: Information can be shared openly within $X$ (insert name of organization); I feel encouraged to do a good job at $X$; I have positive feelings about the future direction of $X ; X$ offers a supportive work environment; Processes within $X$ are fair, etc.

\section{Results}

Table 1 depicts Mean, Standard Deviation, Range and Alpha Reliability Coefficients of each Measure ( $\mathrm{N}=141)$. According to the above information, the scale of Organizational trust shows highest value of alpha (.902). Whereas, the minimum value of alpha coefficient (.878) was for turnover intention which shows that questionnaires were reliable as they meet the minimum acceptable standard for alpha, which should be at least 0.70 (Nunnally, 1978).

\subsection{Regression}

Table 2 shows the results of regression analysis. Hypotheses were tested through linear regression anal- ysis using SPSS. We do not take control variables in our study as it did not have any significant relation with variables. Mediation analysis is carried by following Baron and Kenny (1986). According to the statistical results, first hypothesis is accepted $(=.650, \mathrm{p}=.000)$ and shows that perception of employees about the means and methods of organization which are used by organization to take decisions about employees, leading to higher the trust level of employees. Second hypothesis tested that when employees found their organization procedurally fair; they have fewer intentions to leave the organization. And statistical analysis supports it (= -.707, $\mathrm{p}=.000$ ). Third hypothesis is also supported in our study which tested $(=-.777, \mathrm{p}=.000)$ that the higher trust in organization, the lower is turnover intention of employees.

Table 3: Regression for Outcomes

\begin{tabular}{lccc}
\hline Predictors & \multicolumn{3}{c}{ Turnover Intention } \\
& $\beta$ & $R^{2}$ & $\Delta R^{2}$ \\
\hline Step 1 & & & \\
Organizational trust & $-.777^{* * *}$ & 0.297 & 0.292 \\
Step 2 & & & \\
Organizational trust & $-.413^{* *}$ & & \\
Procedural justice & $-.438^{* *}$ & 0.353 & 0.344 \\
\hline$N=141^{* * *} p<.001,{ }^{* *} P<.01$ & &
\end{tabular}

Fourth hypothesis tested that organizational trust mediated the relation between procedural justice and turnover intention. It has also been accepted as per the results of regression shown in table 3. As effect of procedural justice on turnover intention $(=-.707$, 
$\mathrm{p}=.000)$ was significantly declined when effect of organizational trust is controlled (from $=-.707, \mathrm{p}=.000$, to $=.438, \mathrm{p}=.001$ ). It shows that organizational trust has partial mediation effect on this relation.

\section{Discussion}

Our findings prove that the higher Perception of procedural justice, the stronger the trust of employees on the organization. Evidences from prior studies (Colquitt and Rodell, 2011; Greenberg, 1987; Pillai et al., 2001) also support it. Our research provides the pragmatic evidence that the trust of employees on the organization has a dominant impact on the organization. Our second hypothesis stated that higher Perception of procedural justice; leads to lower turnover intention of employees. Our findings proved this and it is also consistent with prior studys findings (Aryee et al., 2002; Folger and Cropanzano, 1998). Our third hypothesis is the higher trust in organization; the lower is turnover intention of employees. Our research provides the empirical evidence that the trust on the organization has a dominant impact on the turnover intentions of employees. The study shows that the organizational trust leads to the lowering of intensions among the employees to leave the organization. In previous researches it has demonstrated that more trust stifles undesirable outcomes, i.e. absence and turnover (Way et al., 2007). When we look at the previous studies, the relationship between trust and intension to quit is strongly supported. Fourth hypothesis of our study is the relationship between procedural justice and turnover intention is mediated by organizational trust. In fact, using fair procedures enhances the trust of employees on the organization as result of which they own their organization and subsequently the intensions of the employees to leave the organization are decreased. There is support from previous researches that organizational trust mediates between procedural justice and turnover intention (Hopkins and Weathington, 2006). Fifth hypothesis is the higher Perceived alternative job opportunities, the higher are turnover intention. Our findings strongly proved this hypothesis. Researches of previous studies also show consistent results to this (Hwang, 2006; Rahman et al., 2008).

\subsection{Implications}

This research has implications for organizational policy makers and researchers. It is aimed at improving the effectiveness of the organizations. This study provides more comprehensive understanding about how trust \& justice impact the intentions of employee to leave the organization. Firstly our study tells about the procedural justice and organizational trust which improve the employees job related attitudes and behav- iors.

This research finds the impact of procedural justice and turnover intention, organization trust as a mediator between them. The results show that the fairness perception of procedures, processes and the level of employee trust on the organization affect the employees intentions to leave the organization. So the research also has implications for the social exchange theory. Organizations have impact on motivating the social exchange indicators among employees through building trust among the employees and ensuring the fairness of procedures of making decisions.

The organizational authorities should try to ensure that the procedures of allocating the outcomes to the employees are fair and consistently applied to all employees equally. More specifically organizations can control turnover rate of employees by not just focusing procedural fairness, but also by developing employees trust on the organization. Through this process employees would become more trusted one to the organization and never try to quit.

\subsection{Limitations}

The generalizability of our research is restricted by some limitations. First of all the scales were adapted from the researches which conducted in West used for the research. So such scales would not be very much effective in the Asian conditions. Such measure must be adapted and refined to make them fit to the particular conditions. Secondly, we collected all the data at the same time, while we wanted to see the causal relationships between different variables. So the data collected through cross-sectional method would not be able to confirm such casual relationships, instead a longitudinal research design is needed for confirmation. Thirdly, the data collected for this research can be subjected to common- method bias, because same questionnaires were used to collect all the data. Another important limitation would be that because the data were collected from the universities of Rawalpindi and Islamabad, the effect of gender on variables of our study, was not considered. Similarly, all the data collected from the teachers in the universities of Rawalpindi and Islamabad; there is a need to replicate the results in the corporate sector using the larger samples so that the variables relationship strength may differ with other work settings. Lastly, technique of sampling would be a big question mark to the generalizability of the results. Although, our study gives explanation for causal relationship; it does not recognize correlation relationship.

\subsection{Future recommendations}

Our research gives opportunity for many possibilities in future. Further research should confirm the 
finding of this paper. We have taken procedural justice as an independent variable in our model which is basically concerned with the perception of employees about how fair are the procedures of allocation of outcomes to them. Such perceptions of employees build up trust of employees on the organization and lead to many attitudes. But many questions are still unexplored including what effects, if any, a fair process has on the performance of the employees individually and in team settings also? Can this perception of fairness of procedures be helpful in overcoming the weaknesses present in the employees? To what extent the fairness of procedures lead to the overall effectiveness of the organization?

Along with answering these questions, future research can also focus on other dimensions of justice including interactional and systematic justice which will lead to individual level outcomes and job outcomes (DeConinck and Stilwell, 2004; Sweeney and McFarlin, 1993; Tekleab et al., 2005) it will provide more comprehensive understanding.

Further researches should segregate the results of private and public sector; researchers should investigate how much result is different in both sectors. Comparison of both sectors is recommended in future. We have seen the effect of perception of fairness of procedures in the model of turnover intensions in the education sector. Future researchers can focus on economic sector also. Moreover next studies can make comparison between public sector institutes and private sector institutes. They can investigate that which sector is more procedurally fair and how much results are dissimilar.

\section{References}

Aryee, S., Budhwar, P. S., and Chen, Z. X. (2002). Trust as a mediator of the relationship between organizational justice and work outcomes: Test of a social exchange model. Journal of organizational Behavior, 23(3):267-285.

Baron, R. M. and Kenny, D. A. (1986). The moderatormediator variable distinction in social psychological research: Conceptual, strategic, and statistical considerations. Journal of personality and social psychology, 51(6):1173.

Çelik, D. A., Yeloğlu, H. O., and Yıldırım, O. B. (2016). The moderating role of self efficacy on the perceptions of justice and turnover intentions. Procedia-Social and Behavioral Sciences, 235:392-402.

Choi, K. (2006). A structural relationship analysis of hotel employees' turnover intention. Asia Pacific Journal of Tourism Research, 11(4):321-337.

Colquitt, J. A., Conlon, D. E., Wesson, M. J., Porter, C. O., and
$\mathrm{Ng}$, K. Y. (2001). Justice at the millennium: a meta-analytic review of 25 years of organizational justice research.

Colquitt, J. A. and Rodell, J. B. (2011). Justice, trust, and trustworthiness: A longitudinal analysis integrating three theoretical perspectives. Academy of Management Journal, 54(6):1183-1206.

Currivan, D. B. (1999). The causal order of job satisfaction and organizational commitment in models of employee turnover. Human resource management review, 9(4):495-524.

DeConinck, J. B. and Stilwell, C. D. (2004). Incorporating organizational justice, role states, pay satisfaction and supervisor satisfaction in a model of turnover intentions. Journal of Business Research, 57(3):225-231.

Folger, R. G. and Cropanzano, R. (1998). Organizational justice and human resource management, volume 7 . Sage.

Geurts, S. A., Schaufeli, W. B., and Rutte, C. G. (1999). Absenteeism, turnover intention and inequity in the employment relationship. Work E Stress, 13(3):253-267.

Gopinath, C. and Becker, T. E. (2000). Communication, procedural justice, and employee attitudes: Relationships under conditions of divestiture. Journal of management, 26(1):6383 .

Greenberg, J. (1987). A taxonomy of organizational justice theories. Academy of Management review, 12(1):9-22.

Hemdi, M. A. and Nasurdin, A. M. (2007). Investigating the influence of organizational justice on hotel employees' organizational citizenship behavior intentions and turnover intentions. Journal of Human Resources in Hospitality $\mathcal{E}$ Tourism, 7(1):1-23.

Hopkins, S. M. and Weathington, B. L. (2006). The relationships between justice perceptions, trust, and employee attitudes in a downsized organization. The Journal of Psychology, 140(5):477-498.

Hubbell, A. P. and Chory-Assad, R. M. (2005). Motivating factors: Perceptions of justice and their relationship with managerial and organizational trust. Communication Studies, 56(1):47-70.

Hwang, I.-S. (2006). Dr. dan jyh-huei kuo, 2006,effects of job satisfaction and perceived alternative employment opportunities on turnover intention-an examination of public sector organizations. The Journal of American Academy of Business, Cambridge, 8.

Ingersoll, R. M. (2001). Teacher turnover and teacher shortages: An organizational analysis. American educational research journal, 38(3):499-534.

Johan, M., Talib, M., Joseph, T. M., and Mooketsag, T. L. (2013). Procedural and distributive justice on turnover intention: an exploratory analysis. Interdisciplinary journal of contemporary research in business, 4(9):182-191.

Khatri, N., Fern, C. T., and Budhwar, P. (2001). Explaining employee turnover in an asian context. Human Resource Management Journal, 11(1):54-74. 
Khattak, N. A. (2010). Customer satisfaction and awareness of islamic banking system in pakistan. African Journal of Business Management, 4(5):662.

Koslowsky, M. and Caspy, T. (1991). Stepdown analysis of variance: A refinement. Journal of Organizational Behavior, 12(6):555-559.

Lambert, E. G., Hogan, N. L., Dial, K. C., Jiang, S., and Khondaker, M. I. (2012). Is the job burning me out? an exploratory test of the job characteristics model on the emotional burnout of prison staff. The Prison Journal, 92(1):3-23.

Lehmann-Willenbrock, N., Grohmann, A., and Kauffeld, S. (2013). Promoting multifoci citizenship behavior: Timelagged effects of procedural justice, trust, and commitment. Applied Psychology, 62(3):454-485.

Li, A. and Bagger, J. (2012). Linking procedural justice to turnover intentions: A longitudinal study of the mediating effects of perceived job characteristics. Journal of Applied Social Psychology, 42(3):624-645.

Lin, C.-P. and Chen, M.-F. (2004). Career commitment as a moderator of the relationships among procedural justice, perceived organizational support, organizational commitment, and turnover intentions. Asia Pacific Management Review, 9(3):519-538.

Mobley, W. H., Griffeth, R. W., Hand, H. H., and Meglino, B. M. (1979). Review and conceptual analysis of the employee turnover process. Psychological bulletin, 86(3):493.

Mobley, W. H., Horner, S. O., and Hollingsworth, A. T. (1978). An evaluation of precursors of hospital employee turnover. Journal of Applied psychology, 63(4):408.

Moorman, R. H. (1991). Relationship between organizational justice and organizational citizenship behaviors: Do fairness perceptions influence employee citizenship? Journal of applied psychology, 76(6):845.

Neininger, A., Lehmann-Willenbrock, N., Kauffeld, S., and Henschel, A. (2010). Effects of team and organizational commitment-a longitudinal study. Journal of Vocational Behavior, 76(3):567-579.

Nunnally, J. (1978). Psychometric methods.

Pillai, R., Williams, E. S., and Justin Tan, J. (2001). Are the scales tipped in favor of procedural or distributive justice? an investigation of the us, india, germany, and hong kong (china). International Journal of Conflict Management, 12(4):312-332.

Poon, J. M. (2012). Distributive justice, procedural justice, affective commitment, and turnover intention: A mediation-moderation framework. Journal of Applied Social Psychology, 42(6):1505-1532.
Rahman, A., Naqvi, S., and Ramay, M. I. (2008). Measuring turnover intention: A study of it professionals in pakistan. International Review of Business Research Papers, 4(3):45-55.

Robinson, S. L. (1996). Trust and breach of the psychological contract. Administrative science quarterly, pages 574-599.

Rousseau, D. M., Sitkin, S. B., Burt, R. S., and Camerer, C. (1998). Not so different after all: A cross-discipline view of trust. Academy of management review, 23(3):393-404.

SPENCE LASCHINGER, H. K., Wong, C. A., Grau, A. L., Read, E. A., and PINEAU STAM, L. M. (2012). The influence of leadership practices and empowerment on canadian nurse manager outcomes. Journal of nursing management, 20(7):877-888.

Sweeney, P. D. and McFarlin, D. B. (1993). Workers evaluations of the. Organizational behavior and human decision processes, 55(1):23-40.

Tekleab, A. G., Bartol, K. M., and Liu, W. (2005). Is it pay levels or pay raises that matter to fairness and turnover? Journal of Organizational Behavior, 26(8):899-921.

Tulubas, T. and Celep, C. (2012). Effect of perceived procedural justice on faculty members silence: the mediating role of trust in supervisor. Procedia-Social and Behavioral Sciences, 47:1221-1231.

TZAFRIR, S. S., BEN-GAL, H. C., and DOLAN, S. L. (2012). 13 exploring the etiology of positive stakeholder behavior in global downsizing. Downsizing: Is less still more?, page 389.

Tzafrir, S. S., late Gedaliahu H. Harel, Baruch, Y., and Dolan, S. L. (2004). The consequences of emerging hrm practices for employees' trust in their managers. Personnel Review, 33(6):628-647.

Way, C., Gregory, D., Davis, J., Baker, N., LeFort, S., Barrett, B., and Parfrey, P. (2007). The impact of organizational culture on clinical managers' organizational commitment and turnover intentions. Journal of Nursing Administration, 37(5):235-242.

Wong, Y.-T., Wong, C.-S., and Ngo, H.-Y. (2012). The effects of trust in organisation and perceived organisational support on organisational citizenship behaviour: A test of three competing models. The International Journal of Human Resource Management, 23(2):278-293.

Zeinabadi, H. and Salehi, K. (2011). Role of procedural justice, trust, job satisfaction, and organizational commitment in organizational citizenship behavior (ocb) of teachers: Proposing a modified social exchange model. ProcediaSocial and Behavioral Sciences, 29:1472-1481. 


\title{
Global Portfolio Diversification and Equity Market: Evidence from Trading Partners of Pakistan
}

\author{
Muhammad Husnain $^{1}$, , Um-e-Habiba ${ }^{2}$, Shahnaz Akhtar Arifullah ${ }^{3}$, Izhar Muhammad ${ }^{4}$ \\ ${ }^{1}$ Universidad de Extremadura, Spain. \\ ${ }^{2}$ School of Finance $\mathcal{E}$ Economics, Jiangsu University, China. \\ ${ }^{3}$ Institute of Development Studies, The University of Agriculture, Peshawar, Pakistan. \\ ${ }^{4}$ Capital University of Science and Technology, Islamabad, Pakistan.
}

\begin{abstract}
The influential work of Markowitz $(1952,1959)$ provides foundation to modern investment philosophy. Investors can reap the potential benefit of portfolio diversification only if the involved asset classes in investment basket are not perfectly correlated. Objective of this study is to empirically investigate the cointegration among equity market of Pakistan and its major trading partners (China, France, Germany, Hong Kong, Japan, Korea, Malaysia, UK and USA). Sample period of study starts from 2004 to 2015, on weekly basis. Bivariate cointegration (Johansen, 1991, 1995) analysis reveals that equity market of Pakistan has no long term relationship with any of the equity markets of its major trading partners. Therefore, we recommend to potential investors, portfolio managers, and policy makers that prospective benefit of portfolio diversification can be achieved by investing in the equity markets of major trading partners of Pakistan. Further, they should be vigilant regarding the co-movement among equity markets during portfolio management decisions.
\end{abstract}

\section{Introduction}

Globalizations of economies, deregulation of economic activities and rapid advances in communication technologies have enabled the stock markets to effectively mobilize savings across international borders. This phenomenon is contributing to well being of all nations in the shape of increased savings and investments, competitive prices, developed financial as well as product markets. Advanced capital markets and liberalization of stock markets have increased the investors interest in international diversification (Cotter and Stevenson, 2006; Kallberg et al., 2002; Liow et al., 2009). Diversification means reducing investment risk and increasing the probability of returns by putting investment in different security assets, subject to the condition that the values of the securities do not dance in unison (having no perfect or near perfect correlation).

Theory of diversification suggests that there are two major causes of risk in investment. Firstly, the security in which investor invests loses its value abruptly due to some unexpected or unforeseen events. The second major cause of downward movement of the value of a security asset is due to factors like overinvestment in it. If the value of a firm starts upward movement due to some favourable news, investors start buying it. The buying momentum may continue till the asset

*Corresponding author.

Email: husnain207@hotmail.com is overpriced. When investors realise that the security has been overpriced, they start selling it. As a result of selling, value of the asset starts declining, bringing the value of the security down below its real (intrinsic) value. If funds are invested in more than one assets, the chances or (risks) of losing all investment due to some unforeseen incident(s) diminishes because it is less likely that the values of all invested assets would fall simultaneously (Ghosh and John, 1999; Gupta and Guidi, 2012; Hoque et al., 2007; Mukherjee and Bose, 2008; Siklos and Ng, 2001; Wong et al., 2004). In case there is a synchronised up and downward movement of values among securities, investing in them would be like investment in a single security and thus chances of losses would be maximum. Therefore, investors and fund managers should initially examine the past history of the changing values of asset and then invest in the security that is having independent movement trend in its values.

Looking from a different perspective, linking of international markets can pose another challenge to the investors as well as international financial integration. Recently, some financial markets have been showing synchronised reactions to some common events (e.g; stock markets response to credit market failure in United States in 2008). This trend has forced the financial analysts to reassess the heterogeneity in the 
movement of stock prices in different countries. If the integration of equity markets of different countries has reached to a level that one common shock can affect it equally, then diversified investment in it may not give the expected positive results (Chuluun and Graham, 2016; Cohen et al., 2008; Fu and GuptaMukherjee, 2014). The purpose of this study is to empirically investigate co-movement in the stock markets of the countries with which Pakistan has major trade relations. Hence, it is an attempt to analyze the long term as well as short term relationship between Pakistani equity market and equity markets of its major trading partners.

If there is long term relationship between Pakistani equity market and equity markets of its major trading partners then it can be safely concluded that there is no opportunity in term of portfolio diversification for Pakistani investor in the equity markets of its major trading partners. Hence this study will contribute in the existing literature by giving proper guidelines to investors, financial institutions and policy makers that they should be vigilant regarding the co-movement between equity markets before taking any prosperous investment decision. This study is important and lucrative for international investors as it may prove helpful to guide their investments decisions. They should be vigilant regarding the long term relationship between equity market of Pakistan and its major trading partners before attracting any flourish decision.

\section{Literature Review}

The followers of the modern portfolio theory believed that investors and fund managers can put their total assets into different baskets and can invest into different across boarder markets until and unless the return from the international markets is perfectly correlated with the return of domestic market. The prior studies examined that this portfolio diversication include Lessard (1973), Levy and Sarnat (1970) and Solnik (1974). But these are the earliest studies that proved the theory of diversification, i.e. it reduces the risk of basket. Hence if the stock markets of different countries are highly interrelated then this interdependence can wipe out the benefit of diversification for investors. Moreover, if markets are integrated then any financial crises in one economy may proof a source of disturbance for other interlinked economies (Cotter and Stevenson, 2006; Liow et al., 2009; Liow and Yang, 2005). A number of studies explored the interdependences between the equity markets of different countries by using various econometrics models such as Kasa (1992), Liow et al. (2009), Nasseh and Strauss (2000), Bekaert et al. (2011), Shamsuddin and Kim (2003), Cotter and Stevenson (2006); Pukthuanthong and Roll (2009), and Ryan and Gerard (2003).
A plethora of literature concludes that interdependence of stock market prices in different countries increases during and after financial hardships (Bekaert et al., 2011, 2008; Berger, 2011; Donadelli and Persha, 2014; Eiling and Gerard, 2007; Lahrech and Sylwester, 2011; Rajan and Zingales, 2003).Arshanapalli and Doukas (1993) analyzed the stock price comovement in major stock exchanges namely, the Dow Jones, FAZ (Frankfurt), FTSE 100, Nikkei and CAC (Paris). The study indicated that except for the Nikkei, stock prices of the under study markets have shown significant synchronization after the stock market crises of October 1987. Arshanapalli et al. (1995) also found significant increase in interdependence of Asian-Pacific markets after the 1987 collapse. Longin and Solnik (1995) and Karolyi and Stulz (1996) while investigating the interdependence of major European countries and Japanese and U.S stock markets respectively, concluded that correlation between stock prices increases during unstable and volatile market conditions, highly depressing the returns expected from portfolio diversification.

Interdependence of stock prices of international stock markets was also investigated by Hassan and Naka (1996) and Bekaert et al. (2008) for the period before and after 1987 stock markets crash. The study revealed that there was a significant multilateral relationship among the stock prices of United States, United Kingdom, Japan, and Germany for the period under investigation. In addition, the results of the study also highlighted that the United States stocks were the most influential in affecting the stocks of the remaining under investigation countries during stock market crises. Studies such as Lucey and Zhang (2010), Brooks and Del Negro (2004); Lahrech and Sylwester (2011), and Höchstötter et al. (2014) also discussed the co-movements among equity markets. Liu et al. (1999) have studied the changes in stock prices of Japan, U.S, Singapore, Hong Kong, Taiwan and Thailand. The study found that relation between stock returns of Asian-Pacific markets has gained strength after 1987 stock market crash. The study also concluded that increased relationship between stock price changes has reduced the benefit of diversification in equity market.

The influence of the Japanese and the United States markets on the stocks of Asian countries was empirically analyzed by the study of Cha and Oh (2000). The findings of the study indicated that co-movement between the stock markets of Japan and United States, and developing Asian countries has started to change after 1987 stock market crash. Financial contagion further explored by the different researchers such as Bae et al. (2003), Rua and Nunes (2009), Chue (2005), Van Rijckeghem and Weder (2003), Pretorius (2002), Johnson and Soenen (2003), Asgharian et al. (2013), Claus and Lucey (2012) and Forbes and Rigobon (2002). Another interesting finding of the study was that cor- 
relation between these markets has gained strength after the 1997 currency crises in Asia. Yang (2002) seeks to determine the long-term co-movement in the stock markets of East Asian countries namely, Hong Kong, Indonesia, Korea, Malaysia, Thailand, the Philippines, Singapore and Taiwan. The results of his study suggested that there was no synchronization among the stock prices of these countries during the 1997 to 1998 financial distress. Daly (2003) examined the static and dynamic linkages among the stock markets of Indonesia, Malaysia, Philippines, Singapore, Thailand, and that of the stock markets of developed countries like Australia, Germany and the United States from April 1990 until October 2001. The study concluded that there was a strong correlation among these stock markets. The study also suggested that except for Malaysia and Singapore the co-movement of stock prices gained more strength after 1997 financial crises.

Another group of studies have investigated the comovement of stock markets returns citing reasons like influence of some advanced stock markets on other markets, economic interdependence, trade relationship, and geographical location on the stock markets synchronization. Findings of Eun and Shim (1989) indicated that US stock markets were the most influential in affecting the stock markets of other countries. Roca, Selvanathan and Shepherd (1998) analyzed the equity prices correlation among the stock markets of Malaysia, Singapore, Thailand, Indonesia and Philippines (five countries of Association of South East Asian Nations). The findings of the study pointed out that there was no long run co-movement in the stock market of these countries. Another conclusion of the study was that Malaysia was the most influential market in these countries; also, Neaime (2012), Thalassinos et al. (2003), Caporale et al. (2005), Forbes and Rigobon (2002), Agarwal and Taffler (2008), Voronkova (2004), Johnson and Soenen (2003), Barari (2004), Phylaktis and Xia (2006), Berben and Jansen (2005) and Brooks and Negro (2006) focused on the long term relationship in equity markets. Hashmi and Xingyun (2001) sought to determine the linkages among Southeast Asian countries, Tokyo and New York stock markets before and after the Asian financial crash. The study concluded that New York stock market had a strong influence on the Southeast Asian stock markets but the effect is unilateral. The Tokyo stock market appeared to be isolated in the region. The Malaysian Stock Exchange was also found to be isolated from the regional stock markets after the Asian financial crash.

In the same footing, Walti (2005) while studying the stock returns of fifteen industrialized countries for the period 1973 to 1997, concluded that trade, financial integration and fixed exchange rates enhanced crossmarkets co-movements. Morgado and Tavares (2007) investigated the effect of trade on the co-movements of share prices of 40 developed and emerging markets for the period 19701990. The study concluded that trade linkages have significant impact on stock prices synchronization. Further studies such as Sun and Zhang (2001), Sun and Seiler (2013), Chi et al. (2009), Chien (2010), Mei and Clutter (2010), and Cascio and Clutter (2008) focused on the long run relationships in real estate markets. Forbes and Rigobon (2002) pointed out that during volatile market conditions the relation between various market prices were strongly affected by heteroskedesticity. They concluded that it was economic interdependence and not the markets volatility which force these markets to move together. Ampomah (2008) concluded that African stock markets were not synchronized with international equity markets and thus suitable for returns from portfolio diversification.

On the basis of all above discussion it can be summarized that different researchers studied the equity markets of different countries with different perspective. Some of them analyzed the cointegration among the equity markets of different countries by employing different econometric models. But there exists limited literature which focuses on analyzing the cointegration between Pakistan and its major trading partners. To do this, we use different latest methodologies available in the econometrics literature for cointegration. We apply the Johansen approach for co-integration along with error correction model, variance decomposition analysis and impulse response analysis. The discussion regarding the data and methodological issues are presented in the following section.

\section{Data and Research Methodology}

Study uses the Bloomberg database to collect the time series of the equity indices of major trading partners of Pakistan. Our study period consists of almost twelve years on weekly basis from January 2004 to October 2015. This study considers the major trading partner of Pakistan consisting of China, France, Germany, Hong Kong, Japan, Korea, Malaysia, UK and USA. Table 1 presents the details of selected stock indices of Pakistan and its major trading partner.

The change in the price of each index is calculated by using the following equation:

$$
R_{t}=\ln \left(\frac{Y_{t}}{Y_{t-1}}\right) \ldots \ldots(1)
$$

Where $R_{t}$ is the continuous compounded return for week $t$ and $Y_{t}$ and $Y_{(t-1)}$ stand for closing values for week $t$ and $t-1$ respectively.

Stationarity of the time series is one of the basic assumptions of the Cointegration analysis. This study uses the Augmented Dickey Fuller (ADF) test (Dickey and Fuller, 1979) and Phillips-Perron (PP) test (Phillips and Perron, 1988), to test the level of integration of the 
Table 1: Indices of the Pakistani equity markets and its major trading partner

\begin{tabular}{ll}
\hline Country Name & Index \\
\hline Pakistan & KSE-100 INDEX \\
China & CHINA SHANGHAI COMPOSITE INDEX \\
France & CAC 40 \\
Germany & DAX \\
Hong Kong & HANG SENG INDEX \\
Japan & NIKKEI 225 \\
Korea & KOSPI COMPOSITE INDEX \\
Malaysia & KLSE \\
UK & FTSE-100 \\
USA & S \& P 500 INDEX \\
\hline
\end{tabular}

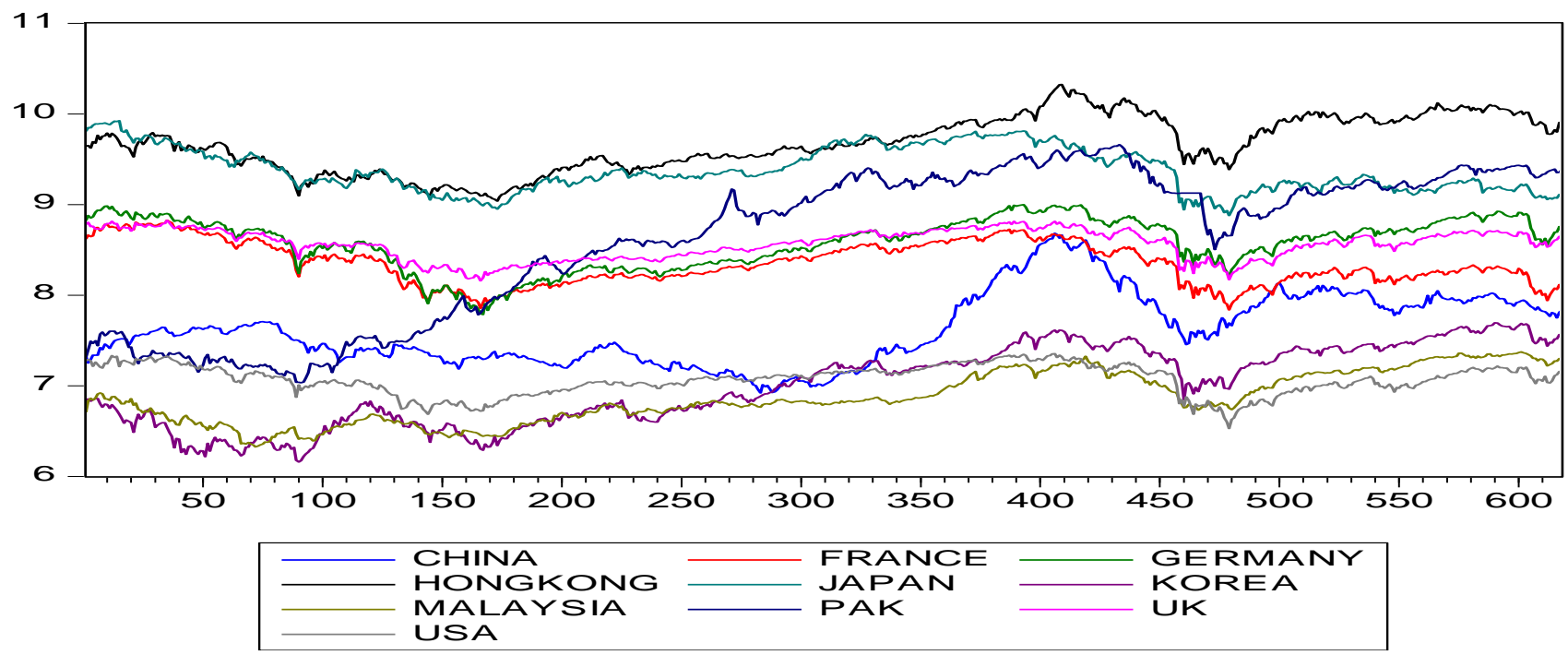

Figure 1:

all the time series. Here the null hypothesis, i.e. the series has a unit root is tested. The acceptance or rejection of this null hypothesis will determine the stationarity in the time series data. The Augmented Dickey Fuller (ADF) test finds out the possibility or existence of unit root by employing an autoregressive (AR) model. The equation for an autoregressive AR (1) model is given below:

$$
P_{t}=\varphi P_{t-1}+\varepsilon_{t}
$$

Where, $P_{t}$ is the variable under study, $t$ shows the time period and $\varepsilon_{t}$ denotes the error term for that period. The following equation can be used as regression equation:

$$
\Delta P_{t}=(\varphi-1) P_{t-1}+\mu_{t}=\delta P_{t-1}+\varepsilon_{t}
$$

Here, $\Delta$ is the symbol of first difference operator. The model of above equation can be estimated for unit root in ADF test. The assumptions behind the Augmented Dickey Fuller (ADF) test are quite strict and it believes on the assumption that the disturbance terms are independent and are homo-skedastic i.e. the variance of the disturbance term is constant over time. So this study also uses a relatively less strict test for the same purpose. The Phillips-Perron (PP) test also applies to check out the stationarity of the time series. The PP test considered a less strict test than of ADF test and it works under the assumption that the error terms are heterogeneously distributed. Mathematically, it can be 
written as:

$$
P_{t}=\rho+{ }_{1} P_{t-1}+{ }_{t}\left\{t-\frac{T}{2}\right\}+\varepsilon_{t}
$$

This study uses the maximum likelihood based Johansen (1994) approach to investigate the long-term relationship. Johansen (1994) co-integration analysis examines the existence of long term co-movement of the any time series. This approach of co-integration put forwards two types of likelihood ratio test for the presence of cointegration equations among the variables. It includes the Trace statistics and maximum eigenvalue test. The maximum eigenvalue test considers the null hypothesis i.e. there are at most $r$ co-integrating vector beside the alternative of the $\mathrm{r}+1$ co-integrating vector and statistically, it can be written as:

$$
\lambda(r)=-N \sum^{I} n\left(1-\lambda_{r+1}\right)
$$

In the above equation, $\lambda_{r+1}, \lambda_{r+2}, \ldots, \lambda_{n}$ are the (n r) smallest squared canonical correlation and $\mathrm{N}$ shows the total number of observations. On the other hand the Trace statistics examines the null hypothesis of $\mathrm{r}$ cointegrating vector beside the alternative of $r$ or greater than $\mathrm{r}$ co-integrating vector and statistically, it can be written as:

$$
\lambda(r)=-N \sum^{I} n\left(1-\lambda_{i}\right)
$$

In the co-integration analysis, after the determination of unit root the next step is to find out the appropriate lag length for vector auto-regression (VAR). The appropriate lag length will be found by considering the Akaike information criterion (AIC), Schwarz information criterion (SIC) and Hannan-Quinn information criterion (HQ). The appropriate lag length will be the lag length where the value of these criteria will be found minimum.

If there is co-integration in the equity markets then VECM can be used to find out the short-term interaction between the different time series. ? explored that if there is long run relationship then to capture the short term divergence, a term of error correction is added into the system of equations. Hence the innovation in the explained variable is a function of the level of dis-equilibrium and change in the independent variables. Here the level of dis-equilibrium is confined by the error correction term in the model. According to the Granger representation, an error correction model (with 2 co-integrating variable) has the following form:

$$
\Delta Y_{t}=\rho+\varphi X_{t}+\varphi_{1} \varepsilon_{t-1}+\vartheta_{t}
$$

Where, $\varepsilon_{t-1}$ shows the error correction term and $\varphi_{1}$ is the coefficient of short tern adjustments. To test out of sample causality, variance composition is also used in this study. It shows the decomposition of the change in the variable, in a specified period which occurs due to the changes due to its own dynamics and also shows the contribution of other variables in prior period. Lütkepohl and Poskitt (1991) presents an impulse response analysis to analyze that how quickly the shocks in one equity market are transferred to rest of the equity markets. The moving average of the vector auto-regression model is used to acquire this.

\section{Empirical Results}

To grasp a rough idea about the long term relationship between the equity market of Pakistan and its major trading partners, we present a line graph. The figure 1 plots the equity indices in their natural logarithmic form of all the studied equity markets.

\subsection{Descriptive Analysis}

Table 2 reports the results of descriptive statistics. The average weekly return in percentage terms of the KSE-100 index is 0.34 percent having a standard deviation of 3.7 percent. Equity markets of USA, UK, Japan, Germany and France are offering weekly negative returns to their investors while the equity markets of Malaysia, Korea, Hong Kong and China are offering positive weekly returns. The result of Skewness which is a measure of normality of data shows that the return of all the indices is negatively skewed or skewed towards left. Similarly the value of kurtosis also supports the results of skewness. One can also find the maximum and minimum value of the weekly returns of all the equity markets for the entire study period.

\subsubsection{Correlation Matrix}

Results of correlation analysis are presented in table 3. Correlation matrix can be used to comment upon the direction and strength of relationship between two variables. From table 3, it can be safely concluded that Pakistan has a weak relationship among all its major trading partners equity market. The relatively strong correlation of KSE-100 index is observed with the equity market of Korea having correlation coefficient $(\mathrm{r})$ of 0.18. Interestingly, equity market of Pakistan has positive association with its entire major trading partners although the strength of this association changes from market to market. Generally it is agreed that correlation matrix is a weak measure to check the relationship between variables as it only discusses the strength and direction of relation without discussing any cause and effect of relationship. Hence we also applied powerful test to further analyze the relationship. 
Table 2: Descriptive Analysis

\begin{tabular}{lcccccccccc}
\hline & PAK & USA & UK & Malaysia & Korea & Japan & Hong Kong & Germany & France & China \\
\hline Mean & 0.0034 & -0.0002 & -0.0003 & 0.001 & 0.0012 & -0.001 & 0.0004 & -0.0002 & -0.0009 & 0.0008 \\
Median & 0.0076 & 0.0009 & 0.0019 & 0.0021 & 0.0058 & 0.0016 & 0.0021 & 0.0033 & 0.0014 & 0 \\
Std. Dev. & 0.037 & 0.028 & 0.0269 & 0.0225 & 0.0389 & 0.0321 & 0.0339 & 0.0355 & 0.0326 & 0.0356 \\
Kurtosis & 3.6236 & 6.5485 & 11.6897 & 3.8591 & 3.5755 & 9.4137 & 2.2101 & 5.0041 & 6.5638 & 1.7684 \\
Skewness & -0.982 & -0.619 & -1.1454 & -0.4024 & -0.54 & -1.29 & -0.2142 & -0.6708 & -0.969 & 0.1509 \\
Range & 0.3288 & 0.3368 & 0.3621 & 0.2404 & 0.3996 & 0.3933 & 0.2953 & 0.3929 & 0.3748 & 0.2884 \\
Minimum & -0.2 & -0.2 & -0.2363 & -0.1145 & -0.229 & -0.278 & -0.1782 & -0.2435 & -0.25 & -0.149 \\
Maximum & 0.128 & 0.1359 & 0.1258 & 0.1259 & 0.1703 & 0.1145 & 0.1172 & 0.1494 & 0.1243 & 0.1394 \\
\hline
\end{tabular}

Table 3: Correlation Matrix

\begin{tabular}{|c|c|c|c|c|c|c|c|c|c|c|}
\hline & PAK & USA & UK & Malaysia & Korea & Japan & HongKong & Germany & France & China \\
\hline PAK & 1 & & & & & & & & & \\
\hline USA & 0.131 & 1 & & & & & & & & \\
\hline UK & 0.109 & 0.7621 & 1 & & & & & & & \\
\hline Malaysia & 0.145 & 0.2684 & 0.2903 & 1 & & & & & & \\
\hline Korea & 0.179 & 0.5095 & 0.491 & 0.3647 & 1 & & & & & \\
\hline Japan & 0.116 & 0.5238 & 0.5808 & 0.3722 & 0.6089 & 1 & & & & \\
\hline Hong Kong & 0.127 & 0.5199 & 0.6292 & 0.4574 & 0.6409 & 0.6259 & 1 & & & \\
\hline Germany & 0.146 & 0.76 & 0.8535 & 0.3488 & 0.5551 & 0.5889 & 0.6099 & 1 & & \\
\hline France & 0.142 & 0.7707 & 0.9016 & 0.3111 & 0.5224 & 0.5927 & 0.6046 & 0.9149 & 1 & \\
\hline China & 0.041 & 0.0869 & 0.0958 & 0.2128 & 0.1739 & 0.176 & 0.2598 & 0.1079 & 0.0946 & 1 \\
\hline
\end{tabular}

\subsubsection{Unit Root test}

Stationarity is one of the key concepts in the time series data. It is necessary to check the data for Stationarity to avoid the problem of spurious regression Asaolu and Ogunmuyiwa (2011). This particular study uses the unit root test to check the Stationarity of time series. We apply Augmented Dickey and Fuller (1979) and Phillips and Perron (1988). The results of both of the ADF and PP test are presented in table 4. In unit root test the null hypothesis which is a particular time series hypothesis having a unit root is tested against the alternate hypothesis claiming that particular time series is stationary. From the table, on the basis of ADF test it can be easily concluded that all the equity indices are not Stationarity at first level but all become stationary after their first difference or all the time series data is integrated of order one i.e. I(1). Results of PP also support the results of ADF test. Hence one can confirm the application of Johansen approach as all the time series are integrated at the same level i.e. I(1).

Before the application of JJ approach, the determination of appropriate lag length is considered an important step. To determine the appropriate lag length of this study we apply different tests up to eight lags. The results of AIC, SC and HQ are presented in table 5. According to the Schwarz information criterion the appropriate lag length for this system is one (1). So for onward, we use lag length for VAR model which is equal to one.

This study uses VAR base Johansen (1991, 1995) procedure for the co-integration which is maximum likelihood based procedure. We have applied two types of test which is suggested by Johansen: (1) Trace Test and (2) Max. eigen value test. The results of both of the cointegration test are presented in table 6 and 7 respectively. The result of Trace test in multivariate 
Table 4: Results of Unit Root test

\begin{tabular}{|c|c|c|c|c|}
\hline & ADF (Level) & ADF (First Dif.) & PP (level) & PP (First Dif.) \\
\hline Pakistan & -0.98 & -22.84 & -1.1 & -23.07 \\
\hline USA & -2.31 & -27.4 & -2.22 & -27.4 \\
\hline UK & -2.29 & -26.56 & -2.17 & -26.63 \\
\hline Malaysia & -0.33 & -15.97 & -0.53 & -24.21 \\
\hline Korea & -0.62 & -25.45 & -0.6 & -25.45 \\
\hline Japan & -1.94 & -25.86 & -1.96 & -25.84 \\
\hline Hong Kong & -1.41 & -24.98 & -1.55 & -25.04 \\
\hline Germany & -1.72 & -25.48 & -1.73 & -25.47 \\
\hline France & -1.57 & -26.49 & -1.51 & -26.51 \\
\hline China & -1.3 & -23.54 & -1.62 & -24.07 \\
\hline \multicolumn{5}{|c|}{ Critical Values } \\
\hline $1 \%$ & -3.44 & -3.44 & -3.44 & -3.44 \\
\hline $5 \%$ & -2.87 & -2.87 & -2.87 & -2.87 \\
\hline $10 \%$ & -2.57 & -2.57 & -2.57 & -2.57 \\
\hline
\end{tabular}

framework suggests that there exist two cointegrating equations at $5 \%$ level. On the other hand, Max. Eigen value test authenticates the one cointegrating equation at $5 \%$ level.

To further analyze the long term nature of relationship between equity market of Pakistan and its major trading partner, we also apply the Johansen approach in bivariate framework. For this purpose we run the Johansen approach between Pakistani equity markets and equity market of each of its trading partners. The results of both tests, i.e. Trace test and Max. Eigen value test are presented in table8. On the basis of Bivariate cointegration analysis it is clear that the equity market of Pakistan has no long term relationship with

Table 5: VAR Lag Order Selection Criteria

\begin{tabular}{lccc}
\hline Lag & AIC & SC & HQ \\
\hline 0 & 147.56 & 147.64 & 147.59 \\
1 & 116.91 & 117.7 & 117.21 \\
2 & 116.74 & 118.26 & 117.33 \\
3 & 116.81 & 119.05 & 117.68 \\
4 & 116.91 & 119.88 & 118.07 \\
5 & 116.96 & 120.65 & 118.39 \\
6 & 117.06 & 121.47 & 118.77 \\
7 & 117.11 & 122.25 & 119.11 \\
8 & 117.17 & 123.03 & 119.45 \\
\hline
\end{tabular}


Table 6: VAR Lag Order Selection Criteria

\begin{tabular}{|c|c|c|c|c|}
\hline Hypothesis & Eigen value & Trace Statistic & Critical Value 5\% & Prob.* \\
\hline \multicolumn{5}{|c|}{ Lag Length $=1$} \\
\hline $\mathrm{r}=0$ & 0.1075 & 276.04 & 239.24 & 0.0003 \\
\hline$r_{i} 1$ & 0.082 & 205.95 & 197.37 & 0.0175 \\
\hline$r_{i} 2$ & 0.071 & 153.26 & 159.53 & 0.1041 \\
\hline$r ; 3$ & 0.0603 & 107.92 & 125.62 & 0.3564 \\
\hline$r_{i} 4$ & 0.0439 & 69.585 & 95.75 & 0.7362 \\
\hline $\mathrm{r} ; 5$ & 0.0261 & 41.916 & 69.82 & 0.913 \\
\hline$r ; 6$ & 0.0179 & 25.602 & 47.86 & 0.9016 \\
\hline$r_{i} 7$ & 0.0151 & 14.496 & 29.8 & 0.8117 \\
\hline$r ; 8$ & 0.0082 & 5.097 & 15.49 & 0.7984 \\
\hline r 9 & 0 & 0.001 & 3.84 & 0.9782 \\
\hline
\end{tabular}

*MacKinnon-Haug-Michelis (1999) p-values

Table 7: Multivariate Co-integration test (Max-Eigen Value Statistics)

\begin{tabular}{lcccc}
\hline Hypothesis & Eigen value & Trace Statistic & Critical Value 5\% & Prob.* $^{*}$ \\
\hline Lag Length $=1$ & & & & \\
r $=0$ & 0.108 & 70.086 & 64.505 & 0.013 \\
r $_{i}$ & 0.082 & 52.689 & 58.434 & 0.165 \\
r $_{i}$ & 0.071 & 45.346 & 52.363 & 0.218 \\
r $_{i}$ & 0.06 & 38.332 & 46.231 & 0.272 \\
r $_{i}$ & 0.044 & 27.669 & 40.078 & 0.586 \\
r $_{5}$ & 0.026 & 16.314 & 33.877 & 0.945 \\
r $_{i}$ & 0.018 & 11.106 & 27.584 & 0.963 \\
r $_{i}$ & 0.015 & 9.399 & 21.132 & 0.799 \\
r $_{i}$ & 0.008 & 5.096 & 14.265 & 0.73 \\
r $_{i} 9$ & 0 & 0.001 & 3.841 & 0.978 \\
\hline
\end{tabular}

${ }^{*}$ MacKinnon-Haug-Michelis (1999) p-values

any of the equity markets of its major trading partners i.e. China, France, Germany, Hong Kong, Japan, Korea, Malaysia, UK and USA. Both of the tests for cointegration confirm the results of each other as presented at table 8. Hence Pakistani investor can get the benefit of portfolio diversification in the equity markets of its major trading partners in the long run.

\subsubsection{Pair-wise Granger Causality Tests}

Granger (1969) idea can be used to find out the lead and lag nature of relationship between two variables. There may be unidirectional or bidirectional causality in variables. The results of pair wise Granger Causality test are presented in table 9. From the table it is evident that there exists no causality (unidirectional or bidirectional) between the equity markets of Pakistan and China, France, Korea, Malaysia and USA. But ac- 
Table 8: Bivariate Co-integration test

\begin{tabular}{|c|c|c|c|}
\hline & Country Name & Test type & Result \\
\hline \multirow[t]{2}{*}{ Pakistan } & China & Trace Test & No Cointegration \\
\hline & & Max-Eigen Value Test & \\
\hline \multirow[t]{2}{*}{ Pakistan } & France & Trace Test & No Cointegration \\
\hline & & Max-Eigen Value Test & \\
\hline \multirow[t]{2}{*}{ Pakistan } & Germany & Trace Test & No Cointegration \\
\hline & & Max-Eigen Value Test & \\
\hline \multirow[t]{2}{*}{ Pakistan } & Hong Kong & Trace Test & No Cointegration \\
\hline & & Max-Eigen Value Test & \\
\hline \multirow[t]{2}{*}{ Pakistan } & Japan & Trace Test & No Cointegration \\
\hline & & Max-Eigen Value Test & \\
\hline \multirow[t]{2}{*}{ Pakistan } & Korea & Trace Test & No Cointegration \\
\hline & & Max-Eigen Value Test & \\
\hline \multirow[t]{2}{*}{ Pakistan } & Malaysia & Trace Test & No Cointegration \\
\hline & & Max-Eigen Value Test & \\
\hline \multirow[t]{2}{*}{ Pakistan } & UK & Trace Test & No Cointegration \\
\hline & & Max-Eigen Value Test & \\
\hline \multirow[t]{2}{*}{ Pakistan } & USA & Trace Test & No Cointegration \\
\hline & & Max-Eigen Value Test & \\
\hline
\end{tabular}

cording to table 9, there exists a unidirectional causality between the equity market of Pakistan and Germany, Hong Kong, Japan and UK.

\subsubsection{Error Correction model}

To further analyze the nature of relationship between equity markets of Pakistan and its major trading partners, we also used the vector error correction model. The results of VECM are presented at table 10 . Basically it uncovers the speed of adjustment from the disequilibrium to equilibrium in the short term. From the table, the coefficient of ECM model is -0.8821 . The negative sign of this coefficient shows the direction of movement from disequilibrium to equilibrium. It can be safely said that among the total disequilibrium in the past period, $82 \%$ of this is adjusted in current period. The mathematical equation of VECM is also given below.

\subsubsection{Variance Decomposition Analysis}

Variance decomposition along with the impulse response analysis uncovers the wealth of information regarding the dynamic effect and this focus on the short term nature of interaction among the equity markets of Pakistan and its major trading partners. Variance decomposition analysis uncovers the fact that whether and up to what extent other equity markets are explaining the total variation in the equity markets of Pakistan. Hence it gives the relative importance of other countries equity markets towards explaining the shocks in Pakistani equity markets. The results of variance decomposition test are presented in table 10. On the basis of this it can be said that most of the shocks or variation in the Pakistani equity markets are due to its own dynamics. Anyhow the equity markets of France, Korea and Germany are exerting pressure on the Pakistani equity markets. Impulse response function diagramcally analyze the response of the equity markets of Pakistan towards one period standard deviation variations to the innovation of system. It further shows the direction of response to each of the shocks. The results of impulse response analysis are presented in appendix(Figure2). 
Table 9: Pair-wise Granger Causality Tests

\begin{tabular}{lccc}
\hline R_PAK does not Granger Cause R_FRANCE & 1.0669 & 0.3021 & No \\
R_FRANCE does not Granger Cause R_PAK & 3.5336 & 0.0606 & Causality \\
\hline R_PAK does not Granger Cause R_GERMANY & 0.154 & 0.6949 & Unidirectional \\
R_GERMANY does not Granger Cause R_PAK & 6.267 & 0.0126 & Causality \\
\hline R_PAK does not Granger Cause R_HONG KONG & 1.8431 & 0.1751 & Unidirectional \\
R-HONG KONG does not Granger Cause R_PAK & 5.944 & 0.0151 & Causality \\
\hline R_PAK does not Granger Cause R_JAPAN & 0.8606 & 0.3539 & Unidirectional \\
R_JAPAN does not Granger Cause R_PAK & 4.2326 & 0.0401 & Causality \\
\hline R_PAK does not Granger Cause R_KOREA & 2.1224 & 0.1457 & No \\
R_KOREA does not Granger Cause R_PAK & 0.8303 & 0.3625 & Causality \\
\hline R_PAK does not Granger Cause R_MALAYSIA & 1.448 & 0.2293 & No \\
R_MALAYSIA does not Granger Cause R_PAK & 0.0284 & 0.8662 & Causality \\
\hline R_USA does not Granger Cause R_PAK & 2.6234 & 0.1058 & No \\
R_PAK does not Granger Cause R_USA & 0.0034 & 0.9537 & Causality \\
\hline R_UK does not Granger Cause R_PAK & 5.841 & 0.0159 & Unidirectional \\
R_PAK does not Granger Cause R_UK & 0.6662 & 0.4147 & Causality \\
\hline
\end{tabular}

\section{Conclusions}

The objective of this study was to empirically investigate co-movement in the stock markets of the countries with which Pakistan has major trade relations. Hence it is an attempt to analyze the long term as well as short term relationship between Pakistani equity market and equity markets of its major trading partners. The total study period consists of almost twelve years on weekly basis from January 2003 to October 2014. This research uses KSE-100 index as proxy for the stock index in Pakistan. This study considers the major trading partner of Pakistan consisting of China, France, Germany, Hong Kong, Japan, Korea, Malaysia, UK and USA. Descriptive statistics showed that equity markets of USA, UK, Japan, Germany and France are offering weekly negative returns to their investors while the equity markets of Malaysia, Korea, Hong Kong and China are offering positive weekly returns. On the basis of correlation matrix, it is evident that equity market of Pakistan has positive association with its entire major trading partners although the strength of this association changes from market to market. Generally it is agreed that correlation matrix is a weak measure to check the relationship between variables as it only discusses the strength and direction of relation without discussing any cause and effect of relationship.

Unit root test has been conducted to check the Stationarity of time series. From the Augmented Dickey and Fuller (1979) and Phillips and Perron (1988) test it can be easily concluded that all the equity indices are not Stationarity at first level but all become stationary after their first difference or all the time series data is integrated of order one. On the basis of Bivariate cointegration analysis (VAR base Johansen $(1991,1995)$ it was cleared that the equity market of Pakistan has no long term relationship with any of the equity markets of its major trading partners i.e. China, France, Germany, Hong Kong, Japan, Korea, Malaysia, UK and USA. The results of pair wise Granger Causality test suggested that there exists no causality (unidirectional or bidirectional) between the equity markets of Pakistan and China, France, Korea, Malaysia and USA. On the other hand, there exists unidirectional causality between the equity market of Pakistan and Germany, Hong Kong, Japan and UK. Variance decomposition along with the impulse response analysis reveals that most of the shocks or variation in the Pakistani equity markets was due to its own dynamics. Anyhow the equity markets of France, Korea and Germany were exerting pressure on the Pakistani equity markets.

On the basis of battery of econometrics, it was con- 
Table 10: Error Correction Model

\begin{tabular}{|c|c|c|c|c|}
\hline Regressor & Coefficient & SE & T-Ratio & Prob. \\
\hline USA & 0.0631 & 0.0872 & 0.7228 & 0.47 \\
\hline UK & -0.1618 & 0.1354 & -1.195 & 0.233 \\
\hline Malaysia & 0.1167 & 0.0775 & 1.5057 & 0.133 \\
\hline Korea & 0.1336 & 0.0541 & 2.4691 & 0.014 \\
\hline Japan & -0.0426 & 0.0656 & -0.649 & 0.517 \\
\hline Hong Kong & -0.0159 & 0.0692 & -0.2305 & 0.818 \\
\hline Germany & 0.0419 & 0.108 & 0.3884 & 0.698 \\
\hline France & 0.1137 & 0.1371 & 0.8298 & 0.407 \\
\hline China & 0.004 & 0.0434 & 0.0915 & 0.927 \\
\hline $\operatorname{ecm}(-1)$ & -0.8821 & 0.0396 & -22.2873 & 0 \\
\hline R-Squared & 0.4617 & R-Bar-Squared & & 0.4537 \\
\hline S.E. of Regression & 0.0362 & Equation Log-likelihood & & 1173.8 \\
\hline SB Criterion & 1141.7 & Akaike Info. Criterion & & 1163.8 \\
\hline F-stat. & $57.7594[.000]$ & DW-statistic & & 2.0306 \\
\hline
\end{tabular}

Table 11: Variance Decomposition Analysis

\begin{tabular}{lcccccccccc}
\hline Period & Pak & China & France & Germany & Hong Kong & Japan & Korea & Malaysia & UK & USA \\
\hline 1 & 96.37 & 0.06 & 2 & 0.24 & 0.15 & 0.02 & 0.91 & 0.25 & 0 & 0 \\
2 & 94.27 & 0.07 & 2.69 & 0.85 & 0.47 & 0.06 & 1.07 & 0.41 & 0.11 & 0.01 \\
3 & 94.14 & 0.07 & 2.71 & 0.85 & 0.47 & 0.06 & 1.06 & 0.41 & 0.11 & 0.12 \\
4 & 94.12 & 0.07 & 2.71 & 0.85 & 0.47 & 0.06 & 1.07 & 0.41 & 0.11 & 0.13 \\
5 & 94.12 & 0.07 & 2.71 & 0.85 & 0.47 & 0.06 & 1.07 & 0.41 & 0.11 & 0.13 \\
6 & 94.12 & 0.07 & 2.71 & 0.85 & 0.47 & 0.06 & 1.07 & 0.41 & 0.11 & 0.13 \\
7 & 94.12 & 0.07 & 2.71 & 0.85 & 0.47 & 0.06 & 1.07 & 0.41 & 0.11 & 0.13 \\
8 & 94.12 & 0.07 & 2.71 & 0.85 & 0.47 & 0.06 & 1.07 & 0.41 & 0.11 & 0.13 \\
9 & 94.12 & 0.07 & 2.71 & 0.85 & 0.47 & 0.06 & 1.07 & 0.41 & 0.11 & 0.13 \\
10 & 94.12 & 0.07 & 2.71 & 0.85 & 0.47 & 0.06 & 1.07 & 0.41 & 0.11 & 0.13 \\
\hline
\end{tabular}

cluded that Pakistani equity market has no long term relationship with its major trading countries equity markets. This study is important and lucrative for in- ternational investors as it may help guide their investments decisions. Since all these Pakistani trading partners countries equity markets have no empirical long 
Response to Cholesky One S.D. Innovations \pm 2 S.E.

Response of RPAK to RCHNA

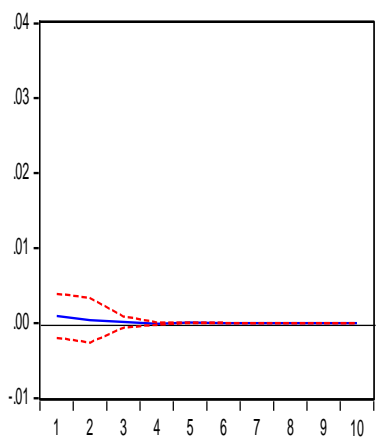

Response of RPAK to RJAPAN

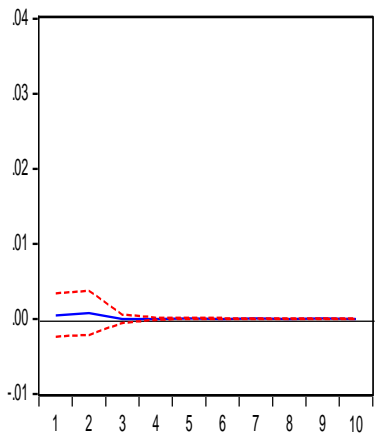

Response of RPAK to RUK

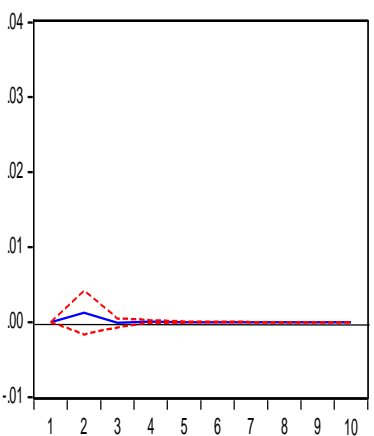

Response of RPAK to RFPANCE

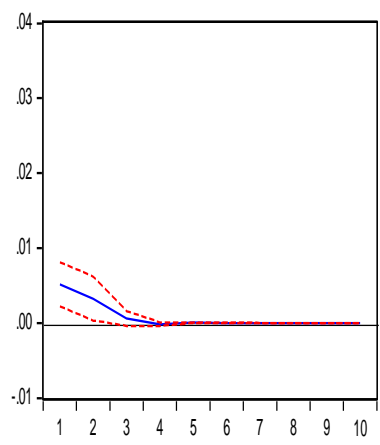

Response of RPAK to RKOREA

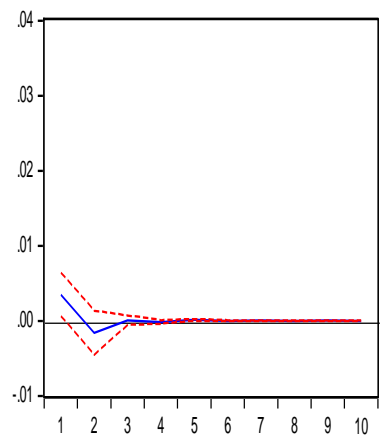

Response of RPAK to RUSA

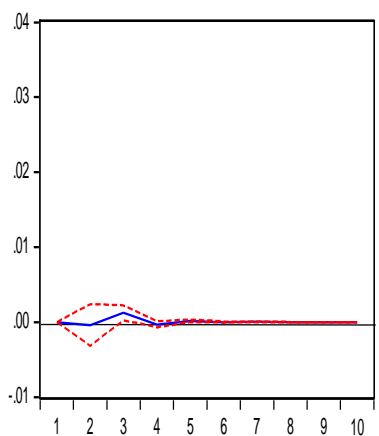

Response of RPAK to RGERMANY

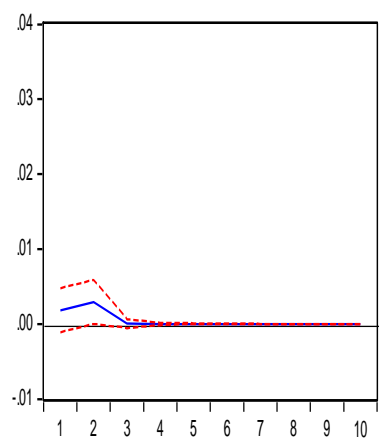

Response of RPAK to RMALAYSIA

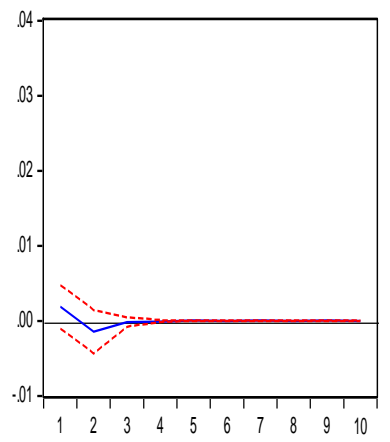

Response of RPAK to RHONGKONG

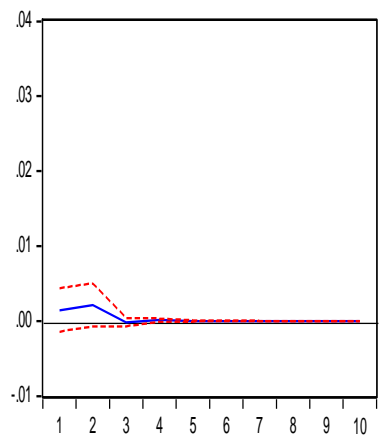

Response of RPAK to RPAK

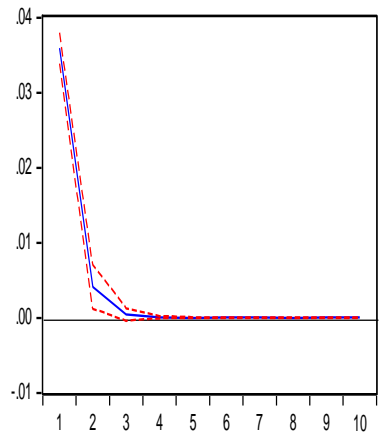

Figure 2: Appendix: Impulse Response Analysis

term relation with Pakistani equity markets so they can get the benefit of portfolio diversification by investing in the equity markets of Pakistan. This study is also helpful for Pakistani investor, fund managers, policy makers and regulators as it guides their investment decisions. They should be vigilant regarding the comovement between equity markets before taking any prosperous decision. Hence Pakistani investors can get the benefit of portfolio diversification in the equity markets of its major trading partners in the long run.

\section{References}

Agarwal, V. and Taffler, R. (2008). Comparing the performance of market-based and accounting-based bankruptcy prediction models. Journal of Banking E Finance, 32(8):15411551.

Ampomah, S. (2008). An empirical examination of the interlinkages between african stock markets. University of Surrey, Guildford, United Kingdom. Electronic copy available at http://ssrn. com/abstract, 1311325.

Arshanapalli, B. and Doukas, J. (1993). International stock 
market linkages: Evidence from the pre-and post-october 1987 period. Journal of Banking E Finance, 17(1):193-208.

Arshanapalli, B., Doukas, J., and Lang, L. H. (1995). Pre and post-october 1987 stock market linkages between us and asian markets. Pacific-Basin Finance Journal, 3(1):57-73.

Asaolu, T. and Ogunmuyiwa, M. (2011). An econometric analysis of the impact of macroecomomic variables on stock market movement in nigeria. Asian Journal of Business Management, 3(1):72-78.

Asgharian, H., Hess, W., and Liu, L. (2013). A spatial analysis of international stock market linkages. Journal of Banking $\mathcal{E}$ Finance, 37(12):4738-4754.

Bae, K.-H., Karolyi, G. A., and Stulz, R. M. (2003). A new approach to measuring financial contagion. The Review of Financial Studies, 16(3):717-763.

Barari, M. (2004). Equity market integration in latin america: A time-varying integration score analysis. International Review of Financial Analysis, 13(5):649-668.

Bekaert, G., Harvey, C. R., Lundblad, C. T., and Siegel, S. (2011). What segments equity markets? The Review of Financial Studies, 24(12):3841-3890.

Bekaert, G., Hodrick, R. J., and Zhang, X. (2008). Is there a trend in idiosyncratic volatility. Available at SSRN 1108170.

Berben, R.-P. and Jansen, W. J. (2005). Comovement in international equity markets: A sectoral view. Journal of International Money and Finance, 24(5):832-857.

Berger, P. G. (2011). Challenges and opportunities in disclosure researcha discussion of the financial reporting environment: Review of the recent literature. Journal of Accounting and Economics, 51(1):204-218.

Brooks, R. and Del Negro, M. (2004). The rise in comovement across national stock markets: market integration or it bubble? Journal of Empirical Finance, 11(5):659-680.

Brooks, R. and Negro, M. D. (2006). Firm-level evidence on international stock market comovement. Review of Finance, 10(1):69-98.

Caporale, G. M., Cipollini, A., and Spagnolo, N. (2005). Testing for contagion: a conditional correlation analysis. Journal of Empirical Finance, 12(3):476-489.

Cascio, A. J. and Clutter, M. L. (2008). Risk and required return assessments of equity timberland investments in the united states. Forest Products Journal, 58(10):61.

Cha, B. and Oh, S. (2000). The relationship between developed equity markets and the pacific basin's emerging equity markets. International Review of Economics $\mathcal{E}$ Finance, 9(4):299-322.

Chi, W., Huang, H., Liao, Y., and Xie, H. (2009). Mandatory audit partner rotation, audit quality, and market perception: Evidence from taiwan. Contemporary Accounting Research, 26(2):359-391.
Chien, M.-S. (2010). Structural breaks and the convergence of regional house prices. The Journal of Real Estate Finance and Economics, 40(1):77-88.

Chue, T. K. (2005). Conditional market comovements, welfare, and contagions: The role of time-varying risk aversion. The Journal of Business, 78(3):949-968.

Chuluun, T. and Graham, C. (2016). Local happiness and firm behavior: Do firms in happy places invest more? Journal of Economic Behavior \& Organization, 125:41-56.

Claus, E. and Lucey, B. M. (2012). Equity market integration in the asia pacific region: Evidence from discount factors. Research in International Business and Finance, 26(2):137-163.

Cohen, L., Frazzini, A., and Malloy, C. (2008). The small world of investing: Board connections and mutual fund returns. Journal of Political Economy, 116(5):951-979.

Cotter, J. and Stevenson, S. (2006). Multivariate modeling of daily reit volatility. The Journal of Real Estate Finance and Economics, 32(3):305-325.

Daly, K. J. (2003). Southeast asian stock market linkages: evidence from pre-and post-october 1997. ASEAN Economic Bulletin, pages 73-85.

Dickey, D. A. and Fuller, W. A. (1979). Distribution of the estimators for autoregressive time series with a unit root. Journal of the American statistical association, 74(366a):427431.

Donadelli, M. and Persha, L. (2014). Understanding emerging market equity risk premia: Industries, governance and macroeconomic policy uncertainty. Research in International Business and Finance, 30:284-309.

Eiling, E. and Gerard, B. (2007). Dispersion, equity returns correlations and market integration. Unpublished working paper). University of Toronto, Toronto, Ontario, Canada.

Eun, C. S. and Shim, S. (1989). International transmission of stock market movements. Journal of financial and quantitative Analysis, 24(2):241-256.

Forbes, K. J. and Rigobon, R. (2002). No contagion, only interdependence: measuring stock market comovements. The journal of Finance, 57(5):2223-2261.

Fu, R. and Gupta-Mukherjee, S. (2014). Geography, informal information flows and mutual fund portfolios. Financial Management, 43(1):181-214.

Ghosh, M. and John, G. (1999). Governance value analysis and marketing strategy. The Journal of Marketing, pages 131-145.

Granger, C. W. (1969). Investigating causal relations by econometric models and cross-spectral methods. Econometrica: Journal of the Econometric Society, pages 424-438.

Gupta, R. and Guidi, F. (2012). Cointegration relationship and time varying co-movements among indian and asian developed stock markets. International Review of Financial Analysis, 21:10-22. 
Hashmi, A. R. and Xingyun, L. (2001). Interlinkages among south east asian stock markets (a comparison between preand post-1997-crisis periods) 1 .

Hassan, M. K. and Naka, A. (1996). Short-run and long-run dynamic linkages among international stock markets. International Review of Economics \& Finance, 5(4):387-405.

Höchstötter, M., Meyer, S., Riordan, R., and Storkenmaier, A. (2014). International stock market comovement and news. Journal of Financial Research, 37(4):519-542.

Hoque, H. A., Kim, J. H., and Pyun, C. S. (2007). A comparison of variance ratio tests of random walk: A case of asian emerging stock markets. International Review of Economics $\mathcal{E}$ Finance, 16(4):488-502.

Johansen, S. (1991). Estimation and hypothesis testing of cointegration vectors in gaussian vector autoregressive models. Econometrica: Journal of the Econometric Society, pages 1551-1580.

Johansen, S. (1994). Likelihood-based inference in cointegrated vector autoregressive models. Oxford University Press on Demand.

Johansen, S. (1995). Likelihood-based inference in cointegrated vector autoregressive models. Oxford University Press on Demand.

Johnson, R. and Soenen, L. (2003). Economic integration and stock market comovement in the americas. Journal of Multinational Financial Management, 13(1):85-100.

Kallberg, J. G., Liu, C. H., and Pasquariello, P. (2002). Regime shifts in asian equity and real estate markets. Real Estate Economics, 30(2):263-291.

Karolyi, G. A. and Stulz, R. M. (1996). Why do markets move together? an investigation of us-japan stock return comovements. The Journal of Finance, 51(3):951-986.

Kasa, K. (1992). Common stochastic trends in international stock markets. Journal of monetary Economics, 29(1):95-124.

Lahrech, A. and Sylwester, K. (2011). Us and latin american stock market linkages. Journal of International Money and Finance, 30(7):1341-1357.

Lessard, D. R. (1973). International portfolio diversification: a multivariate analysis for a group of latin american countries. The Journal of Finance, 28(3):619-633.

Levy, H. and Sarnat, M. (1970). International diversification of investment portfolios. The American Economic Review, 60(4):668-675.

Liow, K. H., Ho, K. H. D., Ibrahim, M. F., and Chen, Z. (2009). Correlation and volatility dynamics in international real estate securities markets. The Journal of Real Estate Finance and Economics, 39(2):202-223.

Liow, K. H. and Yang, H. (2005). Long-term co-memories and short-run adjustment: securitized real estate and stock markets. The Journal of Real Estate Finance and Economics, 31(3):283-300.
Liu, Y., Gopikrishnan, P., Stanley, H. E., et al. (1999). Statistical properties of the volatility of price fluctuations. Physical review e, 60(2):1390.

Longin, F. and Solnik, B. (1995). Is the correlation in international equity returns constant: 1960-1990? Journal of international money and finance, 14(1):3-26.

Lucey, B. M. and Zhang, Q. (2010). Does cultural distance matter in international stock market comovement? evidence from emerging economies around the world. Emerging Markets Review, 11(1):62-78.

Lütkepohl, H. and Poskitt, D. S. (1991). Estimating orthogonal impulse responses via vector autoregressive models. Econometric Theory, 7(4):487-496.

Markowitz, H. (1952). Portfolio selection. The journal of finance, 7(1):77-91.

Markowitz, H. (1959). Portfolio Selection, Efficent Diversification of Investments. J. Wiley.

Mei, B. and Clutter, M. L. (2010). Evaluating the financial performance of timberland investments in the united states. Forest Science, 56(5):421-428.

Morgado, P. and Tavares, J. (2007). Economic integration and the co-movement of stock returns.

Mukherjee, P. and Bose, S. (2008). Does the stock market in india move with asia?: A multivariate cointegration-vector autoregression approach. Emerging Markets Finance and Trade, 44(5):5-22.

Nasseh, A. and Strauss, J. (2000). Stock prices and domestic and international macroeconomic activity: a cointegration approach. The Quarterly Review of Economics and Finance, 40(2):229-245.

Neaime, S. (2012). The global financial crisis, financial linkages and correlations in returns and volatilities in emerging mena stock markets. Emerging Markets Review, 13(3):268-282.

Phillips, P. C. and Perron, P. (1988). Testing for a unit root in time series regression. Biometrika, 75(2):335-346.

Phylaktis, K. and Xia, L. (2006). Sources of firms' industry and country effects in emerging markets. Journal of International Money and Finance, 25(3):459-475.

Pretorius, E. (2002). Economic determinants of emerging stock market interdependence. Emerging Markets Review, 3(1):84-105.

Pukthuanthong, K. and Roll, R. (2009). Global market integration: An alternative measure and its application. Journal of Financial Economics, 94(2):214-232.

Rajan, R. G. and Zingales, L. (2003). The great reversals: the politics of financial development in the twentieth century. Journal of financial economics, 69(1):5-50. 
Rua, A. and Nunes, L. C. (2009). International comovement of stock market returns: A wavelet analysis. Journal of Empirical Finance, 16(4):632-639.

Ryan, M. and Gerard, K. (2003). future research reflections. Applied health economics and health policy, 2:55-64.

Shamsuddin, A. F. and Kim, J. H. (2003). Integration and interdependence of stock and foreign exchange markets: an australian perspective. Journal of International Financial Markets, Institutions and Money, 13(3):237-254.

Siklos, P. L. and Ng, P. (2001). Integration among asiapacific and international stock markets: Common stochastic trends and regime shifts. Pacific Economic Review, 6(1):89-110.

Solnik, B. H. (1974). An equilibrium model of the international capital market. Journal of economic theory, 8(4):500524.

Sun, C. and Zhang, D. (2001). Assessing the financial performance of forestry-related investment vehicles: Capital asset pricing model vs. arbitrage pricing theory. American Journal of Agricultural Economics, 83(3):617-628.
Sun, H. and Seiler, M. (2013). Hyperbolic discounting, reference dependence, and its implications for the housing market. Journal of Real Estate Research, 35(1):1-23.

Thalassinos, E., Kiriazidis, T., et al. (2003). Degrees of integration in international portfolio diversification: Effective systemic risk. European Research Studies Journal, 6(1-2):119130.

Van Rijckeghem, C. and Weder, B. (2003). Spillovers through banking centers: a panel data analysis of bank flows. Journal of International Money and Finance, 22(4):483-509.

Voronkova, S. (2004). Equity market integration in central european emerging markets: A cointegration analysis with shifting regimes. International Review of Financial Analysis, 13(5):633-647.

Walti, S. (2005). The macroeconomic determinants of stock market synchronization. Journal of International Banking Law, 11(10):436-441.

Wong, W.-K., Penm, J., Terrell, R. D., and Ching, K. Y. (2004). The relationship between stock markets of major developed countries and asian emerging markets. Journal of Applied Mathematics E Decision Sciences, 8(4):201-218. 


\title{
The Relationship of Employee Engagement, Organizational Commitment and Organizational Citizenship Behavior
}

\author{
Pir Sajad Ullah*, Waseef Jamal, Muhammad Naeem \\ Institute of Management Sciences, Peshawar, Pakistan
}

\begin{abstract}
This study aims to examine the relationship between employee engagement, organizational commitment and organizational citizenship behavior. With the help of literature, current study developed two hypotheses regarding employee engagement, organizational commitment and organizational citizenship behavior. Educational sector was selected for the conducting of this study. Structured closed ended questionnaire was used for the collection of data. Using correlation and regression analysis, the study results showed that there is a significant positive relationship between employee engagement and organizational commitment and furthermore confirmed that there is a significant positive relationship between employee engagement and organizational citizenship behavior. This study provided beneficial insights about employee engagement in the education sector of Pakistan. The study concludes by discussing limitations and future research directions.
\end{abstract}

\section{Introduction}

In this modern world organizations agree that a skillful workforce is the most important asset of any organization and turnover of such workforce is a big problem for most organization. Hence, attracting and retaining such skilled employees is a big challenge for todays organization, because the skilled employees have usually more job options (Joo and Mclean, 2006). However, employees having necessary skills are sufficient to help the organization to accomplish its objectives and goals. It is vital for the organization to manage these skilled employees for active and better performance (Cho and McLean, 2009).

According to Ulrich and Smallwood (2007) for the success of organization, it is necessary that it must have employees with three qualities; commitment or engagement, competence and contribution. Performance of the employees not only depends on the cognitive skills and competence, however employee performance also depends on the emotional response of the worker to the organizational works. Moreover, it has been empirically tested that engaged employees who are engaged in their jobs and organization are less motivated through financial rewards and highly motivated through non-financial rewards. Thus, employee engagement is one of the most crucial topics in the field of management and HRD (Gebauer et al., 2008).

In the past few years, researchers have given greater attention to employee engagement. Organizations can increase their productivity and achieve

*Corresponding author.

Email: pirsajjad20@yahoo.com

http://www.jbrc.pk business outcomes through superior technology, wellorganized work processes and through employee engagement. Different research studies have suggested that organizational outcomes and performance depend on employee engagement (Harter et al., 2002; Saks, 2006). Though, previous literature highlighted that employee engagement level is decreasing while the level of disengagement in the United States has been on the rise (Saks, 2006). For example, about half of the total employees in the United States are reportedly disengaged bearing the annual productivity makes 300 billion losses (Saks, 2006). Sorenson (2013) of employee shows that in United States and Canada the engaged employees are $29 \%$ and not engaged employees are $54 \%$ and actively disengaged are $18 \%$.

According to Flade (2003) the estimated cost of British economy due the disengagement of the employees is ranging from 37 billion to 38 billion per year. While in Japan only nine percent of the workforce is engaged and loss of productivity is about 232 billion dollar (Wellins et al., 2005). According to the recent survey of Sorenson (2013) worldwide result of 142 countries shows that only $13 \%$ of workforce is engaged and $63 \%$ is not engaged and $24 \%$ are disengaged actively.

In Pakistan the level of engaged employees is only $15 \%$, while not engaged employees are $68 \%$ and $16 \%$ of employees are actively disengaged (Sorenson, 2013). However, these findings reveal that companies pay high cost due to the disengagement of the employees. In the past few years employee engagement has taken a fundamental part in the effectiveness of an organiza- 
tion. It is due to the fact that engagement has considerable impact on the employee outcomes and organizational outcomes. Those organizations which have engaged employees, will have committed employees and there will be low chances of turnover. The organization will increase its profitability and productivity and will have loyal and satisfied customer due the result of those engaged employees (Kompaso and Sridevi, 2010). However, there are several studies which have provided an empirical evidences that employee with high engagement level will also have improved performance (Echols and Tsai, 2005; Jeung, 2011; Luthans and Peterson, 2002; Smythe, 2008; Tasker, 2004; Walters, 2008; Whiteoak et al., 2006). To the best of researchers knowledge, this area remained ignored in under developing country like Pakistan.

\section{Literature Review}

Employee engagement is one of the most popular concepts in the field of Human Resource Development. From the past two decades the idea of engagement is initiated in the organization and management literature (Simpson, 2009). Employee engagement plays a key role in the success of any organization. Therefore, considerable attention was given to the term engagement and researchers are giving more consideration on the roles of employee engagement for the organizational success in order to attain competitive advantage.

\subsection{Employee Engagement}

Employee engagement is considered a novel concept in the field of HRD but it is greatly promoted by different consultant companies (Wefald and Downey, 2009). Different scholars and researchers are agreed upon the basic concept of employee engagement, which helps explain the behavior of employees at work; however, scholars present different definitions of employee engagement.Kahn (1990) defined employee engagement as the harnessing of Organization members selves to their work roles; in engagement, people employ and express themselves physically, cognitively, and emotionally during role performances. Whereas, on the contrary, disengagement is defined as uncoupling of selves from work roles in which the individual take out themselves physically, cognitively and emotionally while acting that job. Thus, Kahn stressed that engagement is psychological and physical presence of employee while performing the job.

\subsection{Organizational Citizenship Behaviors (OCB)}

The notion of work behavior comes under the scope of job responsibility and has obtained a lot of attention since the book Organizational Citizenship Behavior: The Good Solider Syndrome was published by Organ (1988). During 1983-1988 about 13 papers were published related to OCB and other related constructs and about 122 papers were published during 1993-1998 (Podsakoff et al., 2000). It shows that OCB is highly important in the business literature. However, it shows that the concept of OCB is not new in the corporate world, the notion of OCB started from works of the earlier scholars Barnard (1938) and then later on to work of Katz (1964) and lastly to the work of LePine et al. (2002).

There are several definitions of OCB which are presented in the following:

Chester Bernard observed the phenomena of OCB for the first time in 1930 and called it extra-role behaviors (Barnard, 1938) while later on citizenship term was used by Katz (1964) to represent those worker which express extra-role behaviors.

OCB is elaborated as Individual behavior that is discretionary, not directly or explicitly recognized by the formal reward system, and that in the aggregate promotes the effective functioning of the organization (Organ, 1988).

Later on in 1997, Organ defined organization citizenship as performance that supports the social and psychological environment in which task performance takes place (Organ, 1997).

There are some researchers who have tried to define OCB from their own lenses, and this definition shows quite resemblance with the works of Organ and his colleagues. Niehoff and Moorman (1993) described OCB as behavior which is not incorporated in the job description of the employees. OCB is also known as good soldier syndrome (Organ, 1988). It is the behavior which is showed by the committed employees of the organization. OCB consists of Punctuality of the employees, helping other colleagues of the organization, presenting innovating ideas, volunteer work in the organization (Organ, 1988). It also has the tendency to stop an individual from undesirable action like complaining, arguing and finding fault with others (Organ, 1988).

Components of Organizational citizenship behaviors Organ (1988), argued that there are five components of OCB:

1. Altruism: Altruism means helping or helpfulness. Altruism is helping other members of the organization in performing their jobs.

2. Conscientiousness: It is a behavior of the employees that is out of the level of compulsory expectation; it differs from term altruism due to dissimilar targets. Its target can be departments 
or whole organization while the objective of altruism is only individual.

3. Sportsmanship: It refers to such behavior an individual manifests while bearing troublesome condition without grievances.

4. Courtesy: it refers to the behavior which helps other members to avert problems in advance, somewhat than helping somebody who is already in difficulties.

5. Civic virtue: It is the behavior of employees concerning contribution in organizational problems, like debating and talking about the organizational problems.

\subsection{Employee Engagement and OCB}

Employee engagement is considered one of significant predictors of organizational financial performance and triumph of any organization (Baumruk, 2004). It is also the fact that presently employee engagement is also declining as organizations and workers mutually tend to be more materialistic and vast engagement gap can be perceived at work places (Saks, 2006).

Employee engagement may lead to OCB as it emphasizes on the employee involvement and employee commitment which are not the explicit part of any employee job description.

Rich et al. (2010) examined that employee engagement is predictor of OCB. Employee engagement is related to OCB because it is based upon social exchange theory (SET) and the principle of mutual interest. OCB includes emotional components due to which employee perform OCB (Bennett and Robinson, 2000).

Ariani (2013) concluded that employee engagement is one of the possible predictors of OCB and employees who have a tendency to engage in helpful and responsible behaviors at work (i.e. OCB). Thus the first hypothesis is given as:

H1. There is a positive relationship between employee engagement and $O C B$.

\subsection{Organizational Commitment}

Organizational commitment is defined by Allen and Meyer as a psychological state that binds an employee to an organization, thereby reducing the incidence of turnover (Allen and Meyer, 1990). Mowday et al. (1982) defined organization commitment as the relative strength of an individuals identification with and involvement in a particular organization. The three components Model of organization commitment gained considerable popularity since its initiation (Wasti, 2005). The three components Model of organizational commitment includes: affective commitment, continuance commitment and normative commitment.
Employee with a high level of normative commitment feels that he/she ought to remain with the organization (p. 67). Among these three components of organizational commitment, affective commitment is considered being the most important one that has an influence on the employee behaviors within their organizations (Ueda, 2011). Consequently, employee with strong affective commitment is considered to have positive effect on the behaviors of the employees like OCB (Ueda, 2011).

\subsection{Employee Engagement and Organiza- tional Commitment}

Studies have been conducted in the developed countries which have found that there is a positive correlation between employee engagement and affective commitment (Richardsen et al., 2006). Llorens et al. (2007) found that organizational commitment increases with an increase in engagement level of employees and employee engagement enhances job satisfaction, and improves performance, higher attendance and makes turnover rates lower.

Similarly, a study was conducted by Saks (2006) amongst 102 employees of Canadian organizations to test the model of antecedents and consequences of employee engagement. The study shows that employee engagement plays a mediating role between the antecedents and consequences of the employee engagement. Affective commitment is one of the consequences of the employee engagement.

Agyemang and Ofei (2013) elaborated that employee engagement and organizational commitment are related positively. If employee engagement increases then organizational commitment can also be increased which helps achieve the organizational objectives. According to Blizzard (2002) engaged workforce is more loyal and highly committed to the organization. Similarly Jordaan and Rothmann (2005) also tested the same view and found the same result.

Consequently, employee engagement and organizational commitment are positively correlated to each other. Similarly Albdour and Altarawneh (2014) have found positive relationship between employee engagement and organizational commitment in the banking sector. Moreover, in Zimbabwe, Shoko and Zinyemba (2014) have worked on higher educational institutions in order to investigate the impact of employee engagement and organizational commitment. They found the similar result as by Albdour and Altarawneh (2014).

H2. There is a positive relationship between employee engagement and organizational commitment. 


\section{Theoretical framework}

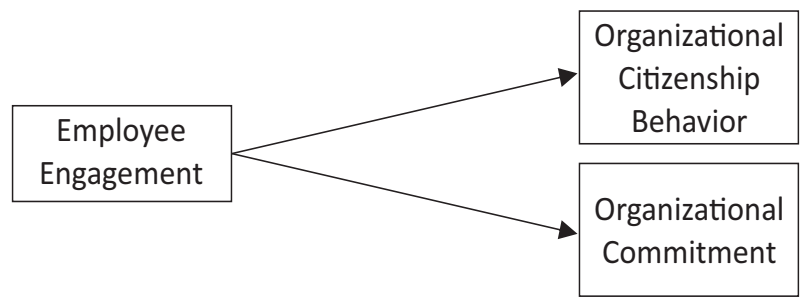

Figure 1: Theoretical Framework

\section{Research Methodology}

\subsection{Research Design}

The given study is correlation in nature. Primary data were collected through survey method. The aim of the research was to examine the correlation of employee engagement, OCB and employee commitment. Hence, correlation and quantitative research approach was considered suitable to collect primary data and address to the research questions.

The questionnaire consisted of 22 questions. Nine questions were used to measure employee engagement which was adopted from the paper of Saks (2006). The Cronbachs alpha value of the instrument was 0.943 . Organizational commitment was measured by the affective commitment and the scale developed by Rhoades et al. (2001); with Cronbachs alpha at 0.940. OCB was measured by the scale used by Lee and Allen (2002). The Cronbachs Alpha value of OCB was 0.86, showing the validity of the scale. A five point Likert scale was utilized for this study which allowed the participants to select from the five outcomes starting from strongly disagree to strongly agree.

\subsection{Population Frame}

Data were gathered from higher educational institutions of Khyber PakhtunKhwa (Malakand division).

Three universities of KPK (Malakand division) were selected through purposive sampling which in- clude UOM, UOS and Shaheed Benazir Bhutto University Sheringal (SBBUS). The rationale for the selection of these Universities was on the following importance.

1. University of Swat and SBBU Sheringal was selected because these universities were establish at the time of Taliban crisis, so the purpose of the selection was in order to find out the employees engagement level in such universities which was established in a difficult time.

2. University of Malakand was selected on basis that Taliban have targeted and attacked this University. The researcher is also interested to find the engagement level of the university which has passed through a difficult time.

\subsection{Sampling}

In the first step the researcher has found the list of universities of kpk which were established after 2000. There were fourteen universities which were established after 2000. Three universities (UOM, UOS \& SBBU) were selected through purposive sampling. In the second step the employees of universities are divided into two strata (1) Administration (2) faculty. The sample from the two strata was selected through disproportionate sampling.

The respondents of study include faculty members and administration of the three universities (UOM Chakdara, UOS \& SBBU Sheringal). Overall, 250 questionnaires were distributed among the employees these universities. From the participants 202 questionnaires were taken back with response rate of 80.2. However, 193 questionnaires were selected for the final analysis, rest of the questionnaires was incomplete, therefore were rendered useless.

\section{Results}

The collected data were analyzed according to the objective and hypotheses of the study. On the given data only three types of statistical analysis were performed i.e. correlation and sample regression.

Table 1: Correlation Analysis

\begin{tabular}{lc}
\hline & Employee Engagement \\
\hline & Pearson Correlation \\
\hline Organizational Commitment & $0.516^{* *}$ \\
Organizational Citizenship Behavior & $0.540^{* *}$ \\
${ }^{* *}$. Correlation is significant at the 0.01 level (2-tailed).
\end{tabular}


Table 2: Regression Analysis

\begin{tabular}{lcccccc}
\hline Predictor & \multicolumn{3}{c}{ Organizational Commitment } & \multicolumn{3}{c}{ OCB } \\
\hline & $\beta$ & $\mathbf{R}^{2}$ & $\mathbf{P}$ & $\beta$ & $\mathbf{R}^{2}$ & $\mathbf{P}$ \\
Employee Engagement & 0.516 & 0.266 & 0.000 & 0.54 & 0.292 & 0.000 \\
\hline
\end{tabular}

\subsection{Correlation Analysis}

Correlation refers to the relationship to the association or relationship between two variables. It measures the degree to which two sets of data are related or not. Table 1 shows the correlation analysis of the study.

Table 1 shows that there is a significant positive relationship among the variables, i.e. employee engagement, organizational commitment, OCB. The Pearson Correlation value between employee engagement and organizational commitment is 0.516 which shows that there is significant positive correlation. The significant value 0.01 shows that the relationship is significant.

The Pearson Correlation value between employee engagement and organization citizenship behavior is 0.540 which shows that there is also significant positive correlation between the variables. The significant value 0.01 shows that the relationship is significant.

\subsection{Regression Analysis}

Regression measures the amount of total variation in dependent variable due the change in independent variables. Table 2 shows Regression analysis of the study.

Regression measures the amount of total variation in dependent variable due the change in independent variables. The value of $R$ square is 0.266 or $26.6 \%$; which shows that there is almost 26.6 percent variation in the dependent variable (organizational commitment) due to the one unit change in independent variable (employee engagement). The beta value of independent variable (employee engagement) is 0.516 and at significant value of 0.00 . This beta value indicates the amount of change in dependent variable (organizational commitment) due the change in independent variable (employee engagement).

For employee engagement and OCB the value of $R^{2}$ is 0.292 which indicates that almost $29.2 \%$ change in dependent variable (organizational citizenship behaviors) is due the one unit change in independent variable (employee engagement).The beta value of independent variable (employee engagement) is 0.540 and at significant value of .000. This beta value indicates the change in dependent variable (organizational citizenship behavior) due the change in independent variable (employee engagement).

\section{Discussion}

Employee engagement has been an area of interest from last decade among the consultants and practitioners. However the contribution of employee engagement for organization product is still in question. This study has aimed to find out empirical support in favor of employee engagement as contributing factor for organization product. The study found that there is a significant positive relationship between employee engagement and organizational commitment with a correlation value of 0.51 at 0.01 , so we accept the first hypothesis of the study. In addition, the same relationship was found by Saks (2006). The same result was also found by Richardsen et al. (2006) and Llorens et al. (2007) who concluded that organizational commitment increases with an increase in engagement level of employees. Agyemang and Ofei (2013) and Blizzard (2002) have elaborated that those employees who have high engagement level are loyal and committed to the organization. Similarly, the same point of view was also approved by Jordaan and Rothmann (2005). Consequently, employee engagement and organizational commitment are correlated to each other and it has positive impact on each other. Similarly, Albdour and Altarawneh (2014) have also found the same relation in the Jordan banking sector. They found that job engagement is positively related to affective commitment ( $\mathrm{r}$ $=.436, \mathrm{p}, 0.01$ ) and organizational engagement is also positively related to affective commitment $(\mathrm{r}=.456, \mathrm{p}$, $0.01)$. As compared to the research of Albdour and Altarawneh (2014) no significant difference was found between both the studies rendering the values $(r=.516 . p$, 0.01 ). If we compare the regression analysis of the both studies the value of $\mathrm{R}$ is 0.293 while in this study it is 0.26 which is not a big difference. This small difference may be due to cultural differences or it may be due to difference in sectors or population.

The result of the study shows those employees who have high level of engagement are more committed to the organization. The result recommends the high level of engagement leads to high affective commitment.

The result of the study also concluded that there is also a significant positive correlation between employee engagement and OCB with a correlation value of 0.50 at 0.01 significant levels. So we accept our second hypothesis of the study. Similarly, the same result was also found by Allen and Meyer (1990), Saks (2006) 
and Ariani (2014). The study conducted by Ahmed et al. (2012) also argued that more enthusiastically an employee is engaged in his work there will be better chances to reveal organizational citizenship behaviors.

\subsection{Limitation and Future Research Recom- mendations}

This research contains a number of limitations. First, for a better result it is important to have a larger sample. This study is limited to academic sector and has been conducted only in education sector. However, the same can be conducted in other sectors i.e. banking sector, manufacturing sector, industrial sector, telecommunication sector etc.

Questionnaire has been used as a data collection tool so the same research can be conducted by using interview, focus group discussion for concrete results.

This study explores the association of employee engagement, Organizational Citizenship behavior and Organizational commitment from the context of less develop areas of Pakistan, so the same study can be conducted in other part of the world with different cultures context or other parts of Pakistan as well.

Lastly, other limitation is the sensitivity of the topic; the employees may be hesitant to express their solid negative emotions, as result participants may mark high engagement due the fear that the data will be not be kept confidential.

\section{References}

Agyemang, C. B. and Ofei, S. B. (2013). Employee work engagement and organizational commitment: A comparative study of private and public sector organizations in ghana. European Journal of Business and Innovation Research, 1(4):20-33.

Ahmed, N., Rasheed, A., and Jehanzeb, K. (2012). An exploration of predictors of organizational citizenship behaviour and its significant link to employee engagement. International Journal of business, humanities and technology, 2(4):99-106.

Albdour, A. A. and Altarawneh, I. I. (2014). Employee engagement and organizational commitment: Evidence from jordan. International Journal of Business, 19(2):192.

Allen, N. J. and Meyer, J. P. (1990). The measurement and antecedents of affective, continuance and normative commitment to the organization. Journal of occupational and organizational psychology, 63(1):1-18.

Ariani, D. W. (2013). The relationship between employee engagement, organizational citizenship behavior, and counterproductive work behavior. International Journal of Business Administration, 4(2):46.
Ariani, D. W. (2014). Relationship leadership, employee engagement, and organizational citizenship behavior. International Journal of Business and Social Research, 4(8):74-90.

Barnard, C. I. (1938). 1968. The functions of the executive.

Baumruk, R. (2004). The missing link: the role of employee engagement in business success.

Bennett, R. J. and Robinson, S. L. (2000). Development of a measure of workplace deviance. Journal of applied psychology, 85(3):349.

Blizzard, R. (2002). Employee engagement: For-profit versus not-for-profit hospitals. Gallup Poll Tuesday Briefing, pages $1-2$.

Cho, Y. and McLean, G. N. (2009). Leading asian countries' hrd practices in the it industry: a comparative study of south korea and india. Human Resource Development International, 12(3):313-331.

Echols, A. and Tsai, W. (2005). Niche and performance: The moderating role of network embeddedness. Strategic Management Journal, 26(3):219-238.

Flade, P. (2003). Great britains workforce lacks inspiration. Gallup Management Journal, 11:1-3.

Gebauer, J., Lowman, D., and Gordon, J. (2008). Closing the engagement gap: How great companies unlock employee potential for superior results. Penguin.

Harter, J. K., Schmidt, F. L., and Hayes, T. L. (2002). Businessunit-level relationship between employee satisfaction, employee engagement, and business outcomes: a metaanalysis.

Jeung, C.-W. (2011). The concept of employee engagement: A comprehensive review from a positive organizational behavior perspective. Performance Improvement Quarterly, 24(2):49-69.

Joo, B.-K. and Mclean, G. N. (2006). Best employer studies: A conceptual model from a literature review and a case study. Human resource development review, 5(2):228-257.

Jordaan, G. and Rothmann, S. (2005). Work engagement of academic staff in south african higher insfitufions. WorkWell: Research Unit for People, Policy and Performance.

Kahn, W. A. (1990). Psychological conditions of personal engagement and disengagement at work. Academy of management journal, 33(4):692-724.

Katz, D. (1964). The motivational basis of organizational behavior. Systems Research and Behavioral Science, 9(2):131146.

Kompaso, S. M. and Sridevi, M. S. (2010). Employee engagement: The key to improving performance. International journal of business and management, 5(12):89.

Lee, K. and Allen, N. J. (2002). Organizational citizenship behavior and workplace deviance: the role of affect and cognitions. Journal of applied psychology, 87(1):131. 
LePine, J. A., Erez, A., and Johnson, D. E. (2002). The nature and dimensionality of organizational citizenship behavior: a critical review and meta-analysis.

Llorens, S., Schaufeli, W., Bakker, A., and Salanova, M. (2007). Does a positive gain spiral of resources, efficacy beliefs and engagement exist? Computers in human behavior, 23(1):825841.

Luthans, F. and Peterson, S. J. (2002). Employee engagement and manager self-efficacy. Journal of management development, 21(5):376-387.

Mowday, R. T., Porter, L. W., and Steers, R. M. (1982). Employee-organization linkage. The psychology of commitment absenteism, and turn over_ Academic Press Inc. London.

Niehoff, B. P. and Moorman, R. H. (1993). Justice as a mediator of the relationship between methods of monitoring and organizational citizenship behavior. Academy of Management journal, 36(3):527-556.

Organ, D. W. (1988). Organizational citizenship behavior: The good soldier syndrome. Lexington Books/DC Heath and Com.

Organ, D. W. (1997). Organizational citizenship behavior: It's construct clean-up time. Human performance, 10(2):85-97.

Podsakoff, P. M., MacKenzie, S. B., Paine, J. B., and Bachrach, D. G. (2000). Organizational citizenship behaviors: A critical review of the theoretical and empirical literature and suggestions for future research. Journal of management, 26(3):513-563.

Rhoades, L., Eisenberger, R., and Armeli, S. (2001). Affective commitment to the organization: The contribution of perceived organizational support. Journal of applied psychology, 86(5):825.

Rich, B. L., Lepine, J. A., and Crawford, E. R. (2010). Job engagement: Antecedents and effects on job performance. Academy of management journal, 53(3):617-635.

Richardsen, A. M., Burke, R. J., and Martinussen, M. (2006). Work and health outcomes among police officers: The mediating role of police cynicism and engagement. International Journal of Stress Management, 13(4):555.
Saks, A. M. (2006). Antecedents and consequences of employee engagement. Journal of managerial psychology, 21(7):600-619.

Shoko, M. and Zinyemba, A. Z. (2014). Impact of employee engagement on organizational commitment in national institutions of higher learning in zimbabwe. International Journal of Advanced Research in Management and Social Sciences, 3(9):255-268.

Simpson, M. R. (2009). Engagement at work: A review of the literature. International journal of nursing studies, 46(7):1012-1024.

Smythe, J. (2008). Engaging employees. Real-life Leadership.

Sorenson, S. (2013). How employee engagement drives growth. Gallup business journal, 1.

Tasker, J. (2004). Engagement equals productivity. Personnel Today, 5:8-9.

Ueda, Y. (2011). Organizational citizenship behavior in a japanese organization: The effects of job involvement, organizational commitment, and collectivism. Journal of Behavioral Studies in Business, 4:1.

Ulrich, D. and Smallwood, N. (2007). Building a leadership brand. Harvard Business Review, 85(7/8):92.

Walters, D. (2008). How i made a difference employee engagement. Personnel Today, 23:33.

Wasti, S. A. (2005). Commitment profiles: Combinations of organizational commitment forms and job outcomes. Journal of Vocational Behavior, 67(2):290-308.

Wefald, A. J. and Downey, R. G. (2009). Job engagement in organizations: fad, fashion, or folderol? Journal of Organizational Behavior, 30(1):141-145.

Wellins, R. S., Bernthal, P., and Phelps, M. (2005). Employee engagement: The key to realizing competitive advantage. Development Dimensions International, 5:1-31.

Whiteoak, J. W., Crawford, N. G., and Mapstone, R. H. (2006). Impact of gender and generational differences in work values and attitudes in an arab culture. Thunderbird International Business Review, 48(1):77-91. 


\title{
Impact of Ethical Leadership on Project Success: Mediating role of Employee Trust and Moderating role of Ethical Orientation
}

\author{
Maha Matloob* \\ Capital University of Science and Technology, Islamabad, Pakistan
}

\begin{abstract}
This study examined the relationship between ethical leadership and project success with mediating role of employee trust and moderating role of ethical orientation. Data were collected from 100 employees from Kanji Advisory a project based company in Pakistan which designs and develops client responsive business strategies. The results proved that ethical leadership influences project success with the mediation of employee trust and with the moderation of ethical orientation.
\end{abstract}

\section{Introduction}

Following the famous corporate scandals (Enron, Worldcom, and Tyco), interest in ethical leadership has been intrigued; therefore more researches are being done in this domain after Enron scandal (Brown and Treviño, 2006). Ruiz-Palomino et al. (2011) argued that Ethical Leadership behavior spreads like a viral disease and creates an ethical work climate, where managers perform with honesty, employee trust their leaders and feel satisfied and committed to their jobs, which helps employees flourish in their jobs as well as increase organizations efficiency.

When employees have strong positive opinion about their leaders moral conduct and have the freedom to express their concerns, opinions and it leads to a strong sense of responsibility, satisfaction towards their job (Avey et al., 2011). Xu et al. (2016) explained that Ethical Leaders help organization in maintaining relationship based on trust with employees, which motivates employees to positively evaluate organization; this evaluation is based on the conduct of Ethical leader on the basis of which employees trust or refuse to trust organization. According to Brown et al. (2005), Ethical Leadership is linked with Social Learning Theory, as Ethical leaders shouldnt only impose ethical principles in an organization but they should be a model of a moral person. Leaders with extraordinary ethical behavior influence help in flourishing the creativity of subordinates (Chen and Hou, 2016).

Yang et al. (2016) explained that ethical leadership plays a vital role in increasing organizations and employees efficiency by helping supervisor to be an example of moral person, direct ethically and improve employee efficiency. Efficiency and creativity both are en-

*Corresponding author.

Email: mahadar1994@yahoo.com hanced when ethical leadership helps employees identify intrinsic value for job, rather than keeping an eye on external reward (Javed et al., 2017). Companies should select managers who reflect ethical leadership behavior while being employed, ones who can be an ethical role model and support ethical employees (Dinc and Nurovic, 2016).

In the current era, researchers are highly interested in the role of leadership in project success. There has been a research on Ethical Leadership for Virtual Project Teams, which suggests that Ethical Leadership of Virtual Project Teams not only improves organization efficiency but also employees job satisfaction and its one of the reasons for business success (Lee, 2009). A recent study suggests that further research should be conducted on the relationship between ethical leadership and Project success using different variables like intrinsic motivation, psychological safety, creative selfefficacy and trust in leadership as mediators (Javed et al., 2017). Working under ethical leadership, employees trust their organization to treat them with equality and value their concerns (Xu et al., 2016).

Lee-Kelley and Kin Leong (2003) found that perception of Project Manager regarding project success is influenced by his/her leadership style. A positive relation is found between project managers perception of project success and his personality, which shows that Project Managers strong belief on his/her leadership abilities plays a vital role in project success (Lee-Kelley and Kin Leong, 2003).To attain project success, ethical leaders need to promote employees trust by giving ethical orientation and being an example of ethical role model for employees. Trust is an important factor for stakeholders to achieve project success (Brinkhoff et al., 2015). 
Ethical Leadership could help employees develop trust towards their organization by providing an ethical orientation and by acting as a role model of ethical conduct and in result this will lead to project success. Our study contributes to ethical leadership literature in a way that it provides understanding about how ethical leadership can help achieve project success through employee trust. This study will help organizations in understanding how ethical leadership can help in achieving project success.

\section{Literature Review}

\subsection{Ethical leadership and project success}

Brown et al. (2005) explained ethical leadership as the demonstration of normatively appropriate conduct through personal actions and interpersonal relationships, and the promotion of such conduct to followers through two-way communication, reinforcement and decision making. Ethical leaders are the representatives of organizations ethical conduct and theyve to imitate for adherents to get their attention towards ethical message; they must be trustworthy, lawful and charismatic to be alleged as ethical leaders by being honest, being legitimate for employees rights and to influence ethics related outcomes (Brown et al., 2005). Ethical behavior can be seen in leaders when they are supporting something that is morally right and by doing so they are spreading awareness about ethical conduct and moral self-actualization (Zhu et al., 2004). Zhu et al. (2004) defined ethical leader as the one whose behavior is based on moral principles, one who is not focused on looking after his self-interest but concerned about subordinates rights, empowering employees for their growth and treat them fairly.

Project success is attained with the achievement of its targets relevant with the business objectives, product and services; whereas management success is achieved when budget, quality and control of the project related targets are achieved (Müller and Turner, 2010). Hussein et al. (2015) suggested that if projects are based on clear and realistic targets and on realistic criteria for success which helps in attaining top management and stakeholders trust; this can help lead to achieving project success. Ethical management of project teams results in improved production and distribution processes, increase in employee competence and satisfaction and present a leadership that can lead the project towards success (Lee, 2009). Geoghegan and Dulewicz (2008) posited that the aspect of leadership that deals with efficiently managing resources, empowering and motivating employees is found to have a positive relation with project success. Ethical leader is also characterized by these aspects. Mishra et al. (2011) suggested that project management is not only about completing project within time, budget and cost but practicing high level of moral character to get management and project team support which can help in achieving success. We therefore hypothesize that:

\section{H1. Ethical leadership is positively related to project suc-} cess.

\subsection{Mediating role of employee trust be- tween ethical leadership and project success}

Rousseau et al. (1998) defined trust as a psychological state comprising of the intention to accept vulnerability based upon positive expectations of the intentions or behaviors of another. McCauley and Kuhnert (1992) stated that employees continuously monitor organizations behavior towards them, i.e. if organizations management displays high level of trust in employees this will result in high level of employee trust on organization management. Through trust, employees develop a supportive behavior which helps in reducing conflict; develop a positive perception of employee towards leader, resulting in increased job satisfaction and efficiency (Gill, 2008). Employee trust in leader is his consent to be susceptible to the actions of his supervisor, whose responsibility is to convey top management orders and on whose actions employee does not have any control (Tan and Tan, 2000). Employees trust on leader increases if leaders words are followed by his actions (Wang and Hsieh, 2013). As Confucius said: People will hear what we say and observe what one does

Ethical leaders communicate to employees about what is expected from them in terms of ethics using two way communications; he listens to their ideas and asks them what is a right thing to do? (Brown et al., 2005). The distinctiveness of ethical leadership allows employees to gladly follow their employers actions and decision of their organization (Xu et al., 2016). When employees have a trusting relation with their leader they will communicate any bad conduct in organization with their supervisor without any fear (Payne, 2014). (Xu et al., 2016) study results suggested that employee trust is based on leaders ethical or unethical conduct, so for employees to trust organization, leader should be moral manager but most of all he should be a moral person. They argued that a positive relation exists between ethical leadership and employee performance because when managers are ethical leaders, their relationship with employee is based on trust and employees expect a fair treatment from organization.

Project managers adopt leadership behavior which can help in improving project performance, resulting in project success (Yang et al., 2011). Morris (1986) identified that success of a project is dependent upon real- 
istic and definite goal, resource availability, customer approval, and profitability, and competitive edge, completion of project according to plan and perceived value of project. Mazur et al. (2014) explained that in all phases of project from planning till implementation, top management support is the most critical factor for project success. Top management should keep in check the satisfaction and trust level of project manager towards organization because both are mandatory for project success in complex situations (Rezvani et al., 2016). Project success therefore can be achieved when employees trust their leader to provide them with unambiguous information and instructions for carrying out routine project activities and give them opportunity to reflect their views and ideas on management decisions. Trust is mandatory for successful completion of supply chain project; this success is influenced by supply chain partners relationship based on trust (Brinkhoff et al., 2015). Additionally, when employees trust their leader that he will empower them, treat them righteously and the leader will be an example of moral person then they go out of their way to perform project activities on time and on cost and communicate every problem with their leader, which helps in eradicating flaws in project and achieve project success. We therefore hypothesize that:

H2. Employee trust mediates positively between ethical leadership and project success.

\subsection{Moderating role of ethical orientation between ethical leadership and em- ployee trust}

Ethical orientation cannot be considered as dictatorial; it brings in cognitive processes needed to take an ultimate decision (Bigel, 2000). Webster and Trevino
(1995) argued that ethical orientation varies from person to person, it indicates towards individuals distinctive thinking and the way he counters different ethical dilemmas. They stated that the individuals are most likely to act according to their set standard decisions and according to what they think is right thing to do, they are least expected to cheat and when they see someone else involved in misconduct they are most likely to blow the whistle and they dont leave a chance to help others. Douglas et al. (2001) in their study showed a positive relation between ethical orientation and ethical judgments in intense moral circumstances. Ethical orientation consists of several orientations which are used by an individual to take a decision based on ethical principles; these orientations are justice, utilitarianism, responsibilities, self-interest and cultural recognition (Jones et al., 2003). Greenfield et al. (2008) stated that if individuals ethical orientation is based on relativity, there is a high chance of his involvement in earning management practices. Alder et al. (2008) on the basis of previous research suggested that though organizations operations effect employees ethical orientation but in reverse employees ethical orientation can affect his attitude towards organizations operations. On the contrary, if individuals ethical orientation is based on idealism, there is a low chance of his involvement in earning management behavior. Zweifel and Janus (2017) posited that medical doctors efficiency is dependent upon his ethical orientation, which means that if their ethical orientation is not strong they put minimum effort in taking care of patients.

Javed et al. (2017) stated that employees creativity is influenced by ethical leadership but in order to have that influence a manager needs to take on an ethical leadership style in which he emphasizes on organizations ethical values, justice environment and provides employees with the freedom to express their ideas, which can be utilized by organization. Chughtai et al.

Table 1: Bivariate Correlation

\begin{tabular}{|c|c|c|c|c|c|c|c|c|c|c|c|}
\hline & Variables & Mean & S.D & 1 & 2 & 3 & 4 & 5 & 6 & 7 & 8 \\
\hline 1 & Gender & 1.39 & 0.49021 & 1 & & & & & & & \\
\hline 2 & Age & 2.09 & 1.15553 & $.294^{* *}$ & 1 & & & & & & \\
\hline 3 & Qualification & 4.26 & 0.90587 & $.088^{* *}$ & $0.23^{* *}$ & 1 & & & & & \\
\hline 4 & Experience & 1.98 & 1.19747 & $.210^{* *}$ & $.921^{* *}$ & 0.033 & 1 & & & & \\
\hline 5 & Ethical Leadership & 3.915 & 0.56181 & $.286^{* *}$ & $.261^{* *}$ & $.097^{* *}$ & $.205^{*}$ & 1 & & & \\
\hline 6 & Employee Trust & 3.1733 & 0.97727 & $.241^{* *}$ & $.535^{* *}$ & $.196^{* *}$ & $.515^{* *}$ & 0.104 & 1 & & \\
\hline 7 & Prjct Success & 3.6764 & 0.59843 & 0.016 & 0.115 & 0.006 & 0.107 & $.489^{* *}$ & $.083^{* *}$ & 1 & \\
\hline 8 & Ethical Orientation & 3.9083 & 0.50523 & $.024^{* *}$ & 0.192 & 0.008 & 0.126 & $.313^{* *}$ & 0.045 & $.477^{* *}$ & 1 \\
\hline
\end{tabular}


(2015) stated that implementation of ethical leadership in organization can provide healthy work environment for employees. Nedkovski et al. (2017) study showed that leaders should promote organizations policies that help in the development and maintenance of generous and righteous Overseas Employment Corporation, which has a significant relation with employee and employer mutual trust. For an organizations policy and procedures development, ethical orientation can prove to be a base (Dickson et al., 2001). Employee who is working in an organization for a long period is aware of organizations ethics, rules, policies and values, he may respond to ethical leader in a more trustful manner as compared to employee who is not consistent with organizations principles (Walumbwa et al., 2011). Dinc and Nurovic (2016) suggested that organizations should spend more on ethical leaders training and their training should cover topics like conveying ethical orientation to employees, motivating employees who are involved in ethical conduct and be a role model of ethical conduct. If ethical leaders become an example of ethical role model and an ethical orientation is given regarding organizations ethical values and polices, this may help employees realize that they will be treated fairly and get a chance in decision making; this makes them trust the organization and ethical leader. We therefore hypothesize that:

H3. Ethical orientation moderates the relationship between ethical leadership and employee trust, such that ethical orientation strengthens the relationship.

\section{Theoretical framework}

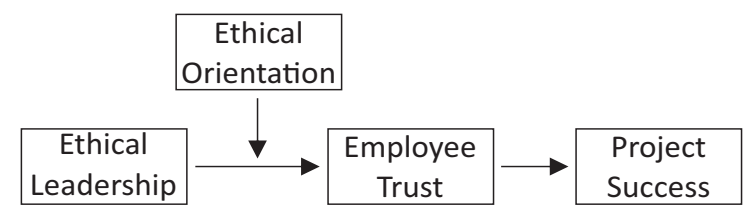

Figure 1: proposed model

\section{Methodology}

\subsection{Sample and Procedures}

Convenient sampling technique was used to study the impact of ethical leadership on project success with mediating role of employee trust and moderating role of ethical orientation. The sample was selected from private sector of Islamabad (Kanji Advisory). Kanji Advisory is a project based organization that designs and executes client responsive business strategies for private sector as well as civil society organizations to make rural area market segment more profitable. The purpose of selecting this company was because of its innovative business models and project plans made by the collaboration of civil and industrial society.

For research purpose, 120 questionnaires were distributed among employees, 105 questionnaires were returned back with full response, 6 questionnaires were incomplete and 9 were not returned. Majority of respondent were male $62 \%$ and female only $38 \%$. In age category, $40 \%$ were 18 to 25 years, $30 \%$ were in the range of $26-33,41 \%$ in the rage of $34-41,13 \%$ in the range of $42-49$ and $3 \%$ in the range of 50 and above years. In regards with qualification, $2 \%$ had Inter degree, 23\% attained bachelors degree, $24 \%$ had masters degree, $49 \%$ had MS/MPhil degree and $2 \%$ had PhD degree. With respect to the experience of employees, $46 \%$ had $0-5$ years of experience, $31 \%$ had $6-10$ years of experience, $7 \%$ in the category of $11-16$ years, $11 \%$ in the category of $17-22$ and $5 \%$ in the category of $23-28$ years of experience. Additionally, all respondents were assured that the collected information will only be used for academic purpose.

\subsection{Instruments}

\subsubsection{Ethical Leadership}

Ethical leadership scale developed by Brown and Treviño (2006) consists of 10 items. Sample items include Make fair and balance decisions and When making decisions, asks What is the right thing to do?. Same scale was used by Javed et al. (2017) and reported good reliability. Cronbach's Alpha was 0.876 .

\subsubsection{Project Success}

With respect to project success, respondents completed 14 item scales. Project success measurement standard tool are not available in published literature, and one tool which consists of previous research (??). Sample items include The outcomes of the project have directly benefited the intended end users, either through increasing efficiency or effectiveness and The project has made a visible positive impact on the target beneficiaries. Cronbach's Alpha was 0.914.

\subsubsection{Employee Trust}

With respect to employee trust respondents completed 3 items scale by (Mooradian et al., 2006). Sample items include I feel quite confident that the firm will always try to treat me fairly and Management at my firm is sincere in its attempts to meet the employees point of view. Cronbach's Alpha was 0.922.

\subsubsection{Ethical Orientation}

With respect to ethical orientation respondents completed 12 item scales by (Redfern and Crawford, 
2004). Sample items include People should make certain that their actions never intentionally harm another person, even to a small degree and Questions of what is ethical for everyone can never be resolved since what is moral or immoral is up to the individual. Five point Likert scale was used to measure all variables with descriptors like Strongly Disagree (1), Disagree (2), Neutral (3), Agree (4) and Strongly Agree (5). Cronbach's Alpha was 0.817.

\section{Results}

Table 3 shows the mediation result of employee trust on ethical leadership and project success relationship. Respondents completed the questionnaire and regression analysis on Hypothesis 1 Ethical leadership (EL) is linked with Project Success (PS) and it is also accepted, supported by the coefficient regression results $(\mathrm{B}=.871, \mathrm{p}<.01)$. Hypothesis 2 shows that $\mathrm{EL}$ is linked with Employee Trust (ET) and it is accepted as supported by the coefficient regression result $(B=1.049$, $\mathrm{p}<.01)$ and ET is linked with PS is also accepted, supported by the coefficient regression results $(\mathrm{B}=.779, \mathrm{p}$ $<.01)$. Furthermore, for hypothesis 2, mediation is run through Baron and Kenny (1986) four steps. EL and PS is regressed that shows the result $(\mathrm{B}=.871, \mathrm{p}<.01)$ then EL is regressed that shows result $(B=1.049, \mathrm{p}<$ $.01)$ then ET and PS are regressed that shows result (B $=.729, \mathrm{p}<.01)$, then in last step EL is regressed with PS with control mediator results shows significance (B $=.309, \mathrm{p}<.01$ ).

Table 4 shows that moderated regression analysis used for hypothesis 3 which states that ethical orientation plays a moderating role between Ethical Leadership and Employee Trust. Here, analysis of Baron and Kenny (1986) a three step regression analysis is done. In the first step, ET is regressed with PS (B $=.742, \mathrm{p}<$ $.01)$. In the second step, EO is regressed with EL along with controlling the effect of ET $(B=1.110, p<.01)$. In the last step, effect of ET is combined with EO then interaction term is formed and then this interaction term is regressed with PS. Result from regression analysis indicates $(\mathrm{B}=1.054, \mathrm{p}<.01)$ shows that $\mathrm{EO}$ is acting as a moderator.

\section{Discussion and Implication}

The purpose of this study was to show the effect of ethical leadership on project success and study the mediator mechanism of employee trust between ethical leadership and project success and an external effect of ethical orientation as moderator between ethical leadership and employee trust. The results showed significant relationship between ethical leadership and project success, employee trust was found to mediate the relationship between ethical leadership and project success and ethical orientation was found to moderate the relationship between ethical leadership and project success.

Above results are also supported by preceding study of Xu et al. (2016) their study result showed ethical leadership as a positive facilitator of employee trust in management. The significant relation between ethical leadership and project success shows that ethical conduct of a leader can enhance employee trust to communicate any issue or ideas with management which leads to decrease in project delay, over consumption of budget and directly lead to project success. Dinc and Nurovic (2016) suggested a positive relationship between ethical leadership and employee attitude. Particular project managers tend to adopt different leadership style for the improved performance of project, which the adoption of leadership style project team performance enhances and so does the project performance Yang et al. (2011).

Our study found that ethical orientation significantly influences the relation between ethical leadership and employee trust. Old employees as compared to new ones are more aware of the ethical orientations, rules and regulations and values of organization, which allows them to trust their ethical leader (Walumbwa et al., 2011). Such employees work hard to achieve the given targets because they are treated well by ethical leader by being given a right to share their views and report any problem faced by them which increases their trust on their leader because they feel honored.

This study confirmed the mediating role of employee trust between ethical leadership and project success and the relationship of ethical leadership and employee trust being moderated by ethical orientation. This helps in consideration of the fundamental mechanism of how ethical leadership effects project success. This study has important message for managers to adopt ethical leadership style to enhance the performance of project by being a moral person, promoting employees rights and empowering employees. Training should be conducted on how to adopt ethical leadership style in organizations.

\subsection{Limitations}

Our study contributes in the existing literature of leadership contribution in project success by collecting data from employees of project based organization for the accuracy of results. All hypotheses were proven with a significant relationship between all variables. This study results demonstrate that ethical leaders can help in achieving project success when employees trust leaders with the involvement of ethical orientation as 
Table 2: Regression Analysis Results

\begin{tabular}{lcccc}
\hline & \multicolumn{4}{c}{ Project Success } \\
Predictors & $\beta$ & $\mathbf{t}$ & $R^{2}$ & $\Delta R^{2}$ \\
\hline Ethical Leadership & 0.779 & 22.575 & 0.84 & 0.858 \\
\hline$p \leq .01$
\end{tabular}

Table 3: Mediated Regression Analysis

\begin{tabular}{|c|c|c|c|c|c|c|}
\hline \multirow[b]{2}{*}{ Predictor } & \multicolumn{3}{|c|}{ Employee Trust } & \multicolumn{3}{|c|}{ Project Success } \\
\hline & $\beta$ & $R^{2}$ & $\Delta R^{2}$ & $\beta$ & $R^{2}$ & $\Delta R^{2}$ \\
\hline \multicolumn{7}{|l|}{ Direct Effects } \\
\hline \multicolumn{7}{|l|}{ Step 1} \\
\hline Control Variables & & & & & 0.026 & \\
\hline \multicolumn{7}{|l|}{ Step 2} \\
\hline Ethical Leadership & $1.049^{* *}$ & 0.933 & 0.933 & $.837^{* *}$ & 0.871 & 0.869 \\
\hline \multicolumn{7}{|l|}{ Indirect Effects } \\
\hline \multicolumn{7}{|l|}{ Step 1} \\
\hline Control Variables & & & & & 0.026 & \\
\hline \multicolumn{7}{|l|}{ Step 2} \\
\hline Employee Trust & & & & $.829^{* *}$ & 0.855 & 0.884 \\
\hline \multicolumn{7}{|l|}{ Step 3} \\
\hline Ethical Leadership & & & & $.309^{* *}$ & 0.894 & 0.891 \\
\hline
\end{tabular}

Note: $N=100 .{ }^{*} p<.05 .{ }^{* *} p<.01,{ }^{* * *} p<.001$

Table 4: Moderated Regression Analysis

\begin{tabular}{lccc}
\hline & \multicolumn{3}{c}{ Employee Trust } \\
Predictor & $\beta$ & $R^{2}$ & $\Delta R^{2}$ \\
\hline Step 1 & & \\
Control Variables & & 0.26 & \\
Step 2 & & \\
Ethical leadership & 0.742 & 0.885 & 0.884 \\
Ethical Orientation & 1.11 & 0.915 & 0.913 \\
Step 3 & & & \\
EL*EO & 1.054 & 0.916 & 0.914 \\
\hline
\end{tabular}

Note: $N=100 .{ }^{*} p<.05,{ }^{* *} p<.01,{ }^{* * *} p<.001$

an external factor. Our study also has some limitation. The first limitation is that our sample size was small due to time limitation. If same size is large it will help in generalizing results. The second limitation is that we used employee trust as mediating variable while there are several other variables that can be used as mediator, e.g. intrinsic motivation and creativity.

\section{References}

Alder, G. S., Schminke, M., Noel, T. W., and Kuenzi, M. (2008). Employee reactions to internet monitoring: The moderating role of ethical orientation. Journal of Business Ethics, 80(3):481.

Avey, J. B., Palanski, M. E., and Walumbwa, F. O. (2011). 
When leadership goes unnoticed: The moderating role of follower self-esteem on the relationship between ethical leadership and follower behavior. Journal of Business Ethics, 98(4):573-582.

Baron, R. M. and Kenny, D. A. (1986). The moderatormediator variable distinction in social psychological research: Conceptual, strategic, and statistical considerations. Journal of personality and social psychology, 51(6):1173.

Bigel, K. S. (2000). The ethical orientation of financial planners who are engaged in investment activities: A comparison of united states practitioners based on professionalization and compensation sources. Journal of Business Ethics, 28(4):323-337.

Brinkhoff, A., Özer, Ö., and Sargut, G. (2015). All you need is trust? an examination of inter-organizational supply chain projects. Production and operations management, 24(2):181200.

Brown, M. E. and Treviño, L. K. (2006). Ethical leadership: A review and future directions. The leadership quarterly, 17(6):595-616.

Brown, M. E., Treviño, L. K., and Harrison, D. A. (2005). Ethical leadership: A social learning perspective for construct development and testing. Organizational behavior and human decision processes, 97(2):117-134.

Chen, A. S.-Y. and Hou, Y.-H. (2016). The effects of ethical leadership, voice behavior and climates for innovation on creativity: A moderated mediation examination. The Leadership Quarterly, 27(1):1-13.

Chughtai, A., Byrne, M., and Flood, B. (2015). Linking ethical leadership to employee well-being: The role of trust in supervisor. Journal of Business Ethics, 128(3):653-663.

Dickson, M. W., Smith, D. B., Grojean, M. W., and Ehrhart, M. (2001). An organizational climate regarding ethics: The outcome of leader values and the practices that reflect them. The Leadership Quarterly, 12(2):197-217.

Dinc, M. S. and Nurovic, E. (2016). The impact of ethical leadership on employee attitudes in manufacturing companies. Nile Journal of Business and Economics, 2(3):3-14.

Douglas, P. C., Davidson, R. A., and Schwartz, B. N. (2001). The effect of organizational culture and ethical orientation on accountants' ethical judgments. Journal of Business Ethics, 34(2):101-121.

Geoghegan, L. and Dulewicz, V. (2008). Do project managers' leadership competencies contribute to project success? Project Management Journal, 39(4):58-67.

Gill, S. (2008). Power and resistance in the new world order: fully revised and updated. Springer.

Greenfield, A., Norman, C. S., and Wier, B. (2008). The effect of ethical orientation and professional commitment on earnings management behavior. Journal of Business Ethics, 83(3):419-434.
Hussein, B. A., Ahmad, S. B., and Zidane, Y. J. (2015). Problems associated with defining project success. Procedia Computer Science, 64:940-947.

Javed, B., Naqvi, S. M. M. R., Khan, A. K., Arjoon, S., and Tayyeb, H. H. (2017). Impact of inclusive leadership on innovative work behavior: The role of psychological safety. Journal of Management $\mathcal{E}$ Organization, pages 1-20.

Jones, J., Massey, D. W., and Thorne, L. (2003). Auditors'ethical reasoning: Insights from past research and implications for the future. Journal of Accounting Literature, 22:45.

Lee, M. R. (2009). E-ethical leadership for virtual project teams. International Journal of Project Management, 27(5):456-463.

Lee-Kelley, L. and Kin Leong, L. (2003). Turner's fivefunctions of project-based management and situational leadership in it services projects. International Journal of Project Management, 21(8):583-591.

Mazur, A., Pisarski, A., Chang, A., and Ashkanasy, N. M. (2014). Rating defence major project success: The role of personal attributes and stakeholder relationships. International Journal of Project Management, 32(6):944-957.

McCauley, D. P. and Kuhnert, K. W. (1992). A theoretical review and empirical investigatiomn of employee trust in management. Public Administration Quarterly, pages 265284.

Mishra, P., Dangayach, G., and Mittal, M. (2011). An empirical study on identification of critical success factors in project based organizations. Global Business and Management Research: An International Journal, 3(3/4):356-368.

Mooradian, T., Renzl, B., and Matzler, K. (2006). Who trusts? personality, trust and knowledge sharing. Management learning, 37(4):523-540.

Morris, P. (1986). Research at oxford into the preconditions of success and failure in major projects.

Müller, R. and Turner, R. (2010). Leadership competency profiles of successful project managers. International Journal of Project Management, 28(5):437-448.

Nedkovski, V., Guerci, M., De Battisti, F., and Siletti, E. (2017). Organizational ethical climates and employee's trust in colleagues, the supervisor, and the organization. Journal of Business Research, 71:19-26.

Payne, H. J. (2014). Examining the relationship between trust in supervisor-employee relationships and workplace dissent expression. Communication Research Reports, 31(2):131140.

Redfern, K. and Crawford, J. (2004). An empirical investigation of the influence of modernisation on the moral judgements of managers in the peoples republic of china. Cross Cultural Management: An International Journal, 11(1):48-61. 
Rezvani, A., Chang, A., Wiewiora, A., Ashkanasy, N. M., Jordan, P. J., and Zolin, R. (2016). Manager emotional intelligence and project success: The mediating role of job satisfaction and trust. International Journal of Project Management, 34(7):1112-1122.

Rousseau, D. M., Sitkin, S. B., Burt, R. S., and Camerer, C. (1998). Not so different after all: A cross-discipline view of trust. Academy of management review, 23(3):393-404.

Ruiz-Palomino, P., Ruiz-Amaya, C., and Knörr, H. (2011). Employee organizational citizenship behaviour: The direct and indirect impact of ethical leadership. Canadian Journal of Administrative Sciences/Revue Canadienne des Sciences de l'Administration, 28(3):244-258.

Tan, H. H. and Tan, C. S. (2000). Toward the differentiation of trust in supervisor and trust in organization. Genetic, Social, and General Psychology Monographs, 126(2):241.

Walumbwa, F. O., Mayer, D. M., Wang, P., Wang, H., Workman, K., and Christensen, A. L. (2011). Linking ethical leadership to employee performance: The roles of leadermember exchange, self-efficacy, and organizational identification. Organizational Behavior and Human Decision Processes, 115(2):204-213.

Wang, D.-S. and Hsieh, C.-C. (2013). The effect of authentic leadership on employee trust and employee engagement. Social Behavior and Personality: an international journal, 41(4):613-624.
Webster, J. and Trevino, L. K. (1995). Rational and social theories as complementary explanations of communication media choices: Two policy-capturing studies. Academy of Management journal, 38(6):1544-1572.

Xu, A. J., Loi, R., and Ngo, H.-y. (2016). Ethical leadership behavior and employee justice perceptions: The mediating role of trust in organization. Journal of Business Ethics, 134(3):493-504.

Yang, C., Ding, C. G., and Lo, K. W. (2016). Ethical leadership and multidimensional organizational citizenship behaviors: The mediating effects of self-efficacy, respect, and leader-member exchange. Group $\mathcal{E}$ Organization Management, 41(3):343-374.

Yang, L.-R., Huang, C.-F., and Wu, K.-S. (2011). The association among project manager's leadership style, teamwork and project success. International journal of project management, 29(3):258-267.

Zhu, W., May, D. R., and Avolio, B. J. (2004). The impact of ethical leadership behavior on employee outcomes: The roles of psychological empowerment and authenticity. Journal of Leadership E Organizational Studies, 11(1):16-26.

Zweifel, P. and Janus, K. (2017). Medical ethics: enhanced or undermined by modes of payment? The European Journal of Health Economics, 18(1):119-129. 


\title{
Impact of Ethical Leadership on Whistle Blowing Intention Through Medi- ating Role of Moral Attentiveness: Moderating Role of Collectivism
}

\author{
Awais Tariq* \\ Capital University of Science and Technology, Islamabad, Pakistan
}

\begin{abstract}
The focus of this research is to check the impact of leadership style on whistle blowing intention with the mediator and moderator. Using an assorted sample of 300 personnel from a variety of banks in Islamabad, the data for this field study were collected using convenient sampling technique. Ethical leadership positively influenced the process of the whistle blowing intention and provides an initiative to the employees that they can also raise their voice about any unethical conduct. Contrary to the prediction that moral attentiveness strengthens the positive role of ethical leadership verses whistle blowing relation. In addition, the cultural dimension collectivism also plays a moderating role and strengthens the relation between the moral attentiveness and whistle blowing intentions. In conclusion, this study offers significant contribution and serves to elicit comprehensive understanding of the organization to create full awareness among employees about whistle blowing intentions, providing ways by which they report the wrong doings in the organization.
\end{abstract}

\section{Introduction}

In the past decades, the researchers studied the different domains of leadership like authentic leadership, transformational leadership, servant leadership and ethical leadership. Brown et al. (2005) defined ethical leadership as the demonstration of normatively appropriate conduct through personal actions and interpersonal relationships, and the promotion of such conduct to followers through two-way communication, reinforcement, and decision-making. Treviño et al. (2003, 2000), say that the ethical leaders are generally thought as honest, trustworthy and principal decision makers, keeping in mind all the perspectives related to their organization and also by taking care of the environment in which their organization is working. There are also some conceptual frameworks of ethical leadership present that show that there are not only the organizational factors, which focus on ethical leadership, but there are also some situational factors that have an impact or determine the ethical leader. This conceptual model was given by Brown and Treviño (2006) show that the situational influences on the ethical side of the manager characterize individual and the overall outcome of the leadership style in the context of the organization and show the intensity whether employees are going to accept the ethical leadership style or not.

Another study (Kanungo and Mendonca, 2001) demonstrated that the situation has a great effect on the ethical leader and also on the decision making side of

*Corresponding author.

Email: awaistariq@gmail.com

http://www.jbrc.pk the leader, as well as on three factors that are ethical role modeling, ethical morality and ethical intensity of the issue. Ethical leader should influence employees pro social behavior. Here we have to note that ultimately ethical leaders have the legitimate role model and they have the main focus on the followers attention toward the ethical standards and the ethical activities in the organization and all it happens due to social learning (Bandura, 1986).

The relationship of ethical leadership and the employee whistle blowing activity starts from that point where the employees have their trust on their leader. Whistle blowing is an activity of reporting some wrong doings in the organization. According to Near and Micelis definition, whistle blowing is: the disclosure by organization members of illegal, immoral, or illegitimate practices under the control of their employers, to persons or organizations that may be able to effect action (Near and Miceli, 1985). This definition is comprised of three things, i.e. illegal means in term that is prohibited under the law, immoral, which means that in the perspective of the whistle blower, it is perceived as wrong and illegitimate, which means that it should be beyond the organization authority. There are also several studies present that show that the whistle blowers have such attitude to report any unethical activity in their organization and it has also been reported that the employees are more likely to report any unethical activity within a group which consists of some ethical environment (Graham, 1986). An ethical leader is re- 
sponsible for making such an ethical environment in the organization in which an employee feels safe to report any unethical activity which he or she sees in the organization.

There is literature available and also has been developed which examines this issue from different perspectives. For an extensive list of sources, see (Miceli et al., 2009). Gender difference also plays an important role, as a study by Rehg et al. (2008) reported that females are being more retaliated toward this issue; i.e. being female was correlated with perceived retaliation (pp.221-240) against whistle blowing; Similarly, another study reports that there are some incentives for those employees and these incentives are being given on the basis of gender (Feldman and Lobel, 2009).

Social cognitive theory given by Bandaura is most effectively related to our study. Specifically social cognitive theory covers all the variables in our study. Social cognitive theory first defined by a psychologist Albert Bandura in 1997 which he defines as Social cognitive theory (SCT), used in psychology, education, and communication, holds that portions of an individual's knowledge acquisition be directly related to observing others within the context of social interactions, experiences, and outside media influences. Based on social cognitive theorys social learning (Bandura, 1977, 1986), Brown et al. (2005) argued that ethical leaders influence followers primarily through modeling processes. The modeling refers to the learning by an individual through their environment by using their mental schemas to evaluate or to note what is happening in the environment and the environment also plays an important role that how a person learns from the environment either in a positive or negative way.

Banduara's social learning theory stresses the importance of things the human beings learn from their environment through the imitation of different things and through the modeling process that we have discussed above. The theory also integrates a continuous process of interaction between the human behaviors, other personal factors, including all those cognitions that are related with the cognition and with the environment, which are being referred as the reciprocal process causation model.

When we are talking about the social learning process, it means what an individual learns from his environment and his workplace. If an organization is ethical and all the employees who are working in that organization are behaving ethically, then automatically those ethical values are being transferred to the employees and above all, a complete ethical atmosphere is being developed and this happens due to the ethical leader. The other leadership styles are also considered for development of ethical values in the organization, as servant leadership has focused on the power distance and the human orientation that can also be synergied with the process or with the help of ethical leadership.

Another main and important thing is that there must be a strong determination of the leader to be ethical, who plays an important role in developing the ethical role models in the organization. This can only happen in the organization, when the leader himself is ethical and has strong determination to be ethical. But if there is no determination of the leader to be ethical then he or she cannot inculcate ethical conscientious among employees.

\section{Literature Review}

\subsection{Ethical leadership and whistle blowing}

There are different researches being conducted in a different formats by taking ethical leadership and also have been checked with the different variables, but when there is hype created in whole world about missrepresenting or some wrongdoing in the organization that raises the question on the ethical leadership. When the media reported the cases about the WorldCom and Enron, the questions were asked to the CEOs of different organization association between ethical leadership and financial misrepresenting of the data (Perel, 2003). Different studies on financial scam in the business ethics literature have focused on the character and honesty of different Chief Executive of several organizations (Bragues, 2008; Morrison, 2001)and tried to answer the question of what ethical leaders should do from a entirely philosophical view based on ethical principles, which are based on ethics taken from Greek philosophers such as Plato and Aristotle (Knights and OLeary, 2006; MacIntyre, 1979).

Different studies in which they have taken a scientific approach, which deal with the ethics within the organization, the contextual factors and also the situational factors, which help ethical leader to build an ethical workplace. Such situational factors are ethical context in which the employees or the followers have trust on their leader and show the follower satisfaction while working with his or her leader (Brown and Treviño, 2006; Brown et al., 2005). Different studies have been carried out on the significance of culture values and norms in determining the behaviors of ethical leaders. The GLOBE study, which focused on comparison between perceptions of leadership among different countries established that character or integrity was sanctioned much less among societies of Middle Eastern countries as compared to the societies of Nordic (Resick et al., 2006; Waldman et al., 2006).

Based on the above literature, following hypothesis has been developed.

H1. There is a positive relationship between ethical; leadership and whistle blowing 


\subsection{Moral Attentiveness mediates the re- lationship between Ethical Leadership and Whistle Blowing}

There are different variables being discussed by the researcher when they are discussing the ethical leadership and whistle blowing so the current study takes a new construct, i.e. moral attentiveness as a mediating variable. This construct is considered very important in part of the ethical leadership, which is being discussed by Waldman et al. (2006). New thing is also being proposed by the followers that the leaders who have high moral attentiveness is considered ethical by their followers. It is of utmost importance that the followers should consider their leader ethical so the ethical values are automatically being transferred in the employees, consequently leading to whistle blowing by the employees, if they have strong ethical values. Researcher have shown that moral attentiveness is considered a trait like character in the followers and it all happens due to ethical leadership and if that trait is being transferred through the ethical leadership then the employees are being more attentive, all the while noticing or seeing any wrongdoing in the organization, they will definitely report that thing. Moral identity and moral attentiveness are being both inculcated by the ethical leader but the moral attentiveness is main thing which is being developed by ethical leader (Mayer et al., 2012). One of the critical factors which affects an individual's sensitivity towards ethical issues is a moral interest, a relatively new construct in the ethical literature, known as "the extent to which envisages chronic individual is ethics and moral elements of his proposed" based on social cognitive theory of knowledge (Bandura, 1986). Reynolds (2008) proposed that some individuals are more interested in cognitive ethical issues than others, and that the moral interest of individuals has a significant impact on experiences. Thus, leaders who are highly morally attentive should pay more attention to the moral aspects of the information the receive.

H2. Moral attentiveness mediates the relationship between ethical leadership and whistle blowing.

\subsection{Collectivism as a moderator between Moral Attentiveness and whistle blow- ing}

There are different cultural dimensions being discussed; such as individualism and collectivism, we have taken collectivism in our research because this research is being conducted in Pakistan, where where collectivisim is dominant in our culture as suggested by Hofstede (1986). The cultural dimension also shows how much an individual stresses his or her own goals or on the other hand the goal of his or her group. Results suggest that in Pakistan a number of factors, such as culture and organizational retaliation, affect the whistle-blowing process. It also highlights that some unique culturally induced factors contribute toward the employees perception and practice of whistle blowing in their organizations. Results are explained in light of Hofstedes cultural indices, which indicate that whistle blowing is culture bound.

There are different ways through which the reporting of whistle blowing or any wrong doing is to be done. Basically, whistle blowing is commonly defined as the disclosure by organization members (former or current) of illegal, immoral, or illegitimate practices under the control of their employers, to persons or organizations that may be able to effect action (Near and Miceli, 1985). Employee utilization channels to report the wrong doings or any misconduct are not sufficient and therefore they are less in amount so in different studies it is being found that employees that are aware of wrongdoing and any type of corruption in the organization, they remain quiet and dont tell anyone about that wrong doing (Near and Miceli, 1985). An employees decision to report individual or organizational misconduct is a complex phenomenon that is based upon organizational, situational, and personal factors (Near and Miceli, 1995).

H3. Collectivism moderates the relationship between moral attentiveness and whistle blowing

\section{Theoretical framework}

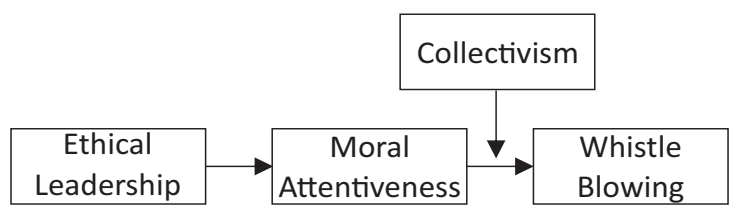

Figure 1: Theoretical Framework

\section{Research Methodology}

\subsection{Population and Sample}

Since the present study seeks to focus on the public sector of Pakistan, the population of the study is the employees of schools and college. The sample mainly consists of administration level of different schools and colleges. Data were collected through a self-administered paper-and-pencil survey. Almost 300 questionnaires were distributed. The convenience sampling technique were used due to time limitations. 


\subsection{Instrumentation}

All the items in the questionnaire were responded to using a 5-points Likert-scale where 1 (strongly disagree) to 5 (strongly agree), unless otherwise stated. Questionnaires also consist of four demographic variables which include information regarding the respondent Gender, Age, Qualification and Experience.

\subsubsection{Ethical leadership}

The 10 item scale developed by Yukl et al. (2013) was used to measure the perception of employees about their leaders ethical behavior. The items show strong concern for ethical and moral values which communicate clear ethical standards for members sets an example of ethical behavior in his/her decisions and actions. Is honest and can be trusted to tell the truth, Is a fair and unbiased when assigning task to members..

\subsubsection{Moral attentiveness}

The 7 item scale developed by Reynolds (2008) was adoped to measure moral attentiveness. The item scale is. I regularly think about the ethical implications of my decisions, I think about the morality of my actions almost every day, I often find myself pondering about ethical issues, I often reflect on the moral aspects of my decisions, I like to think about ethics, In a typical day, I face several ethical dilemmas, I often have to choose between doing whats right and doing something thats wrong..

\subsubsection{Collectivism}

To measure collectivism, 5 item scale developed by Williams et al. (1988) was used. The item scales are Group welfare is more important than individual rewards, Group success is more important than individual success, Being accepted by the members of your workgroup is very important, Employees should only pursue their goals after considering the welfare of the group, and Managers should encourage group loyalty even if individual goals suffer.

\subsubsection{Whistle Blowing}

The 2-item scale developed by Bhal and Dadhich (2011) was adopted to guage the responses of whistle blowing. The scale items are as follows, I feel that I can discuss ethical issues and problems with my supervisor without fear of having the comments held against me, I would be comfortable delivering bad news of an unethical wrongdoing to the supervisor..

\subsection{Sample Characteristics}

Out of the 180 total respondents, majority were young. The respondent between age 18 to 25 years were 113, while the respondents of 26 to 33 year age were 56, as the age between 18 and 33 considered young, they contributed $82.2 \%$ of the total responses of the present study. The middle aged respondents from age 34 to 41 years were 8 and the respondents of age 42 to 49 years were 3 . In the total sample of 180 the population, 103 were male and 77 were female, having percentage of $57.2 \%$ and $42.8 \%$ respectively. As expected, male employees are working in majority then female colleagues, thus showing consistency with perceptions about that Pakistani culture male dominant society.

\section{Results}

\subsection{Correlation analysis}

Table 1 displays the correlation between the variables of the current study. Ethical Leadership is significantly positively correlated to whistle blowing intention at $.663^{* *}$. The maximum value of correlation found was $.705^{* *}$ which was between ethical leadership and moral attentiveness. Whereas, ethical leadership correlates with the collectivism and the correlation value between the ethical leadership and collectivism is .591**. Further in this table other variables also shows the correlation as collectivism correlates between moral attentiveness and whistle blowing intention with a values of $.609^{* *}$ and $.687^{* *}$ respectively. In the last moral attentiveness correlates between whistle blowing intention with a value of $.609^{* *}$.

\subsection{Regression Analysis}

Regression analysis between ethical leadership and moral attentiveness resulted in the $R^{2}$ value of 0.50 , representing that ethical leadership brings $50 \%$ change in the moral attentiveness of followers. Moral attentiveness when regressed with ethical leadership had a statistically significant results. As proposed by the research model, ethical leadership predicts approximately 50 percent variation in moral attentiveness in a positive direction, which is consistent with the study hypothesis. The $R^{2}$ value is 0.50 at $\mathrm{p}<.05$ (table 2 ). Thus concluded that 1 unit change in ethical leadership results in nearly 0.5 percent change in moral attentiveness. Therefore, H2, which indicated that ethical leadership positively affects followers moral attentiveness, substantiated statistically.

Regression analysis between moral attentiveness and whistle blowing intention resulted in the $R^{2}$ value of 0.48 , representing that moral attentiveness brings $48 \%$ change in the whistle blowing intention of followers. Whistle blowing intention when regressed with moral attentiveness also showed significant results. As proposed by the research model, moral attentiveness predicts approximately 48 percent variation in whistle blowing intention in a positive direction, which is con- 
Table 1: Means, Standard Deviations, Correlations, Reliabilities

\begin{tabular}{llcccccc}
\hline & Variables & Mean & S.D & $\mathbf{1}$ & $\mathbf{2}$ & $\mathbf{3}$ & $\mathbf{4}$ \\
\hline $\mathbf{1}$ & Ethical Leadership & 4.7 & 0.9 & $\mathbf{1}(.706)$ & & & \\
$\mathbf{2}$ & Moral Attentiveness & 5 & 0.9 & $.705^{* *}$ & $\mathbf{1 ( . 7 4 3 )}$ & & \\
$\mathbf{3}$ & Whistle Blowing Intentions & 4.83 & 1 & $.663^{* *}$ & $.609^{* *}$ & $\mathbf{1 ( . 6 5 9 )}$ & \\
$\mathbf{4}$ & Collectivism & 4.8 & 1 & $.591^{* *}$ & $.687^{* *}$ & $.629^{* *}$ & $\mathbf{1 ( . 6 4 2 )}$ \\
\hline
\end{tabular}

*. Correlation is significant at the 0.05 level (2-tailed)

**. Correlation is significant at the 0.01 level (2-tailed)

Table 2: Regression Analysis

\begin{tabular}{lccc}
\hline Relationships & $R^{2}$ & F & Sig \\
\hline Ethical Leadership Moral Attentiveness & 0.5 & 175.49 & 0.000 \\
Ethical Leadership and Moral Attentiveness Whistle Blowing Intentions & 0.48 & 81.65 & 0.000 \\
Ethical Leadership Whistle Blowing Intentions (total effect model) & 0.44 & 139.79 & 0.000 \\
\hline
\end{tabular}

sistent with the study hypothesis. The beta value is 0.48 at $\mathrm{p}<.05$. Therefore concluded that 1 unit change in moral attentiveness results in nearly 0.4 percent change in whistle blowing intention. Therefore, $\mathrm{H} 2$, which indicated that ethical leadership positively, affects followers moral attentiveness, substantiated statistically.

Regression analysis between ethical leadership and whistle blowing intention resulted in the $\mathrm{R} 2$ value of 0.44 , representing that ethical leadership brings $44 \%$ change in the whistle blowing intention of followers. Whistle blowing intention when regressed with ethical leadership had a statistically significant model. As proposed by the research model, ethical leadership predicts approximately 44 percent variation in whistle blowing intention in a positive direction, which is consistent with the study hypothesis. The $R^{2}$ value is 0.44 at $\mathrm{p}<.05$ (table 2). Thus, it can be deduced that 1 unit change in ethical leadership results in nearly 0.4 percent change in whistle blowing intention. Therefore, H1, which indicated that ethical leadership positively affects followers whistle blowing intention, substantiated statistically.

A mediation analysis was run through SPSS using PROCESS macro by Preacher and Hayes. Model 4 according Hayes templates works as a mediation model. In the mediation model (table 3 ), the effect of ethical leadership can be partitioned into two parts: 1) the direct effect of EL on WB, and 2) the indirect effect of Ethical leadership on Whistle blowing intention via Moral attentiveness. Combined, the direct and indirect effect of EL on WB or the total effect is 0.72 with positive sign implying the positive relationship. Hence, hypothesis 1 is accepted which stated a positive association between ethical leadership and whistle blowing.

The direct effect of EL on WB when the mediator is included in the model turns out to be 0.50 with positive sign implying a positive relationship between EL and WB. The indirect or mediation effect which is a measure of how much of the effect of EL on WB is being mediated comes out to be 0.22 and is significant with no zero value lying between the upper and lower boot values of confidence interval. Therefore, we accept $\mathrm{H} 2$, i.e. MA mediates the relationship between EL and WB.

Using PROCESS macro, the results of moderation analysis according to table 4 demonstrate that the change in $R^{2}$ due to collectivism as a moderator comes out to be 0.029 , with a significant $p$ value. Therefore, we infer that collectivism moderates between MA and WBI, i.e. H3 is accepted subsequently. A moderation plot is also given for more clarity.

\section{Implications and Recommenda- tions}

\subsection{Theoretical implications}

There are many theoretical implications of the current study which are discussed below:

Firstly, the present study introduced collectivism as 
Table 3: Mediated Regression

\begin{tabular}{lcccccc}
\hline & Effect & SE & T & P & BootLLCI & BootULCI \\
\hline Total effect & 0.72 & 0.06 & 11.82 & 0.00 & 0.60 & 0.84 \\
Direct effect & 0.5 & 0.08 & 6.08 & 0.00 & 0.34 & 0.67 \\
Indirect effect & 0.22 & 0.06 & - & - & 0.1 & 0.35 \\
\hline
\end{tabular}

Table 4: Moderation Analysis

\begin{tabular}{cccc}
\hline & $\Delta R^{2}$ & F & P \\
\hline Moral Attentiveness x Whistle Blowing Intentions & 0.029 & 9.99 & 0.0018 \\
\hline
\end{tabular}

$n=180$

a moderator between moral attentiveness and whistle blowing intention. Collectivism was tested to see its results on whistle blowing intention. Previously, collectivism was tested in major studies to check the impact that either culture has some impact on the overall research or not. Major studies has revealed that the cultural differences plays a vital role in different studies and it also shows the importance that difference in the cultural values also shows the difference in the perception of the employees that how they perceive the word of whistle blowing intention. The word intentions means that it varies in different people that how much cost they have to pay for reporting any wrongdoing in the organization and this cost is measured when we have to do cross cultural comparison.

Secondly, the present research also studied the moral attentiveness as a mediator in this study. Moral attentiveness means how much the employee is attentive in the working environment. Employees who are morally attentive are sometimes loyal to the organization because they always try to work for the benefit for the organization. In Pakistan, there is a great need for such people who are working in the organization, to be morally attentive, such that if they would see any wrongdoing in the organization they will definitely report it.

Thirdly, the study also helps to understand the effects of the ethical leadership and how it enhances performance of employees in terms of moral attentiveness, especially those employees who are working in Pakistani organizations. Very scarce and few researches are available on whistle blowing intention and even fewer are available in Pakistani context. Most of the studies conducted on ethical leadership in relationship with whistle blowing intention are in western societies, which are individualistic culture and low power distance societies.

Moreover,, the study provides support for the So- cial Cognitive Theory (SCT), which proposes that people build the relationships and these relationships are built when the employees are working in the organization, they learn through observing others and from the social media or print media; consequently, they make decisions that are favorable in the perspective of the organization.

Future researchers are advised to investigate the same study using longitudinal study. The researchers should also consider investigating the current relationships for a specific type of different leadership style with whistle blowing intentions. Furthermore, other dimensions should also be explored, such as masculinity, femininity and power distance. Power distance must be checked, as Pakistan is high on power distance, it must be interesting to explore, whether employees do move towards whistle blowing in presence of high power distance.

Further, the researchers should find that what are the actual reasons for starting the whistle blowing process and what are the elements that initiate the process of whistle blowing. The current study just checked the impact of ethical leadership, which would start the process of whistle blowing intentions in the employees.

\subsection{Practical implications}

The present study has certain practical implications, which might provide some help for the organizations in Pakistan. It can be noticed that whistle blowing or whistle blowing intention is a great concern for the organization because as we see in the organizations that are working in Pakistan, large number of cases are present that show that the people have no fear of doing any wrongdoing. Peoples know that there are no proper authority that can check there wrongdoing so there is great need of an ethical leader and a proper channel of reporting the wrongdoing. 
The study will also provide guidance for Pakistani organizations to develop their working environment in which the employees have no fear of reporting any wrongdoing in the organization. It is the duty of the organization to provide such working environment that will be helpful for the employees to report the wrongdoing.

\subsection{Limitations}

The current study tried to eliminate all the problems, but still there are some limitations that must be avoided in the future.

Firstly, that sampling and data collection were done through cross sectional method due to time and resource constraints. In a cross sectional study data are collected from the respondents at one specific point of time. Thus, the sample size was small and might not represent all the population of Pakistan, because the sample was not comprehensive and results might change if sample size might increase.

Moreover, the study focused on different sectors for data collection, but it might also affect the results of this study. Because working conditions of the banking sector organization might offer more support and when we analyses the corporate scandals that occurs in different organizations, it may provide more comprehensive support and facilitation to employees as compared to other sectors that might not support and facilitate their disabled employees much.

\section{References}

Bandura, A. (1977). Self-efficacy: toward a unifying theory of behavioral change. Psychological review, 84(2):191.

Bandura, A. (1986). The explanatory and predictive scope of self-efficacy theory. Journal of social and clinical psychology, 4(3):359-373.

Bhal, K. T. and Dadhich, A. (2011). Impact of ethical leadership and leader-member exchange on whistle blowing: The moderating impact of the moral intensity of the issue. Journal of Business Ethics, 103(3):485-496.

Bragues, G. (2008). The ancients against the moderns: Focusing on the character of corporate leaders. Journal of Business Ethics, 78(3):373-387.

Brown, M. E. and Treviño, L. K. (2006). Ethical leadership: A review and future directions. The leadership quarterly, 17(6):595-616.

Brown, M. E., Treviño, L. K., and Harrison, D. A. (2005). Ethical leadership: A social learning perspective for construct development and testing. Organizational behavior and human decision processes, 97(2):117-134.
Feldman, Y. and Lobel, O. (2009). The incentives matrix: The comparative effectiveness of rewards, liabilities, duties, and protections for reporting illegality. Tex. L. Rev., $88: 1151$.

Graham, J. W. (1986). Principled organizational dissent: A theoretical essay. Research in organizational behavior.

Hofstede, G. (1986). The usefulness of the organizational cultureconcept. Journal of Management Studies, 23(3):253-257.

Kanungo, R. N. and Mendonca, M. (2001). Ethical leadership and governance in organizations: A preamble. Canadian Journal of Administrative Sciences, 18(4):241.

Knights, D. and OLeary, M. (2006). Leadership, ethics and responsibility to the other. Journal of Business Ethics, 67(2):125-137.

MacIntyre, A. C. (1979). Corporate modernity and moral judgment: Are they mutually exclusive? University of NotreDame Press.

Mayer, D. M., Aquino, K., Greenbaum, R. L., and Kuenzi, M. (2012). Who displays ethical leadership, and why does it matter? an examination of antecedents and consequences of ethical leadership. Academy of Management Journal, 55(1):151-171.

Miceli, M. P., Near, J. P., and Dworkin, T. M. (2009). A word to the wise: How managers and policy-makers can encourage employees to report wrongdoing. Journal of Business Ethics, 86(3):379-396.

Morrison, A. (2001). Integrity and global leadership. Journal of Business Ethics, 31(1):65-76.

Near, J. P. and Miceli, M. P. (1985). Organizational dissidence: The case of whistle-blowing. Journal of Business Ethics, $4(1): 1-16$.

Near, J. P. and Miceli, M. P. (1995). Effective-whistle blowing. Academy of management review, 20(3):679-708.

Perel, M. (2003). An ethical perspective on ceo compensation. Journal of Business Ethics, 48(4):381-391.

Rehg, M. T., Miceli, M. P., Near, J. P., and Van Scotter, J. R. (2008). Antecedents and outcomes of retaliation against whistleblowers: Gender differences and power relationships. Organization Science, 19(2):221-240.

Resick, C. J., Hanges, P. J., Dickson, M. W., and Mitchelson, J. K. (2006). A cross-cultural examination of the endorsement of ethical leadership. Journal of Business Ethics, 63(4):345-359.

Reynolds, S. J. (2008). Moral attentiveness: Who pays attention to the moral aspects of life? Journal of Applied Psychology, 93(5):1027.

Treviño, L. K., Brown, M., and Hartman, L. P. (2003). A qualitative investigation of perceived executive ethical leadership: Perceptions from inside and outside the executive suite. Human relations, 56(1):5-37. 
Treviño, L. K., Hartman, L. P., and Brown, M. (2000). Moral person and moral manager: How executives develop a reputation for ethical leadership. California management review, 42(4):128-142.

Waldman, D. A., De Luque, M. S., Washburn, N., House, R. J., Adetoun, B., Barrasa, A., Bobina, M., Bodur, M., Chen, Y.-J., Debbarma, S., et al. (2006). Cultural and leadership predictors of corporate social responsibility values of top management: A globe study of 15 countries. Journal of International Business Studies, 37(6):823-837.
Williams, M. L., Podsakoff, P. M., Todor, W. D., Huber, V. L., Howell, J. P., and Dorfman, P. W. (1988). A preliminary analysis of the construct validity of kerr \& jermier's substitutes for leadershipscales. Journal of Occupational and Organizational Psychology, 61(4):307-333.

Yukl, G., Mahsud, R., Hassan, S., and Prussia, G. E. (2013). An improved measure of ethical leadership. Journal of leadership E organizational studies, 20(1):38-48. 


\title{
Implementation of TAM (Technology Acceptance Model) in Project Based Organizations
}

\author{
Amina Binat-i-Yousaf * \\ Capital University of Science \& Technology, Islamabad, Pakistan
}

\begin{abstract}
This study examines the relationship between perceived usefulness of technology and ease of use with technology usage. Data were collected by 100 respondents of government sector of Pakistan. The results show the positive relation between perceived usefulness of technology and ease of use with technology usage with the mediating role of intention to use technology. This study also has theoretical and practical implication in the context of Pakistani organization having projects, as discussed later in the study.
\end{abstract}

\section{Introduction}

Before the start of Technology acceptance model there were many studies related to the use of information system in projects to make them more effective and efficient. Many people do not consider it as more effective way towards the success of project as compared to the human factor. Since seventies, researchers have been trying to study the usefulness and effectiveness of the information systems. Bagozzi et al. (1992) has done research to prove theoretical model of effectiveness and usefulness of computer-based information system practically.

Technology acceptance model was suggested by Mayer et al. (1995), and it has been used by number of researchers in their studies. Technology acceptance model is the model that basically relates the perceived usefulness and ease of use of technology in projects. This model is formed to develop awareness in the people related to the use of information systems.

Venkatesh and Davis (2000), found the effectiveness and usefulness of technology acceptance model. They explored ease of use and perceived usefulness of technology acceptance model. They did practical research on 4 project base organization and based on organizational data, they concluded that use of information system improves the effectiveness and usefulness of the organizations or the projects. Similarly, Legris et al. (2003) found that the technology acceptance model is a useful model in order to understand the effectiveness of information system in project based organizations. Technology acceptance model is tested along with many different tools and other models, but still this model remains successful model as compared

*Corresponding author.

Email: aminabintiyousaf@gmail.com to the other models.

Recent studies further related technology acceptance model to explain the influence of acceptance of other Google applications. Cheung and Vogel (2013), found the effect of collaborative learning of the students. They collected data from 136 students who were enrolled in the master degree program and asked them regarding the usage of information systems and the group work in either project based organizations or group work of the students. Wallace and Sheetz (2014), found the importance of software measures in project management. They conducted the test to prove the importance of use of software in project based organizations or in projects. Their study was based on technology acceptance model and the construction of software on the desirable properties of software.

Furthermore, Toft et al. (2014) posited that one type of system is not enough for all types of work, and similar system can work efficiently and effectively for years. They suggested that each system should form according to the need of project or organization. Similarly, systems must be updated with the passage of time. Zheng (2016) found technology acceptance model to be a problem solving model for promoting mobile donations for non-profit organizations. Costa et al. (2016), found that it very difficult to use these systems in project based organizations, so their basic research is on the adoption and satisfaction of the people for using these systems. Hwang et al. (2017), in their study also suggested the moderating role of intention to use technology in project based organizations. Using technology in project based organizations is not a very common practice. It influences not only organizations processes and strategy but also the projects.

There is huge gap in project based organizations re- 
lated to the use of technology, especially in Pakistani context. A lot of work is needed to be done now as many organizations have shifted their projects based on technology. The purpose of this study is to increase the use of awareness related to the use of technology in project based organizations, especially in Pakistan. Organizations and project managers will able to enhance projects success rates. It is assumed that study will help many organizations in Pakistan, to learn the importance of technology and its impact on project success by using technology in project based organizations. As it is mentioned above that technology usage has now been considered as the critical success factor for project success and definitely it will also increase the success rate of projects in Pakistan.

\section{Literature Review}

\subsection{Relationship of perceived usefulness of technology with technology usage}

A lot of research has been done previously to understand the usefulness of technology through which it influences the technology usage, like e-tourism is gaining popularity, enhancing the technology usage (Ukpabi and Karjaluoto, 2016). Building information modeling is used to change the construction industry with the extension of theory of acceptance and use technology to increase the use of information technology in construction industry (Howard et al., 2017). The unified theory of acceptance has been used widely in the area of information technology to insure the acceptance of technology usage in different areas (Venkatesh et al., 2016).

The study extends the unified theory of acceptance to find out the use of technology in different areas like the use of technology of social media such as Instagram. In this theory, they studied the use of technology for using social media (Järvinen et al., 2016). This paper focused on digital sakuga means digital drawing. Means they want to increase the use of technology even in the area of arts, which allows the individuals, related to the field of art, to adopt information technology (ICHIKOHJI, 2016). Another study by Cai et al. (2017) explored the major reasons why there is a gender difference while using information technology. They tried to see the difference in the use of information technology in different areas of the world to understand why there is a difference between the use of technology in different areas (Rojas-Méndez et al., 2017). Massive open online courses increased the trend for learning online courses, which means increase in trend for using information system at student life (Ouyang et al., 2017). Another study explored the behavior of students as to why the trend of using technology increased, what are the main reasons for the increase in usage (Padilla-
MeléNdez et al., 2013).

Based on the above literature, following hypothesis has been developed:

H1. Perceived usefulness of technology is positively related to technology usage

\subsection{Relationship of ease of use with tech- nology usage}

Ample literature provides evidence that why there are still limitations in applying the wide range of analysis in human neurosciences, because there is less ease of use in using information technology (Gorgolewski et al., 2017). Literature tells us how the use of information technology varies in different countries because of the culture and its not as easy to use in every area because of the culture at that place. Some people dont appreciate their children to use technology (Hallikainen et al., 2017). Wu and Chen (2017) posited that increase in the ease of use of information technology so that massive open online courses will be able to help and teach a lot of students in those areas who cant afford study in expensive universities. Massive open online courses increased the trend for learning online courses, which means increase in trend for using information system at student life (Ouyang et al., 2017).

Another study conducted to see how banks and financial service providers are delivering their finances through e-banking, because of the ease of use of technology (Wang et al., 2017). Padilla-MeléNdez et al. (2013) studied the behavior of students that why the trend of using information technology increase, what are the main reasons for the increase in usage. The use of technology in medical field is considered easy so that the people who take care of patients other than doctors can also easily operate the systems (Wouters et al., 2017). Gender difference in playfulness of technology acceptance model has also been explored by researchers. The model checks what are the main reasons in order to remove this gender barrier? (PadillaMeléNdez et al., 2013). Similarly, another study posited the advantages of acceptance of wireless internet via information technology and how it is easy to use information systems (Lu et al., 2003).

\section{H2. Ease of use is positively related to technology usage}

\subsection{Relationship of intention to use tech- nology with technology usage}

Researchers have studied the advantages of acceptance of wireless internet via information technology and how it is easy to use information systems ( $\mathrm{Lu}$ et al., 2003). Massive open online courses increase the 
trend for learning online courses, which means increase in trend for using information system at student life (Ouyang et al., 2017). The use of information technology varies in different countries because of the culture and its not as easy to use in every area because of the culture at that place. Some people dont appreciate their children to use technology (Hallikainen et al., 2017).

Gender difference in playfulness of technology acceptance model has also been explored in order to check how can gender barriers in this regard be removed (Padilla-MeléNdez et al., 2013). Similarly, literature provides evidence on how banks and financial service providers are delivering their finances through e-banking, because of the ease of use of information technology (Wang et al., 2017). A study by Wang et al. (2017) highlighted the importance of information technology when you are at the journey and the people intentionally use information technology in order to remain in touch with the world.

The theoretical extension of technology acceptance model and intention to use technology was also studied in order to check the social influence and instrumental process (Venkatesh et al., 2016). Similarly, research elaborates the use of intention to the looks that how a website looks like will attract more people towards it and make more intention to use technology (Al-Qeisi et al., 2014). Relating the performance of person with the data analysis, data searching, mining and also the similar things that are if there is a use of information technology then the work will become easy and it will create the intention to work by using technology (Kwon et al., 2014).

H3. Intention to use technology is positively related to technology usage

\subsection{Relationship of perceived usefulness of technology with intention to use tech- nology}

A lot of research has been done previously to understand the usefulness of technology through which it influences the technology usage, like e-tourism is getting famous, leading to the increase in technology usage (Ukpabi and Karjaluoto, 2016). Building information modeling is used to change the construction industry with the extension of theory of acceptance and use technology to increase the use of information technology in construction industry (Howard et al., 2017). A study has been conducted to see the difference in the use of information technology in different areas of the world to understand why there is a difference between the use of technology in different areas (Rojas-Méndez et al., 2017).

Another study tested the theoretical extension of technology acceptance model and intention to use technology in order to check the social influence and in- strumental process (Venkatesh et al., 2016). However, literature explains that the use of information technology varies in different countries because of the culture and its not as easy to use in every area because of the culture at that place. Some people dont appreciate their children to use technology (Hallikainen et al., 2017).

H4. Perceived usefulness of technology is positively related to Intention to use technology

\subsection{Relationship of Ease of use with inten- tion to use technology}

Researchers posited why there are still limitations in applying the wide range of analysis in human neurosciences, because there is less ease of use in using information technology (Gorgolewski et al., 2017). Wu and Chen (2017) conducted a study, aiming to help increase the ease of use of information technology so that massive open online courses will be able to help and teach a lot of students in those areas where they cant afford to study in expensive universities. Moreover, another study explored the major reasons why there is a gender difference while using information technology, trying to resolve the issue by conducting different studies so that people belonging to any gender can use information technology (Cai et al., 2017).

Padilla-MeléNdez et al. (2013) studied the behavior of students regarding the trend of increased usage of information technology and what are the main reasons for the increase in usage. Moreover, use of technology in medical field must be easy so that the people who take care of patients other than doctors can also easily operate the systems (Wouters et al., 2017).

H5. Ease of use is positively related to Intention to use technology

\section{Theoretical framework}

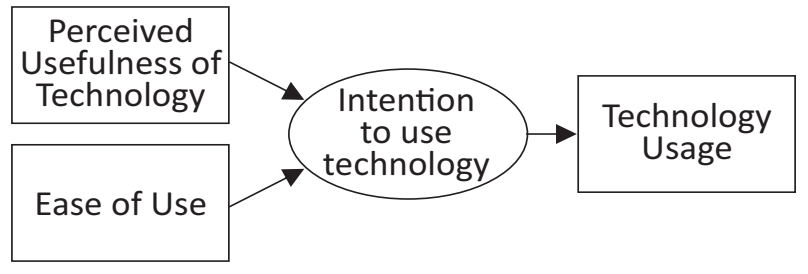

Figure 1: Conceptual Framework

\section{Methodology}

\subsection{Sample and procedures}

For this study, convenient sampling technique was used to examine the impact of perceived usefulness of 
technology and ease of use on technology usage with mediating role of intention to use technology. The sample was selected from government sector of Islamabad (Smart PCB). Smart PCB is multi-disciplinary program agency under the Ministry of Defense Production, Pakistan which is dedicated for evaluation of science and technology for use by the military. For study purpose, 120 questionnaires were distributed among employees, 100 questionnaires were returned back with full response, 10 were incomplete and 10 were not returned back. Additionally, all respondents were assured that their information will be kept only for academic purpose.

\subsection{Measures}

\subsubsection{Perceived usefulness of technology}

Gallivan et al. (2005) used questionnaire of perceived usefulness of technology in their study to measure 5 items of variable. Likert scale was used to measure the level of variable. A sample item was Having a computer available to me would/does improve my productivity. was measured against Strongly Agree (SA), Agree (A), Neutral (N), Disagree (D), and Strongly Disagree (SD). Cronbachs alpha was 0.737.

\subsubsection{Ease of use}

To measure ease of use, a 6 items questionnaire developed by Malhotra and Galletta (2005) was adopted. A sample item was Learning to use [the system] for performance-based activities is easy for me. Strongly Agree (SA), Agree (A), Neutral (N), Disagree (D), and Strongly Disagree (SD). Cronbachs alpha was 0.744.

\subsubsection{Intention to use technology}

Brown et al. (2010) developed questionnaire of Intention to use technology in their study to measure 3 items of variable, which was adopted in order to measure intention to use technology. Likert scale was used to measure the level of variable. A sample item was I intend to use the (collaboration tool) in the next 6 months. Strongly Agree (SA), Agree (A), Neutral (N),
Disagree (D), and Strongly Disagree (SD). Cronbachs alpha was 0.630 .

\subsubsection{Technology usage}

(Chin et al., 2008) used questionnaire of Technology usage in their study to measure 4 items of variable. Likert scale was used to measure the level of variable. A sample item like If the choice of a (technology type) platform were up to me, it would likely be (system). Strongly Agree (SA), Agree (A), Neutral (N), Disagree (D), and Strongly Disagree (SD). Cronbachs alpha was 0.65 .

\section{Results}

Table 1 shows the biveriate correlation result that is significant at $p \leq .01$. Perceived usefulness of technology is correlated with technology usage $(r=.931$, $\mathrm{p}$ $<.01)$, ease of use is correlated with technology usage $(\mathrm{r}=.933, \mathrm{p}<.01)$, and Intention to use technology $(\mathrm{r}$ $=.966, \mathrm{p} \leq .01)$. Technology usage is correlated with Intention to use technology $(\mathrm{r}=.941, \mathrm{p}<.01)$. Ease of use is correlated with intention to use technology ( $r=$ $.991, \mathrm{p}<.01$ ). Respondents were 55 Males and 45 were female and average age of respondents was between 30 35 and average qualification was post graduates.

\subsection{Regression Analysis}

Table 2 shows the results of mediated regression analysis. Respondents completed the questionnaire and regression analysis on Hypothesis 1 shows that PUT is linked with TU and it is accepted as supported by the coefficient regression result $(\mathrm{B}=.837, \mathrm{p}<.01)$. Hypothesis 2 that is EU is linked with TU is also accepted, supported by the coefficient regression results $(\mathrm{B}=.883, \mathrm{p}<.01)$. Hypothesis 3 , mediation is run through Baron and Kenny (1986) four steps. IUT is linked with TU and it is also accepted, supported by the coefficient regression results $(\mathrm{B}=.729, \mathrm{p}<.01)$. Further for hypothesis 4, PUT and IUT is regressed that shows the result $(B=1.049, p<.01)$ then PUT is regressed on

Table 1: Correlation Matrix

\begin{tabular}{llcccccc}
\hline & Variables & Mean & SD & $\mathbf{1}$ & $\mathbf{2}$ & $\mathbf{3}$ & $\mathbf{4}$ \\
\hline 1 & Usefulness of technology & 3.166 & 1.05794 & 1 & & & \\
2 & Ease of use & 2.81 & 0.89016 & $.933^{* *}$ & 1 & & \\
3 & Intention to use & 2.4341 & 1.14915 & $.966^{* *}$ & $.941^{* *}$ & 1 & \\
4 & Tech usage & 2.4341 & 1.05349 & $.955^{* *}$ & $.955^{* *}$ & $.991^{* *}$ & 1 \\
\hline
\end{tabular}

${ }^{* *} p \leq .01$ 
Table 2: Mediated Regression Analysis

\begin{tabular}{|c|c|c|c|c|c|c|}
\hline \multirow[t]{2}{*}{ Predictor } & \multicolumn{3}{|c|}{ Intention to use technology } & \multicolumn{3}{|c|}{ Technology Usage } \\
\hline & $\beta$ & $R^{2}$ & $\Delta R^{2}$ & $\beta$ & $R^{2}$ & $\Delta R^{2}$ \\
\hline \multicolumn{7}{|l|}{ Direct Effects } \\
\hline \multicolumn{7}{|l|}{ Step 1} \\
\hline Control Variables & & & & 0.026 & & \\
\hline \multicolumn{7}{|l|}{ Step 2} \\
\hline Usefulness of tech & $1.049^{* *}$ & 0.931 & 0.931 & $0.837^{* *}$ & 0.871 & 0.869 \\
\hline \multicolumn{7}{|l|}{ Step 3} \\
\hline Ease of use & $1.043^{* *}$ & 0.933 & 0.933 & $0.845^{* *}$ & 0.833 & 0.862 \\
\hline \multicolumn{7}{|l|}{ Indirect Effects } \\
\hline \multicolumn{7}{|l|}{ Step 1} \\
\hline Control variables & & & & 0.026 & & \\
\hline \multicolumn{7}{|l|}{ Step 2} \\
\hline Intention to use tech & & & & $0.729^{* *}$ & 0.885 & 0.884 \\
\hline \multicolumn{7}{|l|}{ Step 3} \\
\hline Usefulness of tech & & & & $0.309^{* *}$ & 0.894 & 0.891 \\
\hline \multicolumn{7}{|l|}{ Step 4} \\
\hline Ease of use & & & & 0.309 & 0.894 & 0.891 \\
\hline
\end{tabular}

$N=11, p<.05^{*}, p<.01^{* *}, p<.001^{* * *}$

TU that shows result $(\mathrm{B}=3.09, \mathrm{p}<.01)$ for hypothesis $5, \mathrm{EU}$ and IUT are regressed that shows result $(\mathrm{B}=$ $1.043, \mathrm{p}<.01)$.

\section{Discussion}

The study results show that there is significant and positive relation between perceived usefulness of technology and technology usage. It can be said that hypothesis 1 has been approved after statistical analysis. It is also supported by other studies for example, the usefulness of technology through which it influence the technology usage, like e-tourism is getting famous, leading to increase in technology usage (Ukpabi and Karjaluoto, 2016). The unified theory of acceptance has been used widely in the area of information technology to insure the acceptance of technology usage in different areas (Venkatesh et al., 2016).

Hypothesis 2 results are also significant and show positive relation between Ease of Use and Technology usage. It has also been proven by other researchers and statistical analysis that is performed in this study.
A study has been conducted to see how banks and financial service providers are delivering their finances through e-banking, because of the ease of use of information technology (Wang et al., 2017). Similarly, Padilla-MeléNdez et al. (2013) tried to study the behavior of students that why the trend of using information technology increase, what are the main reasons for the increase in usage.

Results for hypothesis 3 showed significant and positive relation between Intention to use technology and Technology usage. It has also substantiated by other researchers but also by statistical analysis of the study. Importance of information technology has been studied previously when you are at the journey and the people intentionally use information technology in order to remain in touch with the world (Wang et al., 2017), therefore, supporting the current study results.

Hypothesis 4 showed the positive relation between perceived usefulness of technology and Intention to use technology. The success or failure of an organization or a project depends on the effective use of technology. There is a constant interaction between employees 
and technology to make their work more effective and ideal. Leaders create cultural development mechanism and within the boundaries of the culture. Literature tells us the advantage of acceptance of wireless internet via information technology and how it is easy to use information systems (Lu et al., 2003). Likewise, the theoretical extension of technology acceptance model and intention to use technology has been researched, in order to check the social influence and instrumental process (Venkatesh and Davis, 2000).

Hypothesis 5 results showed the positive relation between Ease of use and Intention to use technology. These results are substantiated by previous studies, which tell us that why there is still limitations in applying the wide range of analysis in human neurosciences, because there is less ease of use in using information technology (Gorgolewski et al., 2017). Literature posits why there is a need to increase the ease of use of information technology so that massive open online courses will be able to help and teach a lot of students in those areas who cant afford study in expensive universities (Wu and Chen, 2017).

\subsection{Conclusion \& Implication}

After the analysis and literature support, it can be said that perceived usefulness of technology and ease of use have a positive effect on technology usage with the presence of mediating role of Intention to use technology. The current study also has theoretical and practical implication in the context of Pakistani organizations and projects. From theoretical perspective, perceived usefulness of technology and ease of use do matter for any achievement or success, if organizations ensure the technology usage. Moreover, Intention to use technology also affects the technology usage in an organization, so it can be said that perceived usefulness of technology and ease of use can help achieve technology usage with the mediating role Intention to use technology. From practical perspective of implication, here in Pakistan, project management is an emerging field of study. Now projects are planned, executed, monitored, evaluated according to the project management iron triangle. As it is said in theoretical implication that this study has significance in major portions of world so it can be said that this study is also significant in the context of Pakistan.

\subsection{Limitations \& Future Directions}

The current study has been conducted in the context of Pakistan, especially in government sector of Islamabad region. For future studies, it is suggested that this study should be conducting in other regions of Pakistan and results might be different for private sector. The other constraint was sample size that can be increased for future studies. Moreover, other variables can also be tested for the effect on technology usage in the context of Pakistan.

\section{References}

Al-Qeisi, K., Dennis, C., Alamanos, E., and Jayawardhena, C. (2014). Website design quality and usage behavior: Unified theory of acceptance and use of technology. Journal of Business Research, 67(11):2282-2290.

Bagozzi, R. P., Davis, F. D., and Warshaw, P. R. (1992). Development and test of a theory of technological learning and usage. Human relations, 45(7):659-686.

Baron, R. M. and Kenny, D. A. (1986). The moderatormediator variable distinction in social psychological research: Conceptual, strategic, and statistical considerations. Journal of personality and social psychology, 51(6):1173.

Brown, S. A., Dennis, A. R., and Venkatesh, V. (2010). Predicting collaboration technology use: Integrating technology adoption and collaboration research. Journal of Management Information Systems, 27(2):9-54.

Cai, Z., Fan, X., and Du, J. (2017). Gender and attitudes toward technology use: A meta-analysis. Computers $\mathcal{E}$ Education, 105:1-13.

Cheung, R. and Vogel, D. (2013). Predicting user acceptance of collaborative technologies: An extension of the technology acceptance model for e-learning. Computers $\mathcal{E}$ Education, 63:160-175.

Chin, W. W., Johnson, N., and Schwarz, A. (2008). A fast form approach to measuring technology acceptance and other constructs. MIS Quarterly, pages 687-703.

Costa, C. J., Ferreira, E., Bento, F., and Aparicio, M. (2016). Enterprise resource planning adoption and satisfaction determinants. Computers in Human Behavior, 63:659-671.

Gallivan, M. J., Spitler, V. K., and Koufaris, M. (2005). Does information technology training really matter? a social information processing analysis of coworkers' influence on it usage in the workplace. Journal of Management Information Systems, 22(1):153-192.

Gorgolewski, K., Esteban, O., Schaefer, G., Wandell, B., and Poldrack, R. (2017). Openneuroa free online platform for sharing and analysis of neuroimaging data. Organization for Human Brain Mapping. Vancouver, Canada, page 1677.

Hallikainen, H., Paesbrugghe, B., Laukkanen, T., Rangarajan, D., and Gabrielsson, M. (2017). How individual technology propensities and organizational culture influence $b 2 b$ customers behavioral intention to use digital services at work? In Proceedings of the 50th Hawaii International Conference on System Sciences.

Howard, R., Restrepo, L., and Chang, C.-Y. (2017). Addressing individual perceptions: An application of the unified theory of acceptance and use of technology to building information modelling. International Journal of Project Management, 35(2):107-120. 
Hwang, Y., Chung, J.-Y., Shin, D.-H., and Lee, Y. (2017). An empirical study on the integrative pre-implementation model of technology acceptance in a mandatory environment. Behaviour E Information Technology, pages 1-14.

ICHIKOHJI, T. (2016). Technology adoption: Influence of personal attributes and person-organization adaptation. Organizational Science, 48(5):33-48.

Järvinen, J., Ohtonen, R., and Karjaluoto, H. (2016). Consumer acceptance and use of instagram. In System Sciences (HICSS), 2016 49th Hawaii International Conference on, pages 2227-2236. IEEE.

Kwon, O., Lee, N., and Shin, B. (2014). Data quality management, data usage experience and acquisition intention of big data analytics. International Journal of Information Management, 34(3):387-394.

Legris, P., Ingham, J., and Collerette, P. (2003). Why do people use information technology? a critical review of the technology acceptance model. Information $\mathcal{E}$ management, 40(3):191-204.

Lu, J., Lu, C., Yu, C.-S., and Yao, J. E. (2003). Exploring factors associated with wireless internet via mobile technology acceptance in mainland china. Communications of the IIMA, 3(1):9.

Malhotra, Y. and Galletta, D. (2005). A multidimensional commitment model of volitional systems adoption and usage behavior. Journal of Management Information Systems, 22(1):117-151.

Mayer, R. C., Davis, J. H., and Schoorman, F. D. (1995). An integrative model of organizational trust. Academy of management review, 20(3):709-734.

Ouyang, Y., Schlub, R. W., Jin, N., and Pascolini, M. (2017). Shared antenna structures for near-field communications and non-near-field communications circuitry. US Patent $9,793,616$.

Padilla-MeléNdez, A., Del Aguila-Obra, A. R., and GarridoMoreno, A. (2013). Perceived playfulness, gender differences and technology acceptance model in a blended learning scenario. Computers $\mathcal{E}$ Education, 63:306-317.
Rojas-Méndez, J. I., Rojas-Méndez, J. I., Parasuraman, A., Parasuraman, A., Papadopoulos, N., and Papadopoulos, N. (2017). Demographics, attitudes, and technology readiness: A cross-cultural analysis and model validation. Marketing Intelligence $\mathcal{E}$ Planning, 35(1):18-39.

Toft, M. B., Schuitema, G., and Thøgersen, J. (2014). Responsible technology acceptance: Model development and application to consumer acceptance of smart grid technology. Applied Energy, 134:392-400.

Ukpabi, D. C. and Karjaluoto, H. (2016). Consumers acceptance of information and communications technology in tourism: A review. Telematics and Informatics.

Venkatesh, V. and Davis, F. D. (2000). A theoretical extension of the technology acceptance model: Four longitudinal field studies. Management science, 46(2):186-204.

Venkatesh, V., Thong, J. Y., and Xu, X. (2016). Unified theory of acceptance and use of technology: a synthesis and the road ahead.

Wallace, L. G. and Sheetz, S. D. (2014). The adoption of software measures: A technology acceptance model (tam) perspective. Information \& Management, 51(2):249-259.

Wang, M., Wang, M., Cho, S., Cho, S., Denton, T., and Denton, T. (2017). The impact of personalization and compatibility with past experience on e-banking usage. International Journal of Bank Marketing, 35(1):45-55.

Wouters, E. J., Weijers, T. C., and Nieboer, M. E. (2017). Professional values: The use of technology and the new generation of clinicians. Handbook of Smart Homes, Health Care and Well-Being, pages 147-154.

Wu, B. and Chen, X. (2017). Continuance intention to use moocs: Integrating the technology acceptance model (tam) and task technology fit (ttf) model. Computers in Human Behavior, 67:221-232.

Zheng, Y. (2016). Toward A Situational Technology Acceptance Model: Combining the Situational Theory of Problem Solving and Technology Acceptance Model to Promote Mobile Donations for Nonprofit Organizations. PhD thesis, University of South Carolina. 


\section{CONTRIBUTOR'S GUIDELINES}

The management of Jinnah Business Review (JBR) encourages researchers to prepare their articles in accordance with the following guidelines and submit their manuscripts online, preferably. Before submitting your articles online, you will have to transform your article in to our Journals template; and for this purpose, you can use a specimen provided for the article on our research center's website (www.jbrc.pk) as a base.

\section{AIMS AND SCOPE}

Jinnah Business Review (JBR) is the academic research journal of the Jinnah Business Research Center of Capital University of Science and Technology, Islamabad (Pakistan). The Journal publishes theoretical and empirical research papers in management, finance, human resource management, marketing and economics, and all other related disciplines of management and social sciences. Its primary focus is on empirical studies with an emphasis on the policy relevance of the findings.

JBRs goals are to inform the academic, business, and public policy communities of the results of relevant current research; to provide expert analysis of current events and reviews of literature in the field; and to add to the business literature material suitable for academics, executives, and professionals.

New innovative concepts, ideas and practices about businesses, industry, and management related disciplines are therefore welcomed. The submitted articles are undergone through a two-tiered review; the first evaluation is carried out by the JBR Editorial Advisory/Working Committee consisting of members from each relevant discipline, and the second review by peer referees and experts working in the related fields in Pakistan and abroad.

\section{INSTRUCTIONS FOR AUTHORS}

The Editors welcome preliminary inquiries about manuscripts for possible publication. There is no standard fixed length for articles, but a 1520 A4 pages, with 12-fonts and 1-line space article would suffice. Manuscripts should be prepared according to the following style rules (deviations from these rules can cause publication delays).

\section{Content, Length, and Formatting}

It is the author's responsibility to make the submitted paper readable, relevant, and interesting, before submission and consideration by referees. This require.

\section{Length}

All submitted papers must be formatted according to the instructions below, and must be no more than 15 20 US letter pages, as defined earlier. This page limit includes all parts of the paper: title, abstract, body, bibliography, appendices and tables.

\section{Abstract}

An abstract not exceeding 250 words comprising the following is required in the following format:

Authors name (s) and affiliation
a) Email address
b) Title and abstract content

The abstract content should clearly state:

a) Research questions and/or objectives

b) Methodology

c) Scope of investigation/findings

\section{Full paper}
a) A4 size paper
b) Margins must be 1 inch on all sides
c) Font size 12 Times New Roman (body text)
d) Title, subtitles, abstract and references single spaced; body text $1 \frac{1}{2}$ - line spaced
e) Referencing, graphics \& tables will be considered in the total page count.
f) Do not include page numbers, header \& footer.
g) Maximum 1520 pages
h) Other formatting details see next section 


\section{Tables and Figures}

a) All unessential tables and figures should be eliminated.

b) Tables must be submitted in Microsoft Word table format, and should be created using Times New Roman text, 10 point size. APA-style provided elsewhere must be preferred.

c) Figures must be clearly produced in black and white. All text included in figures should be Times New Roman (10 point minimum).

d) Each table and figure should fit on a single page. Tables and figures may be oriented horizontally (landscape) or vertically (portrait) within the allotted space.

e) Each table and figure should be submitted on a separate sheet and identified with a table or figure number and a descriptive title.

f) Legends and titles on tables and figures must be sufficiently descriptive such that they are understandable without reference to the text.

g) For data not generated by the author(s), the source of the data should be given (in short form) below the table or figure and listed in full in the references.

h) Every table and figure must be referred to in the text. Each table and figure will appear in the journal after its first mention in the text.

\section{File type}

All papers are to be submitted as a single MS WORD file, formatted for $8.5^{\prime \prime} \times 11^{\prime \prime}$ paper. It is essential that submitted papers print without difficulty on a variety of printers.

\section{Anonymity Requirements for Double-Blind Reviewing}

All research papers submitted to JBR will undergo a "double-blind" reviewing process: the program committee members and referees who review the paper will not know the identity of the authors. To ensure anonymity of authorship, authors must prepare their manuscript as follows:

a) Authors' names and affiliations must not appear on the title page or elsewhere in the paper.

b) You must also use care in referring to related past work, particularly your own, in the paper. The following types of statements must be avoided: In our previous work [1,2], we presented two algorithms for — In this paper, we build on that work by

\section{Footnotes and References}

a) Footnote material should be incorporated into the text whenever possible. If footnotes are necessary, the note number should be typed in the text and superscripted. The notes should be collected at the end of the text as endnotes.

b) References should be (a) integrated into the text in short form and (b) collected together at the end of the article. APA format needs to be followed.

i) In-text, citations should be placed in parentheses and
noted as follows:

For book or academic journal - (last name of author[s], date); such as: (Hill, 1988); (Beatty, 1989; Feltham, et al. 1991; Leland \& Pyle, 1977).

If no author, cite journal, institution, or publisher. For works with three or more authors, list the first author followed by et al. as shown above. For multiple citations, alphabetize citations by first authors last name.

ii) The full bibliographic information in the references should be composed as follows:

For book - author[s]. year. book title. edition number [if applicable]. location: publisher. Such as: Yin, R.K. (2003). Case Study Research:

Design and Methods. 3rd Edition. Thousand Oaks, California: Sage Publications, Inc.

For edited volumeeditor[s] (ed[s].). year. book title. edition number [if applicable]. location: publisher.

Such as: Nelson, R.R.(ed.).(1993). National Systems of Innovations: A Comparative Analysis. Oxford: Oxford University Press.

For chapter in edited volume - author[s]. year. chapter title. in editor[s] (ed[s].). book title, pp. chapter page numbers. location: publisher.

Such as: Groenewegen, John and Jack Vromen (1997). Theory of the firm revisited: New and neoinstitutional perspectives. In Lars Magnusson and Jan Ottosson (eds.) Evolutionary Economics and Path Dependence, pp. 33-56. Cheltenham, UK: Edward Elgar.

For article in academic journal - author. year. article title. journal title. volume number (issue number): page numbers.

Such as: Black, J. S., Gregersen, H. B. \& Mendenhall, M.E. (1992). Toward a Theoretical Framework of Repatriation Adjustment. Journal of International Business Studies 23 (4): 737-760. 
The author(s) should make sure that there is a strict one-to-one correspondence between the in-text citations (including citations in footnotes, tables, and figures) and the list of references in the References.

\section{Copy Preparation}

JBR accepts manuscripts via internet or post or email. All hard-copy submissions must be accompanied by a disk or CD containing an electronic version of the manuscript. The manuscript should be prepared using a recent version of Microsoft Word and should utilize standard fonts and symbols. Ideally, such a manuscript should be formatted with regard to the following guidelines:

a) Do not use tabs except in tables.

b) Do not indent block quotations.

c) Do not hyphenate or otherwise break words across lines.

d) Use headings sparingly and logically. Do not use more than three levels of headings. Use consistent formatting for each heading level employed.

\section{Copyright Transfer}

a) Submission of a paper will be held to imply that it contains original unpublished work and is not being submitted for publication elsewhere.

b) Submission of a paper also implies that, upon acceptance of an article by the journal, the author(s) will transfer copyright of the article to the publisher. The transfer will ensure the widest possible dissemination of information.

c) It is understood that submission of the paper for publication has been approved by all of the authors and by the institution where the work was carried out; it is further understood that any person cited as a source of personal communications has approved such citation.

\section{Miscellaneous}

a) Papers must be in English. Use American spelling instead of British (e.g., labor, not labour). Use the American terms such as billion (one billion $=1,000,000,000$; one trillion = $1,000,000,000,000)$, rather than lakhs and crores.

b) Spell out all numbers from one to ninety-nine, unless:

i) the number contains a decimal point, e.g., 6.2 and 0.12 .

ii) the number precedes a percent sign or a unit of measure, e.g., $47 \%$ and $16 \mathrm{~m}$.

c) Italicize and define non-English words at their first occurrence; at subsequent occurrences, format the word in roman (no italicized) type.

d) A short abstract of the paper should always be included with the submission.

e) Please keep a copy of everything sent to JBR, both hard copy and electronic copy, and bear in mind that the electronic version received at JBR will be considered the master copy. The Editors do not accept responsibility for damage to or loss of submitted papers or electronic media.

f) A short note listing each authors institutional affiliation, current address, telephone numbers, email address, and other relevant biographical information, including publications and a photograph should be provided.

g) Any manuscript that does not conform to the above instructions may be returned for the necessary revision before publication.

h) Each author is entitled to one copy of the issue in which his or her article appears.

\section{Note:}

Editor reserves the right to amend, abridge or otherwise alter the contents of the paper to make it suitable for publication. However every endeavor will be made not to affect the spirit or effectiveness of the paper. 




\section{J I N N A H \\ BUSINESS RESEARCH CENTER}

Capital University of Science and Technology

Islamabad Expressway, Kahuta Road, Zone-V, 